\title{
Unlocking patients' records in general practice for research, medical education and quality assurance : the registration network family practices
}

Citation for published version (APA):

Metsemakers, J. F. M. (1994). Unlocking patients' records in general practice for research, medical education and quality assurance : the registration network family practices. [Doctoral Thesis, Maastricht University]. Thesis Publishers. https://doi.org/10.26481/dis.19940616jm

Document status and date:

Published: 01/01/1994

DOI:

10.26481/dis.19940616jm

Document Version:

Publisher's PDF, also known as Version of record

Please check the document version of this publication:

- A submitted manuscript is the version of the article upon submission and before peer-review. There can be important differences between the submitted version and the official published version of record.

People interested in the research are advised to contact the author for the final version of the publication, or visit the DOI to the publisher's website.

- The final author version and the galley proof are versions of the publication after peer review.

- The final published version features the final layout of the paper including the volume, issue and page numbers.

Link to publication

\footnotetext{
General rights rights.

- You may freely distribute the URL identifying the publication in the public portal. please follow below link for the End User Agreement:

www.umlib.nl/taverne-license

Take down policy

If you believe that this document breaches copyright please contact us at:

repository@maastrichtuniversity.nl

providing details and we will investigate your claim.
}

Copyright and moral rights for the publications made accessible in the public portal are retained by the authors and/or other copyright owners and it is a condition of accessing publications that users recognise and abide by the legal requirements associated with these

- Users may download and print one copy of any publication from the public portal for the purpose of private study or research.

- You may not further distribute the material or use it for any profit-making activity or commercial gain

If the publication is distributed under the terms of Article 25fa of the Dutch Copyright Act, indicated by the "Taverne" license above, 
UNLOCKING PATIENTS' RECORDS IN GENERAL PRACTICE FOR RESEARCH, MEDICAL EDUCATION AND QUALITY ASSURANCE: THE REGISTRATION NETWORK FAMILY PRACTICES 
Publication of this thesis was supported by grants from:

VVAA Nederlandse Vereniging Van Artsen te Utrecht

E. Merck Nederland B.V. te Amsterdam

SmithKline Beecham Farma bv te Rijswijk

Cover design: Guus van Rooy, RL Design

Printed by: Drukkerskollektief Geulle

Publisher: Thesis Publishers Amsterdam 
UNLOCKING PATIENTS' RECORDS IN GENERAL PRACTICE FOR RESEARCH, MEDICAL EDUCATION AND QUALITY ASSURANCE: THE REGISTRATION NETWORK FAMILY PRACTICES

\section{PROEFSCHRIFT}

ter verkrijging van de graad van doctor aan de Rijksuniversiteit Limburg te Maastricht, op gezag van de Rector Magnificus, Prof.dr. H.Philipsen, volgens het besluit van het College van Dekanen, in het openbaar te verdedigen op donderdag 16 juni 1994 om 14.00 uur

door

Jacobus François Maria Metsemakers 
Promotor:

Prof.dr. J.A. Knottnerus

Beoordelingscommissie:

Prof.dr. W.H.F.W. Wijnen (voorzitter)

Prof.dr.ir. A. Hasman

Prof.dr. J. Heyrman, KU Leuven, Belgiē

Prof.dr.J.D. Mulder, RUL

Prof.dr. F. Sturmans 
Paranimfen

Drs. Wilbert GM Bakx

Drs. Paul BN Hulshof 


\section{Contents}

1. General introduction

2. Sentinel stations and general practice registrations.

History and current situation

$\begin{array}{ll} & \text { Summary } \\ \text { 1. Introduction } \\ \text { 2. }\end{array}$

2.1 The starting period of general practice registration

2.2 Different types of general practice registrations

2.2.1 Time limited morbidity study

2.2.2 Continuous "Morbidity" Registration

2.2.3 Sentinel practice registration

2.3 A study of current general practice registrations

2.3.1 Methods

2.3.2 Results

2.4 Discussion

$3 . \quad$ Other countries

3.1 General practice based registrations in Europe

3.2 Primary care based registrations in Canada and the United States

3.2.1 Canada

3.2.2 United States

3.3 Primary care based registrations around the world

3.4 Discussion

4. Conclusion

3. The Registration Network Family Practices: a computerized health information system in the Netherlands
Summary
1. Introduction
2. General practice as a source of information
$3 . \quad$ Registration network of family practices
4. General data held on the database
$5 . \quad$ Use of the database
6. Discussion 
4. The problem list: an essential tool in the Registration Network Family Practices

$\begin{array}{ll} & \text { Summary } \\ \text { 1. } & \text { Introduction } \\ 2 . & \text { The problem list } \\ 2.1 & \text { Basic principles } \\ 2.2 & \text { Time as a factor } \\ 2.3 & \text { Active or inactive } \\ 3 . & \text { Other relevant medical data } \\ 4 . & \text { Problem types } \\ 5 . & \text { The Registration Network Family Practices } \\ 6 . & \text { Results } \\ 6.1 & \text { General data } \\ 6.2 & \text { Health problems and diagnoses } \\ 7 . & \text { Discussion }\end{array}$

5. Doctors, patients and data of the Registration Network Family Practices

$\begin{array}{ll} & \text { Summary } \\ \text { 1. } & \text { Introduction } \\ \text { 2. } & \text { General Practitioners } \\ \text { 3. } & \text { Population } \\ \text { 4. } & \text { Data }\end{array}$

4.1 Introduction

4.2 Instruction and training sessions

4.3 Registration Handbook

4.4 Regional consensus groups

4.5 Special software for data control in the health information system used by the general practitioner

4.6 Special software for data control in the database of the Medical and Social Information Center

4.7 Quality control experiments

4.7.1 Experiment 1: Patient Dummy

4.7.2 Experiment 2: Data base evaluation

5. General conclusions 
Summary

1. Introduction

2. General Background

2.1 The Maastricht Epilepsy Case Register

2.2 The Registration Network Family Practices

3. Patients and methods

3.1 Patients

$3.2 \quad$ Methods

3.2.1 Stage 1 - matching the database

3.2.2 Stage 2-classification in groups and verification of the data

3.2.3 Stage 3 - arranging the results and analysis

$4 . \quad$ Results

4.1 Group classification and verification of the data

4.2 Processing the results and analysis

4.2.1 General results

4.2.2 Results of group B

4.2.2.1 Patients of group B with epilepsy after verification

4.2.2.2 Patients of group B not having epilepsy after verification

4.2.2.3 Patients of group B in which the diagnosis of epilepsy was regarded as doubtful after verification

4.2.3 Results of group C

4.2.4 Results of group D

$5 . \quad$ Discussion

5.1 The study process

5.2 The control group D

5.3 Epilepsy: yes, no or doubtful

5.4 Comparison between the discordant groups

6. Evaluation and conclusions

6.1 Matching

6.2 Completeness

6.3 Reliability

6.4 Future actions 
7. Do we teach what we preach?

Comparing the content of a problem-based medical curriculum with primary health care data

$\begin{array}{ll} & \text { Summary } \\ \text { 1. } & \text { Introduction } \\ \text { 2. } & \text { Curriculum analysis } \\ \text { 3. } & \text { Primary health care data } \\ \text { 4. } & \text { Results } \\ \text { 5. } & \text { Discussion }\end{array}$

8. Chronic Illnes in the Community and the Concept of 'Social Prevalence'

$\begin{array}{ll} & \text { Summary } \\ \text { 1. } & \text { Introduction } \\ \text { 2. } & \text { Methods } \\ \text { 3. } & \text { Results } \\ \text { 4. } & \text { Discussion }\end{array}$

9. A child with a health problem: more health problems in the parents?
Summary
1. Introduction
2. Method
$3 . \quad$ Results
4. Discussion

10. Computerization of General Practices and Quality Control. Blood glucose regulation in type 2 diabetics investigated in the Registration Network Family Practices.

$\begin{array}{ll} & \text { Summary } \\ \text { 1. } & \text { Introduction } \\ \text { 2. } & \text { Method } \\ \text { 3. } & \text { Results } \\ \text { 4. } & \text { Discussion }\end{array}$



Summary
1. Introduction
2. Is it possible to establish a computerized anonymous database continuously fed by general practitioners with certain patient characteristics and relevant health problems?

3. Can the data of the Registration Network Family Practice be used for research, medical education and quality assurance?

3.1 The possibilities

3.1.1 Use of the database for the present study

3.1.2 Use of the database for other studies

3.1.2.1 Use of the database as a source of information

3.1.2.2 Use of the database as a sampling frame

3.2 Limitations

4. Future developments

5. General conclusion

12. Summary

13. Samenvatting

Dankwoord

Deelnemende praktijken/huisartsen 
Chapter 1:

\section{General introduction}

Job FM Metsemakers 


\section{General introduction}

In his book: "The Third Wave" the American sociologist Alvin Toffler states: "Until now the human race has undergone two great waves of change, each one largely obliterating earlier cultures or civilizations and replacing them with ways of life inconceivable to those who came before. The First Wave of change - the agricultural revolution - took thousands of years to play itself out. The Second Wave the rise of the industrial civilisation -took a mere three hundred years. Today history is even more accelerative, and it is likely that the Third Wave will sweep across history and complete itself in a few decades". " The Third Wave is the result of technological developments especially in the field of informatics. Toffler predicts that these developments will bring a genuinely new way of life with great impact on all sectors of society. Futhermore, he incites us to take part in these new developments. Van Bemmel, the author of the book Introduction to Medical Informatics, calls the present period: "the century of communication" ${ }^{2}$. Information and transfer of information are key words in our time.

These technological developments in informatics are also visible in health care. Computers have been introduced into hospitals many years ago and now play a prominent role in clinical care both for administrative and medical data. The introduction of health information systems in general practice has been a process of ebb and flow, which started around 1980 with a small group of computer pioneers. ${ }^{3}$ Hoppener has documented and analysed the first ten years of this process in his thesis. ${ }^{4}$ At the same time, the introduction of computers in general practice coincided with a growing interest on the part of general practitioners in using their medical notes for research purposes. One way to make use of the practice computer for that purpose was described in 1984 by De Geus, von Höfen and Metsemakers. ${ }^{5}$ Their ideas were based on a project at the Department of General Practice of the University of Limburg. The purpose of the project, named Record keeping and Registration in General Practice, was to document input, throughput and output of a consultation, meaning documentation of the history, the physical examination, the assesment and the plan of action, including prescriptions. ${ }^{6}$ It was thought that entering these data in SOAP* structured notes would enable the coding of all elements, although at that time no sufficient classification was available. General practitioners cooperating in the project participated in a trial using the Reason for Encounter Classification (RFE-C), the predecessor of the International Classification of Primary Care (ICPC), and developed a coding list for physical examination. ${ }^{7-9}$ Furthermore, they collaborated with the Department of Medi-
$S$ ubjective
O bjective
A ssesment
$P$ lan 
cal Informatics in building a health information system suitable for the project's specific registration needs. ${ }^{10}$ During that process it became evident that gathering data on all elements of all consultations would be a tremendous task, attended by great risks. First of all, it would require an enormous computer capacity to store and retrieve all these data. But more importantly, it was questionable whether the data would be useful for research, which was the project's original purpose. Would researchers ask for more detailed data on some aspects, if the data already gathered had proved of no use to them? Would the database be able to answer superficial questions but unable to provide answers to more detailed studies? It was feared that the project would create a dead database.

It was therefore believed that it would be wiser to leave all detailed consultation data in the health information system of the general practitioners and find a way of unlocking this detailed database if needed. It became the basic philosophy of the Registration Network Family Practices to establish a University based computerized anonymous database containing certain patient characteristics and all relevant health problems. ${ }^{11}$ Höppener has demonstrated that computerization of general practices participating in the Registration Network Family Practices facilitates research. ${ }^{4}$

This study of the Registration Network Family Practices is focused on the instrument itself, its possibilities and limitations.

The leading questions were:

Is it possible to establish a computerized anonymous database continuously fed by general practitioners with certain patient characteristics and relevant health problems?

More specifically: does the concept of the problem list work ? are the data reliable?

Can the data from the Registration Network Family Practices be used for research, medical education and quality assurance?

More specifically: what are the possibilities?

what are the limitations?

The answer to these questions is given in Chapters 3, 4, 5 and 11 , which deal with the description and evaluation of the instrument. Chapters 6 - 10 can be seen as examples of the use of the database of the Registration Network Family Practices. This thesis contains several published articles. A repeated description of the Registration Network Family Practices and its use was, therefore, inevitable. 
The rich Dutch history of registration in general practice is described in Chapter 2. This chapter also provides a detailed overview of current registrations in general practice in the Netherlands, while attention is also given to (sentinel) health information projects with general practitioners in Europe and primary care registrations in other countries.

Chapter 3 describes the Registration Network Family Practices in greater detail, providing insight into the instrument and the participating general practices, as well as general information on the database and its use.

How and when health problems and diagnoses are to be defined and recorded in the Registration Network is described in Chapter 4, which also provides an analysis of certain problem types present in the general database.

Chapter 5 deals with doctors, patients and the quality of the data. The participating general practitioners are compared with the population of general practitioners in the Netherlands on several characteristics. Likewise, the patient population of the network is compared with the Dutch population as a whole. A detailed description of our quality control programme is given and several experiments are described.

Chapter 6 describes the matching of epilepsy cases in the Registration Network Family Practices and the Maastricht Epilepsy Case Register. This study was undertaken to investigate the completeness of both registers.

A comparison of the content of the problem-based medical curriculum in use at the University of Limburg at Maastricht with primary health care data coming from the Registration Network Family Practices is presented in chapter 7, showing the use of data from the registration for educational purposes.

Chapter 8 demonstrates that data from the Registration Network can be used at macro-level in assessing the burden of illness in a community.

Use of registration data at the level of families is described in Chapter 9, which compares the number of health problems in parents of children with health problems and parents of children without health problems.

How the sampling frame of the Registration Network can be used to identify diabetes mellitus patients for a quality assurance study is demonstrated in Chapter $\mathbf{1 0 .}$

In Chapter 11 the original questions of this study are evaluated and the possible future course of the Registration Network Family Practices is anticipated. 


\section{References}

1. Toffler A. The Third Wave. Toronto: Bantam Books Inc., 1980

2. Bemmel JH van. Inleiding Medische Informatica. Utrecht: Bohn Scheltema \& Holkema, 1981

3. Springer HP, Slager JN, Perk HA van der. Waarom automatiseren in de huisartspraktijk? Med Contact 1984;39:1445-1446

4. Hōppener P. Automatisering en wetenschappelijk onderzoek in de huisartspraktijk. [PhD thesis University of Limburg] Maastricht: 1990

5. Geus CA de, Hōfen R von, Metsemakers JFM. Op weg naar een geautomatiseerd registratiesysteem voor wetenschappelijk onderzoek in de huisartspraktijk. Med Contact 1984;39:1289-1290

6. Metsemakers J, Seelen A. Het Basisproject Verslaglegging en Registratie in de huisartspraktijk. Een rapportage. Rapport RNH/RL 3. Rijksuniversiteit Limburg. Maastricht, 1985

7. Lamberts $\mathrm{H}$, Meads $\mathrm{S}$, Wood $\mathrm{H}$. Waarom gaat iemand naar de huisarts. Huisarts Wet $1984 ; 27: 234-244$

8. Horst F van der, Metsemakers J, Vissers F, Saenger G, de Geus C. The reason for encounter mode of the ICPC: reliable, adequate and feasible. Scan J Prim Health Care 1989;7:99-103

9. Leclercq R, de Geus C. De CO codelijst. Huisarts Wet 1985;7:235-238

10. Dupuits F, Hasman A, Schoonbrood G, Plagge H. A research tool for GP's. Int J Biomed Comput 1987:21:275-286

11. Metsemakers JFM, Hōppener P, Knottnerus JA, Kocken RII, Limonard CBG. Computerized health information in the Netherlands: a registration network of family practices. Brit J Gen Pract 1992;42:102-106 
Chapter 2:

Sentinel stations and general practice registrations.

History and current situation.

Job FM Metsemakers 


\section{Summary}

Sentinel stations and general practice registrations have been developed in many countries. This chapter describes the history of the Dutch registrations, starting with the Intermittent Morbidity Study in 1966. Based on the different types of general practice registrations, such as time limited morbidity studies, continous morbidity registrations, and sentinel stations, an overview is provided of the 13 current general practice registrations. Although the purpose of all registrations is to collect data on general practice, the specific aim and, therefore, the nature of the data collection vary considerably. Nevertheless, the entire spectrum of morbidity and related activities is covered.

General practice based registrations also exist in many other European countries, Canada, and the United States. A general picture of these registrations is given.

Computerization of general practices has facilitated the creation of national and international networks of collaborating practices, which can harvest the wealth of information on the health of patients available in general practice. 


\section{Introduction}

The history of medicine shows that much knowledge has been accumulated due to painstakingly accurate description of patient complaints, observations and investigations. Gathering and arranging facts and knowledge is the underlying principle of the empirical cycle. This is still true our days, now that our knowledge is based on the analysis of data collected in the field of medicine. Good record keeping and registration of specific items is a prerequisite not only for adequate care but also for research, either by general practitioners or specialists in other medical disciplines.

This chapter first describes the history of general practice registrations in the Netherlands. Subsequently, current sentinel stations and general prar tice health information registrations in the Netherlands will be reviewed and compared. The: chapter ends with a short overview of European and other international primary care registrations.

A great difficulty in providing this overview of general practice registrations is the fact that relatively few registrations have made their existence known by publication in a indexed journal. Results are often locally distributed, and publications on the basis of these registrations are difficult to trace.

\section{The Netherlands}

\subsection{The starting period of general practice registration}

The process of growth of general practice as a distinct discipline in the medical field brought many changes. The general practitioner had to define his role among other generalists and to defend his position against specialists. General practitioners talked about their profession at conferences and working parties. They organised themselves in the Dutch College of General Practitioners. One of the first items on the agenda of the College was the need for more detailed information on the morbidity seen by general practitioners. Although the first steps towards a national morbidity study were taken in 1956, it took until 1966 before the "Intermitterend Morbiditeits Onderzoek" (Intermittent Morbidity Study) got underway. ${ }^{2}$ Its goal was to provide information on the prevalence of diseases in a sample of the Dutch population observed by general practitioners. 52 general practitioners participated in the study by recording the morbidity they encountered during one week per quarter over the period of December 1966 until December 1967. This study by Oliemans is seen as the starting point of general practice morbidity studies in the Netherlands. Around the same time, Huygen developed the structure of the Continuous Morbidity Registration (CMR). Several general practitioners who had participated in the Intermittent. Morbidity Study joined the CMR between 1967 and 1970. This registration was later linked to the Department of General Practice at Nijmegen University and has proved to be a very valuable 
source of information, on which many studies have been based. ${ }^{3}$ The Intermittent Morbidity Study was done by 52 general practitioners distributed evenly over the country, in order to guarantee representativity with regard to the degree of urbanisation. This profile of the participating practices was useful for a national sentinel practice network, which was felt to be necessary by the Ministry of Health Care. Several sentinel practices were already monitoring some infectious diseases such as measles and influenza, but their representativity was believed to be insufficient. The incorporation of the practices of the original Intermittent Morbidity Study meant that the Dutch Sentinel Practice Network had started. ${ }^{4,5}$ By the end of the 1960s these activities led to the development of several local, regional and national general practice registrations.

\subsection{Different types of general practice registrations}

Based on the experiences of the first registrations and on the need for further studies, three types of general practice registrations came into existence:

- $\quad$ time limited morbidity studies such as the Intermittent Morbidity Study ${ }^{2}$ continuous morbidity registrations such as the Continuous Morbidity Registration Nijmegen ${ }^{3}$ sentinel stations such as the Dutch Sentinel Practice Network ${ }^{4,5}$

Most registration projects or studies are based on the principles of one of these types of general practice registrations.

\subsubsection{Time limited morbidity study}

The purpose of these studies is to gather data on morbidity and morbidity-related items such as reason for encounter, diagnostic procedures, prescriptions, referrals and outcome.

Ceneralization of the conclusions often require both the participating general practitioners and patients to be representative of a certain area or country. Since participation in such a study is very time-consuming general practitioners often participate only for a few months, in a rotating scheme.

The morbidity data gathered have been used in a number of morbidity related studies.

Examples of this type of time limited morbidity study are:

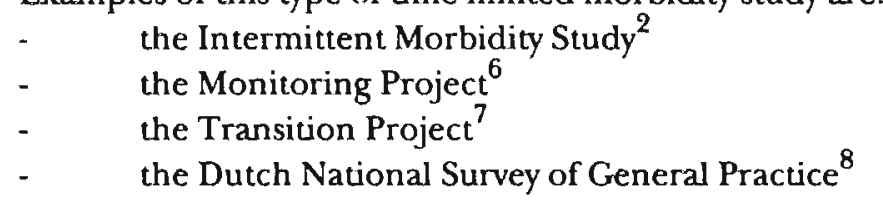

The Transition Project is carried out in seperate phases of several years each. It is therefore included as a time limited morbidity study. 


\subsubsection{Continuous "Morbidity" Registration}

The purpose of this type of registration is the monitoring of morbidity in a well defined, relatively stable patient population. The term "morbidity" is placed between quotation marks to indicate that not only morbidity data can be gathered, but depending on the registration, other health problems such as risk factors, family history and social problems as well. Since general practices who participate in such a continuous registration have to be highly motivated, there is often some form of selectivity. These registrations are often used as sampling frames.

The data gathered are available for further analysis and constitute the basis for further projects.

Examples of such types of Continuous "Morbidity" Registration are:

- Continuous Morbidity Registration Nijmegen

- Registration Network Family Practices ${ }^{9}$

- Registration Network Leiden ${ }^{10}$

- Registration Network Groningen ${ }^{11}$

- $\quad$ Rotterdam General Practice Project (ROHAPRO) 12

\subsubsection{Sentinel practice registration}

The purpose of a sentinel practice registration is to monitor certain health prob-lems, health questions or trends in health care. In the beginning, infectious diseases were the most important items registered. Later, other topics were added to the registration. Representativity of the general practitioners for a well-defined domain or area is important in allowing the finding to be generalized. The Dutch Sentinel Practice Network has a long history as a national project. At the regional level, several sentinel projects have been developed to serve the local needs experienced by local health authorities.

Examples of this type of Sentinel Practice Registration are:

$\begin{array}{ll}\text { - } & \text { Dutch Sentinel Practice Network } \\ \text { - } & \text { Sentinel stations Rotterdam } \\ \text { - } & \text { Sentinel stations Amsterdam } \\ \text { - } & \text { Sentinel stations Groningen } \\ \text { - } & \text { Sentinel stations Amstelland - de Meerlanden }\end{array}$

\subsection{A study of current general practice registrations}

\subsubsection{Methods}

All ongoing general practice registrations were reviewed. Based on the data published by Höppener, the general practice registrations received a questionnaire asking for detailed information on a number of items. ${ }^{17}$ The remaining questions were resolved in personal or telephone contacts with key persons of the general practice registrations. The questionaire was mailed in 1993; all registrations were given the opportunity to update their information in January 1994. 


\subsubsection{Results \\ 1. Sentinel Stations Rotterdam}

Management

Purpose

History

Participants

Computerization

of practices

Population covered

Registration content

Registration method

Usage of health

problems registered

Can the central

database be used for

patient selections
Municipal Health Department, Rotterdam

Early detection of a number of common infectious diseases; monitoring of prevalence; seasonal variance; distribution of infectious diseases per neighbourhood; monitoring infectious diseases which are notifiable according to existing law.

Started 1965 with 13 general practitioners and 5 dermatologists.

26 general practices; 27 general practitioners in the city and suburbs of Rotterdam, and in municipalities around Rotterdam

No

ca 65000 persons

Mainly infectious diseases

Forms with sex and age of the registered patients are sent weekly to the central facility at the municipal health service

At present used for research and health care policy

\section{Continuous Morbidity Registration Nijmegen}

Management

Purpose

History

Participants

Computerization

of practices

Population covered

Registration content
Department of General Practice, University of Nijmegen, Nijmegen

Registration for education and research purposes

Spectrum of morbidity in primary care; incidence and prevalence rates; longitudinal epidemiological descriptions of the history of diseases Contribution to family medicine and life stage medicine.

Index for selection of patients with certain diseases for further studies

Longitudinal analyses on more than 20 years of morbidity registration

Started 1967, in one large general practice; division of that practice and addition of two other practices in 1971; at present 4 general practices

4 general practices; 1 in the city; 1 in a neighbouring town and 2 in small communities; 7 general practitioners

Yes; age and sex register available on practice computer; practice computers are being tested for registration in the practices; Promedico HIS ca 12000 persons

Referrals; diagnoses; admissions 
Registration method

Usage of health

problems registered

Can the central

database be used for patient selections
General practitioners code on forms with patient identification; use of the E-list (Eimerl); forms are entered into the computer at the university; currently testing practice computers and decentralized data entry

Research, medical education and health care policy

Yes; each patient is anonymous in the central database but has a specific microsection number which identifies the patient in the practice

\section{Dutch Sentinel Practice Network}

Management

Purpose

History

Participants

Computerization

of practices

Population covered

Registration content

Registration method

Usage of health

problems registered

Can the central dacabase

be used for patient

selections
Netherlands Institute of Primary Health Care, Utrecht

Gathering reliable data on health problems, actions and occurrences in general practices covering $1 \%$ of the Dutch population

Started 1970

46 sentinel stations spread over the country; 65 general practitioners

No

ca 155000 persons

The topics are selected by a counselling committee. 10-15 topics are covered annually, most of them for several years. For instance: myocardial infarction; influenza like diseases; abortions; AIDS, pap smears

Data are entered on forms; weekly return to the Netherlands Institute of Primary Health Care (NIVEL)

Research and health care policy

No

\section{Sentinel Stations Amsterdam}

Management

Department of General Practice, University of Amsterdam, Amsterdam,

Purpose

Gathering data on morbidity, interventions and services relevant for general practice. Special emphasis on HIV; sexually communicable diseases; heart disease

History

Started in 1979 by the Amsterdam Municipal Health Service; since 1999 operated by the University of Ansterdam

Participants
31 general practices, all in the city of Amsterdam; 38 general practitioners covering $10 \%$ of the total population of Amsterdam 
Computerization of practices

Population covered

Registration content

Registration method

Usage of health

problems registered

Can the central

database be used for

patient selections
Around $50 \%$ of the general practitioners have been computerized; computers are not used for the sentinel registration at this moment, although plans are being made to start doing so; no specific health information software program

ca 72000 persons

For the 4 - 5 topics which are selected each year by the Department of General Practice, several items are registered: reason for encounter, complaints, investigations, procedures, prescriptions, referrals, diagnoses

Precoded forms are returned weekly to the data entry unit of the Department of General Practice

Research, medical education and health care policy

\section{Registration Network Family Practices}

Management

Purpose

History

Participants

Computerization

of practices

Population

covered

Registration content

Registration method

Usage of health problems registered
Department of General Practice, University of Limburg, Maastricht

Establishing a computerized anonymous database containing certain patient characteristics and all relevant health problems, in order to support research and educational programmes

Started officially 1981, as the Registration and Record keeping project Changed to Registration Network Family Practices in 1985

Computerization of general practices and registration in 1988

15 general practices with 45 general practitioners. Thirteen practices located in the southern part of the province of Limburg; two practices situated further to the north in the province of Limburg

All practices are fully computerized; MicroHIS

ca 80000 persons

All relevant health problems are registered on patient problem lists, together with a limited set of patient characteristics. All health problems are classified using the International Classification of Primary Care (ICPC)

The general practitioners complete the records for their patients on a daily basis. Every three months the data are made anonymous and transferred by floppy disc to the Medical and Social Information Center at the university

Research, medical education, practice management 
Patient selections can be made in the central database. The identification code allows for identification of the patient in the general practitioner's computer

\section{Registration Network Leiden}

Management

Purpose

History

Participants

Computerization

of practices

Population covered

Registration content

Registration method

Usage of health problems registered

Can the central database be used for patient selections

Department of General Practice, University of Leiden, Leiden

Establishing an index database with health problems and diagnoses to facilitate research projects. Problem lists and chronic medication are recorded in particular. Furthermore, encounter registration is to be undertaken in future.

Started 1989

4 general practices with 13 general practitioners; two practices are located in Leiden while the others are situated in nearby communities.

All practices are fully computerized; Medicom HIS

ca 20000 persons (3/93); expected growth 25000 persons

Problem lists and chronic medication for all patients. Registration of all encounters with regard to investigation, procedures, prescription, referrals, diagnoses. Data are classified using the International Classification of Primary Care (ICPPC)

Computerized data are transferred to the central database of the Department of General Practice

Research and medical education

Patient selection can be made in the central database. A patient number allows retrieval of the patient in the general practice computer

\section{Registration Network Groningen}

Management

Purpose

History

Participants

Computerization

of practices

Population covered
Department of General Practice, University of Groningen, Groningen

The purpose of the episode oriented morbidity registration is to gather data for research, medical education and heal th care policy

Started 1989

6 general practices with 15 general practitioners

All practices are fully computerized; MieroHIS

ca 20000 persons 
Registration content

Registration method

Usage of health problems registered

Can the central database be used for patient selections
Diagnoses, prescriptions, referrals and chronic medication of all encounters are recorded. The International Classification of Primary Care (ICPC) is used for diagnoses and referrals. Medications will be coded with the ATC

Data are entered by the general practitioner in the general practice health information system. Transfer to the Department of General Practice at the university

Research and health care policy

Patient selection can be made in the central database. A patientnumber allows retrieval of the patient data in the computer of the general practitioner

\section{Rotterdam General Practitioners Project (ROHAPRO)}

Management

Purpose

History

Participants

Computerization

of practices

Population covered

Registration content

Registration method

Usage of health problems registered

Can the central database be used for patient selections
Municipal Health Department, Rotterdam

Epidemiological and other scientific research based on data of computerized general practices in Rotterdam and surroundings.

Special emphasis on the use of problem lists

Started 1990

14 general practices with 20 general practitioners; $90 \%$ in the city of Rotterdam

All practices are fully computerized; MicroHIS and Elias HIS

ca 43000 ; expected to grow to 75000 persons

The registration is based on the health problems as registered on the problem list of the general practitioner. The International Classification of Primary Care (ICPC) is used. Furthermore, specific topics agreed upon by the Department of General Practice and the municipal health service are registered, for instance cardiovascular risk factors in men aged $40-70$.

All data are entered in the practice computer by the general practitioners. Every three months data are transferred on a floppy disc to the municipal health service

Data are used for research purposes and hopefulty for health care policy

Patient selection can be made in the central database. A patient number with a general practitioner code allows retrieval of the patient data in the practice computer of the general practitioners 


\section{Sentinel Stations Groningen}

Management

Purpose

History

Participants

Computerization

of practices

Population covered

Registration content

Registration method

Usage of health

problems registered

Can the central

database be used for

patient selections

Municipal Health Department, Groningen

Collecting data for textarch in general practice; gaining insight into practice management; developing a health calt policy especially fou primary prevention; surveillance of certain diseases. In the near titure special attention will be paid to the registration of on infections disease each year

Started 1990

13 practices with 13 general practitioners, $90 \%$ of whom work in a city

Only a few practices are computerized

ca 25000 persons

Each year 4 - 6 topics are selected by a committer represenung the municipal health services, the regional general practitioners and the Deparment of General Practice of the University of Groningen. Investigations, procedures, and diagnoses with regard to these topic's are registered

General practitioners fill in a form which is returned to the municipal health service on a weekly basis

Research, medical education and health care policy

No

\section{General Practitioners Network Utrecht}

Management

Purpose

History

Participants

Computerization

of practices

Population covered

Registration content
Department of General Practice, University of Utrecht, Utrecht

Conducting research with data collected in a general practice health information system. Longitudinal studies, sometimes episode criented, are undertaken as well as monitoring of preventive activities, prescriptions and referrals

Started 1985 as a network of practices participating in research

5 practices with 19 general practitioners, $30 \%$ located within the city of Utrecht, $70 \%$ in rural areas

All practices are fully computerized, using Elias HIS

ca 40000 persons

Each year, one topic is studied in detail, looking at reason for encounter, complaints, investigations, procedures, prescriptions, referrals, diagnoses. Furthermore, risk factors are registered continuously and 

(ICPC)

Registration method

Patients suitable for the current research topic are labelled in the computer. The computer presents the general practitioner with additional questions whenever the labelled patient consults his GP

Usage of health

problems registered

For research and medical education

Can the central

database be used for

patient selections

No

\section{Sentinel Station Amstelland - de Meerlanden}

Management

Purpose

History

Participants

Computerization

of practices

Population covered

Registration content

Registration methods

Usage of the registered

health problems

Can the central

database be used for

patient selections
Municipal Health Department Amstelland - de Meerlanden, Amstelveen

Gaining insight into the health situation of the population; Spotting certain trends and stimulating cooperation with the curative field

Started 1992

19 practices with 20 general practitioners; $60 \%$ located in a city

No computerization at this moment but there are plans

ca 50000 persons

Every year some topics are selected for further study. 1992/1993: trauma treatment; lung diseases; problem drinkers; 1993/1994: respiratory tract infections; requests for second opinion; psychosocial referrals. Certain items are registered per topic

General practitioners fill in a form which is returned weekly to the municipal health service, where data are entered into the computer

Health care policy

\section{Nationwide Information Network GP Care}

Management

Purpose

History

Participants
Netherlands Institute of Primary Health Care (NIVEL), Utrecht

Investigating ways of gathering continuously both qualitative and quantitative information on care provided by general practitioners

Started 1992

22 practices with 40 general practitioners, $30 \%$ working in a city, the rest in rural areas 
Computerization

of practices

Population covered

Registracion content

Registration method

Usage of health

problems registered

Can the central

dacabase be used for

patient selections
All practices are fully computerized; MicroHIS and Flias HIS

At this moment 83000 but growth to 350000 is expected

Registration of actions such as investigations, referrals and prescriptions. Follow up on the use of standards of care as proposed by the Dutch College of General Practitioners

General practitioners use their practice computer to enter the requested information. Data are transferred to the Netherlands Institute of Primary Health Care (NIVEL) for further analysis

Research and health care policy

Yes, in the near future

\section{Transition Project (Phase III)}

Management

Purpose

History

Participants

Computerization

of practices

Population covered

Registration content

Registration method

Usage of health

problems registered

Can the central

database be used for patient selections
Department of General Practice, University of Amsterdarn, Amsterdam

To create an episode-oriented epidemiology in general practice and to investigate transitions in time of relations between reasons for encounters, diagnoses and interventions within episodes of a continumus registration

Transition Project Phase I: 1985 - 1988; Transition Project Phase II: 1988 - 1994; Transition Project Phase III: pilot 1994; final: 1995 - 1997

Pilot phase: 3 practices with 7 general practitioners, $30 \%$ located within the city, $70 \%$ in rural areas; final: 20 general practitioners

All practices will be fully computerized using TransHIS

Pilot phase: ca 20000 ; final: ca 40000 persons

Reasons for encounters, sypmtoms/complaints, diagnoses, the process of care including examinations, diagnostic investigations, prescriptions and referrrals are recorded.

The International Classification of Primary Care (ICPC) is used for classification.

Continuous registration and classification of all doctor - patient contacts in a computerized general practice health information system (TransHIS)

Research, medical education and health care policy

Yes 


\subsection{Discussion}

This study describes 13 sentinel stations and general practice registrations, 9 of which had been studied by Höppener. ${ }^{17}$ The Sentinel Stations The Hague have stopped their registration activities, as have some other local and regional sentinel stations, such as Sentinel Stations Zuid-Kennemerland and Sentinel Stations Almete. One of the reasons for stopping was the disproportion between the elaborate method of data collection and the time left for analysis and implementation of changes. On the other hand, new registrations like the Registration Network Groningen, the Sentinel Stations Amstelland - de Meerlanden, and the Nationwide Information Network of GP Care have started their activities. Table I gives an overview of current registrations, with some key data. Although the purpose of all registrations is to collect data on general practice, their specific aims and hence the data collected vary considerably (Table 2). Another difference between the registrations is the relation with their general practitioners. Almost all projects provide general feedback on the data collected by the general practitioners, but only seven hold regular meetings (at least once every 3 months) with the participating general practitioners to discuss difficulties with the registrations or guidelines, systematic errors or individual mistakes (Table 3). The differences between the registrations can be explained by looking at the institution establishing the registration. The older sentinel stations, established by municipal health departments, were at first focused on infectious diseases, but have changed their direction and now record data on certain topics relevant to both the municipal health authorities and the general practices. Some sentinel stations have established formal relations between the local health authorities and the general practice department; this is the case for instance at the Sentinel Stations Amsterdam and the Sentinel Stations Groningen. Several aspects of morbidity in general practice have been documented in morbidity surveys such as the Monitoring Project, the Transition Project and the Dutch National Survey of General Practice. . $^{6-8}$ Continuous registration of all morbidity in general practice is executed in the Continuous Morbidity Registration Nijmegen and also, although to a limited extent, in the Dutch Sentinel Practice Network. ${ }^{3-5}$

Several registration networks for general practices which are linked to a university general practice department use the problem list as their "morbidity" registration, sometimes with additional registration of encounter based data. The general practices of these registrations are fully computerized, which makes it possible to select patients from the central database and to retrieve data for these patients from the general practitioner's computer, all within limits set by privacy regulations. Examples are the Registration Network Family Practices (1988); the Registration Network Leiden (1989); the Registration Network Groningen (1989) and the Rotterdam General Practitioner Project Rotterdam (ROHAPRO) (1990). ${ }^{9-12}$ The General Practitioner Network Utrecht operates as a computerized research facility for specific projects and does not include a continuous registration of morbidity. The Nationwide Information Network of GP Care uses computerized general 


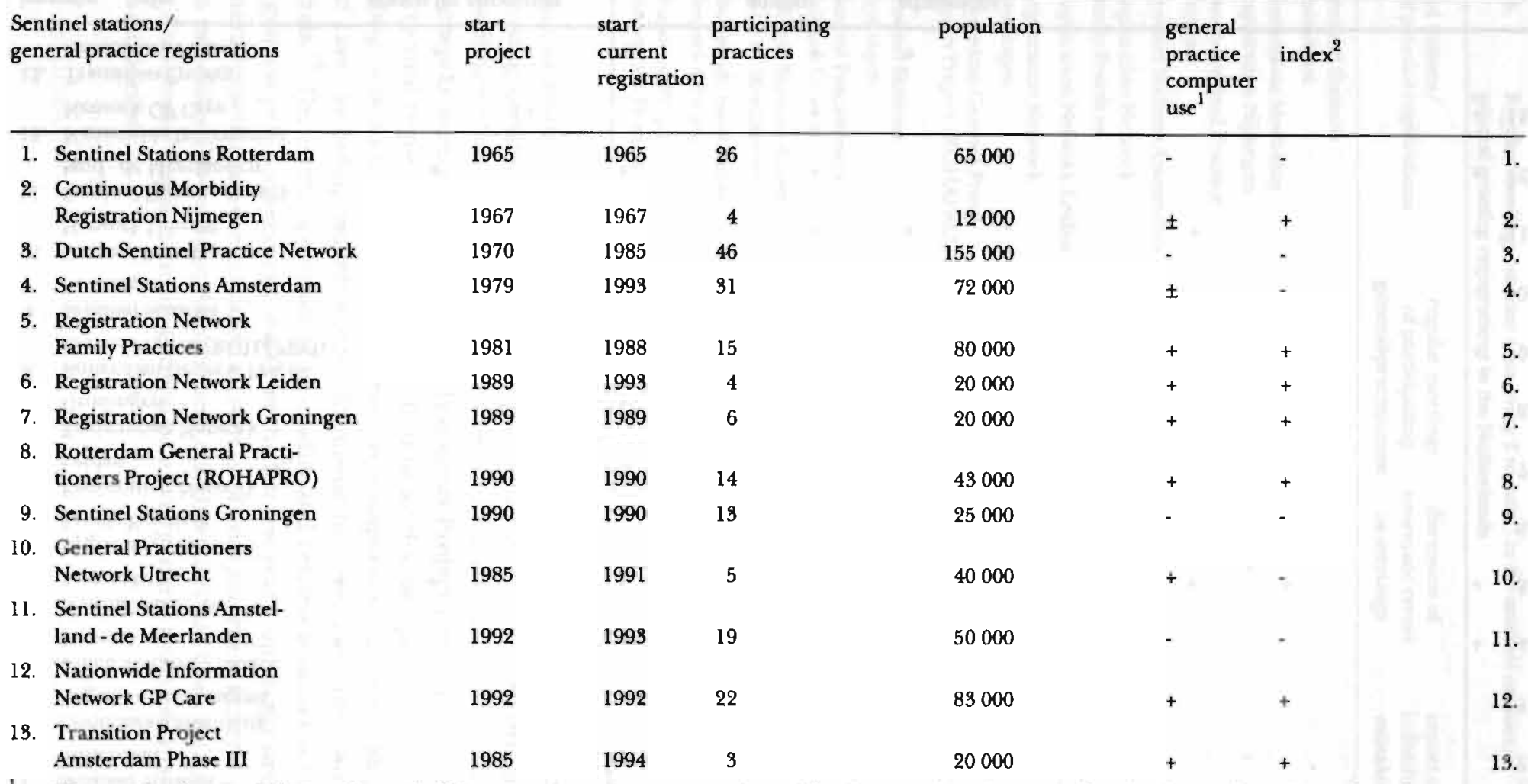

The question is regarded as positive only if the general practice computer is used for diata entry into the sentinel station/general practice registration.

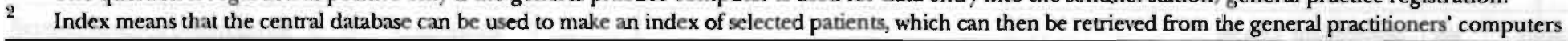



general practice registrations

\section{fe sympt/ investig proced prescr} complaints

\section{presc}

referr diagn

1. Sentinel Stations Rotterdam

2. Continuous Morbidity Registration Nijmegen

3. Dutch Sentinel Practice Network

4. Sentinel Stations Amsterdam

5. Registration Network Family Practices

6. Registration Network Leiden

7. Registration Network Groningen

8. Rotterdam General Practitioners Project (ROHLAPRO)

9. Sentinel Stations Groningen

10. General Practitioners Network Utrecht

11. Sentinel Stations Amstelland - de Meerlanden

12. Nationwide Information Network GP Care

13. Transition Project Amsterdam Phase III

$+$

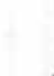

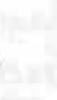

$+$


Sentinel stations/

general practice registrations

$\begin{array}{ccc}\begin{array}{c}\text { regular meetings } \\ \text { of participating }\end{array} & \begin{array}{c}\text { discussion of } \\ \text { systematic errors }\end{array} & \begin{array}{c}\text { report on } \\ \text { individual }\end{array} \\ \text { general practitioners } & \text { in meetings } & \text { mistakes }\end{array}$

1. Sentinel Stations Rotterdam

2. Continuous Morbidity Registration Nijmegen

3. Dutch Sentinel Practice Network

4. Sentinel Stations Amsterdam

5. Registration Network Family Practices

6. Registration Network Leiden

7. Registration Network Groningen

8. Rotterdam General Practitioners Project (ROHAPRO)

9. Sentinel Stations Groningen

10. General Practitioners Network Utrecht

11. Sentinel Stations Amstelland - de Meerlanden

12. Nationwide Information Network GP Care

13. Transition Project Amsterdam Phase III

practices as sentinel stations monitoring certain items and also as research practices studying certain topics concerning quality of care. ${ }^{18}$ Furthermore, it provides the possibility of patient selections from the central database, as do the registration networks mentioned above. The Transition Project now pilots a computerized decentral registration and classification of all doctor - patient contacts, while recording reasons for encounters, sypmtoms/complaints, diagnoses and the process of care including examinations, diagnostic investigations, prescriptions and referrrals. ${ }^{19}$ The entire spectrum of morbidity and related activities is covered by these general practice registrations. Over the last few years university departments of general practice have established networks of computerized general practices, and in two cities (Rotterdam; Amsterdam) collaboration has been established between a university department of general practice, general practitioners and local health authorities. 


\section{Other countries}

\subsection{General practice based registrations in Europe}

The development of general practice registration started in the United Kingdom. The Weekly Returns Service, which monitors the incidence of common communicable and infectious diseases, was established in $1962 .{ }^{20}$ It has been an example to other monitoring projects in the United Kingdom but also in the Netherlands, where the Intermittent Morbidity Study was based on the same principles. ${ }^{2}$ Furthermore, Britain has carried out national morbidity surveys, the last one in the beginning of $1980 .{ }^{21}$ Again, these were seen as examples of how to conduct such a study. Many countries have established general practice registrations, certainly after the introduction of general practice health information systems. In 1987, and again in 1990, an inventory of sentinel health information systems involving general practitioners was made by Van Casteren on behalf of the European Community. ${ }^{22,23}$ This inventory was based on a questionnaire sent to all known persons in charge of or at key positions in sentinel and research networks involving general practitioners. Although Switzerland is not a member country of the European Community, it was also included. This method does not guarantee completeness, and there may be other general practice registrations or health information systems at local or regional level which were not included in the inventory. The study identified 36 health information systems involving general practitioners.

Table 4 shows the distribution of national versus regional/ local networks in the different countries. Most countries have at least one national registration involving general practitioners, except Denmark and Greece, where efforts are being

Table 4. Distribution of general practice health information registration systems in European countries

\begin{tabular}{lccc}
\hline & National & Regional/Local & Total \\
\hline Country & & & \\
Belgium & 1 & 0 & 1 \\
Denmark & 0 & 0 & 0 \\
France & 1 & 6 & 7 \\
Great Britain & 2 & 3 & 5 \\
Germany & 0 & 2 & 2 \\
Greece & 0 & 0 & 0 \\
Ireland & 1 & 0 & 1 \\
Italy & 2 & 1 & 3 \\
Portugal & 1 & 0 & 1 \\
Spain & 0 & 5 & 5 \\
Swizzerland & 1 & 0 & 1 \\
Necherlands & 1 & 9 & 10 \\
\hline & 10 & 26 & 36 \\
\hline
\end{tabular}


made to establish a sentinel network. Germany and Spain have regional networks but no national sentinel practices. The Netherlands has a relatively large number of regional/local registrations.

Infectious diseases such as mumps, measles, chickenpox, influenza, viral hepatitis and venereal diseases are monitored by 21 sentinel practices. Most practices also monitor non-infectious diseases. There is a great variety of items, ranging from dependence on nasal vasoconstriction and methadone prescription to asthma, hypertension and dementia. Three items show up in several registrations: suicide or attempts; abortion and cerebrovascular accidents. Only in the Netherlands do general practice health information systems exist which record the complete spectrum of diseases and health problems.

Although computers have become indispensable for data analysis in all registration projects, they are generally not used for data entry at the source. Most general practitioners record the data gathered in their practice on a form which is sent on a weekly or monthly basis to the central office of their registration project, where they are entered into a computer data base and reports are generated.

France is the only country in which tele-informatics or direct telephone link-up with the central computer (Minitel) is practised by 4 of the 7 general practice based registrations. In Great Britain general practitioners in one of the national morbidity networks use microchips (EPROM data pack) to transmit their data to the research unit. Two general practice registrations in the Netherlands use the general practice office computer to gather the requested data. These are then transmitted by tape or disk to the central facility.

As a result of the first report on sentinel general practice registration, Eurosentinel was established in 1988. The purpose of Eurosentinel is to coordinate activities in the field of sentinel networks and to establish a European sentinel network. Under the aegis of Eurosentinel several studies have been undertaken in which sentinel networks of different countries participate. Subjects studied range from comparison of the number of laboratory tests and requests for HIV tests in general practices in different countries to the surveillance of measles and mumps. Eurosentinel offers an opportunity to compare health care data from different European countries.

\subsection{Primary care based registrations in Canada and the United States}

One of the most difficult aspects of reviewing other sentinel health information systems is obtaining basic information about them. The inventory made by Van Casteren in the European Community does not claim completeness. For non-Furopean or trans-atlantic countries it is even more difficult to take stock of existing sentinel health information systems or primary care networks, since only a few have made their existence known by publication. Publications were found from Canada and the United States. Health information systems in Canada and the United States are described more in detail in the following paragraphs. 


\subsubsection{Canada}

The prospect of a swine flu epidemic and the question of how to set up an early warning system led in 1976 to the development of a nationwide system in Canada, originally labelled the National Recording System (NaReS) ${ }^{24}$ Later on NaReS became involved in other research studies, sometimes on a nationwide scale, sometimes at provincial level. Studies were undertaken on geriatric patients, on the effect of a quit smoking test, and on new drugs. In fact, NaReS became a network of practices participating in research and was in 1988 renamed as the National Research System (NaReS), reflecting its potential as a tool for family practice research. NaReS is now both a nationwide and a provincial network. Furthermore, several university based networks exist on a continuous basis or only for a specific study.

\subsubsection{United States}

Around 1970, family medicine as developed in the United States was a young discipline, lacking a good description of what was seen in primary care. From July 1 , 1973 to August 1, 197582 family practice residents and 36 practising family physicians in the State of Virginia recorded all patient problems, creating a database with 526196 patient problems for patient care, curriculum and research. ${ }^{25}$ This Virginia study is considered a first important step towards collaboration between family physicians. This led in other states and regions to the creation of networks, often under the auspices of the regional Academy of Family Physicians or a Medical College. A survey by the Ambulatory Sentinel Practice Network (ASPN) of other existing practice based networks in family practice (United Stated and Canada) identified 13 networks around the two countries. ${ }^{26,27}$ Some groups have published reports about their existence, such as the Cooperative Information Project (COOP), the Family Medicine Information System (FMIS), and the Missouri Network. ${ }^{28-31}$ The existence of these regional networks and the possibilities for research led to the idea of the Ambulatory Sentinel Practice Network (ASPN). It was proposed as a binational research network involving practices from the US states and Canadian provinces. The network was created to study problems as they presented in the primary care setting. ${ }^{26,32}$ Initially, 25 primary care practices were sought in 1982 and 36 were actually recruited. The network had increased to 65 practices by the end of 1987 and to 71 in the beginning of 1992 . Several research topics have been studied, such as spontaneous abortion, headache, pelvic inflammatory disease, chest pain, AIDS. ${ }^{33-37}$ According to Green, practice based networks hold great promise as the primary care research laboratories of the next century. ${ }^{38}$

\subsection{Primary care based registrations around the world}

When primary care researchers found out that sentinel health information systems and practice based networks were in existence or being developed in many countries, they envisioned the International Primary Care Network (IPCN). This 
network of existing sentinel health information system was set up to study problems of primary care in an international context, comparing the differences between nations. ${ }^{39}$ The International Primary Care Network started with 9 participating countries and helped initiate networks in several other countries. The first topic of their international collaboration was a study on the diagnosis and antibiotic treatment of acute otitis media. ${ }^{40}$ The structure of such an international network composed of country networks and sentinel practices has several limitations, since representativity is very difficult to achieve. Cultural differences may influence the behaviour of patient and doctor. Nevertheless, it is felt that international cooperation does expand the knowledge of primary care.

\subsection{Discussion}

Since the survey by the Ambulatory Sentinel Practice Network identified 13 practice based networks in family practice in the United States and Canada, it will be clear that many more local and regional collaborations between general practices and institutions must exist, probably in all countries where general practice or family medicine is well developed. Many of these networks are functioning at a local or regional level and are therefore not well known. The National Research System (NaReS) in Canada and the binational Ambulatory Sentinel Practice Network (ASPN) have proved themselves as established networks for research. ${ }^{24-26}$ Further cooperation between different international networks has been established in the International Primary Care Network (ICPN). ${ }^{40}$

\section{Conclusion}

General practitioners possess a wealth of information on the health of their patients, and on many aspects of medical treatment. Many of these illnesses have a low prevalence, making the design of an appropriate study difficult. Monitoring for certain conditions, mostly communicable and infectious diseases, and reporting them to a central office has been the basis of the well-established sentinel stations in the United Kingdom and the Netherlands. Studying morbidity and related activities in general practices has followed both in the United Kingdom and the Netherlands. Collaboration between several general practices in the creation of a network dedicated to the study of topics relevant to general practice has proved to be possible in research networks in several countries. The computerization of general practices has led to the belief that large databases could be created, serving all future research needs. Providing general practices with a computer and having them record, in a standardized manner, information on demographic data, all medical diagnoses, referrals to hospitals, and all prescriptions proved to be more difficult than had been assumed. ${ }^{41,42}$ The use of large clinical databases for outcome research has been proposed by others, although the greatest problem would be to establish an accepted description of what clinical information should be recorded and in which format. ${ }^{43-45}$ Linking general practices in a natio- 
nal or international network would therefore be very difficult, regardless of the differences between computer programs. Defining a limited data set with some patient characteristics and relevant health problems could create a database that many general practices could easily contribute to.

Such a database can then be used as a sampling frame, allowing researchers to identify patients with particular health problems or combinations of problems. Study and control groups can be assembled for various study designs, such as clinical trials, cohort studies and case control studies. Additional data can be collected either in the general practitioner's health information system or by interviewing or examining the patients selected. ${ }^{9}$ The role of the general practitioners is crucial in all these sentinel stations and general practice registrations. They require discipline in record keeping and motivation to do so for many years, as well as financial support from governments, medical insurance companies or health agencies, to create a suitable environment for general practice registrations.

\section{Acknowledgements}

The author would like to thank all the correspondents of the general practice registrations for returning the questionaires.

\section{References}

1. Whithering $W$. An account of the foxglove and some of its medical uses: with practical remarks on dropsy and other diseases. Birmingham: 1785

2. Oliemans AP. Morbiditeit in de huisartsprakujk [PhD thesis University of Leiden] Leiden: Stenfert Kroese, 1969

3. Weel C van, Bosch WJHM van den, Hoogen HJM van den. De Continue Morbiditeitsregistratie Nijmegen. Huisarts Wet 1986;29:373-377

4. Bartelds AIM, Fracheboud J, Zee J van der. The Dutch Sentinel Practice Network: relevance for public health policy. Utrecht: Netherlands Institute of Primary Health Care, 1989

5. Bartelds AM. Continue Morbiditeits Registratie Peilstations Nederland 1987. Huisarts Wet 1990 33;2:74:77

6. Limberts H. Morbidity in General Practice. Diagnosis related information from the Monitoring Project. Utrecht: Huisartsenpers, 1984

7. Lanberts H, Brouwer H. Groen ASM, Huisman H. Het transitiemodel in de huisartspraktijk. Huisar ts Wiet 1987:30: 105-113

8. Van der Velden I. De Bakker DH, Claessens AAMC, Schellevis FG. Morbidity in general prartice. Dutch National Survey of general pracuce. Utrecht: Netherlands Institute of Primary Health ( iare, 1992

9. Mrtsemakers JFM, Höppener P. Knottnerus JA, Kocken RJJ, I imonard CHBG. Computerized health information in the Netherlands: a registration network of family practices. Br J Cir:n Pract 1992;42: 102-106

10. Registration Network Leiden (RNH-IEO). Gezondheidsproblemen en diagnoses in de huisartspraktijk. Leiden: Department of General Practice, 1992

11. Werf G van der. Regisuatienet Groningen. Projectbeschrijving. Groningen: 1992 (Internal Report) 
12. Middelkoop B, Beek A, Boon WM, van der Does E. Geautomatiseerde huisartspraktijken als basis voor onderzoek. TMI 1992;21:75-78

13. Huisman J. Vijftien jaar peilstationonderzoek - vijftien jaargangen Epidemiologisch Bulletin. Huisarts Wet 1980;23:360-364

14. Leentvaar-Kuypers A. Jaarverslag 1988 Amsterdam Peilstation Project. Amsterdarn: 1989

15. GGD Groningen Stad en Ommelanden. Huisartsenpeilstation Groningen. Groningen: 1993

16. Projectgroep HPS. Handleiding Huisartsenpeilstation Amstelland - de Meerlanden 1992-1993. Amstelveen: 1992

17. Hōppener P. Automatisering en wetenschappelijk onderzoek in de huisartspraktijk. $[\mathrm{PhD}$ thesis University of Limburg] Maastricht: 1990

18. Stokx L, Van der Velden J, Grol RPTM, Berden BJIM. De noodzaak van goede informatievoorziening in de gezondheidszorg. Med Contact 1994;18;611-613

19. Lamberts H, Oskam SK, Hofman-Okkes IM, Brouwer HJ, Mohrs J, Groen ASM, Veltman MTM. Episodegegevens uit het Transitieproject op de personal computer: gebruiksmogelijkheden van "Trans". Huisarts Wet 1994 (Submitted for publication)

20. Fleming DM, Crombie DL. The incidence of common infectious diseases: the weekly returns service of the Royal College of General Practitioners. Health Trends, 1985; 17: $13-16$

21. Royal College of General Practitioners, Office of Population Censuses and Surveys and Department of Health and Social Security: Morbidity Statistics from general practice. Third national study 1981-1982 London: HMSO, 1986

22. Van Casteren V. A descriptive study on sentinel health information systems with GP's in the countries of the European Community. Brussels: Institute of Hygiene and. Epidemiology, 1987

23. Van Casteren V. Inventory of Sentinel Health Information Systems with GP's in the European Community. Brussels: Institute of Hygiene and Epidemiology, 1991

24. The National Influenza Surveillance Working Party. Canadian Influenza Surveillance: First report: Methods of the National Recording System. Can Fam Physician 1977;23: 1054-1062

25. Marsland DW, Wood M, Fitzhugh M. A data bank for patient care, curriculum, and research in Family Practice: 526.196 patient problems. J Fam Pract 1976;1:25-28

26. Green LA, Wood M, Becker LA et al. The Ambulatory Sentinel Practice Network: Purpose, methods and policies. J Fam Pract 1984;18:275-280

27. Nutting P. Survey of practice based research networks in Family Medicine. (1993, personal communication)

28. Nelson EC, Kirk JW, Bise BW et al. The Cooperative Information Project; Part 1: A Sentinel Practice Network for Service and Research in Primary care. J Fam Pract 1981;5:641-649

29. Nelson EC, Kirk JW, Bise BW et al. The Cooperative Information Project; Part 2: Some Initial Clinical, Quality Assurance and Practice Management Studies. J Fam Pract 1981;6:867-876

30. Green LA, Simmons RL, Reed FM, Warren PS, Morrison JD. A family medicine information system: the beginning of a network for practicing and resident family physicians. J Fam Pract $1978 ; 7: 567-576$

31. Williamson HA, Hector MG, LeFevre M, White RD. Establishing a rural family practice research network. Fam Med 1988;20:51-54

32. Iverson DC, Calonge BN, Miller RS, Niebauer LJ, Reed FM. The development and management of a primary care research network, 1978-87: A report from ASPN. Fam Med 1988;20:177-181

33. Green LA, Becker LA, Freeman WL, Elliot E, Iverson DC, and Reed FM. Spontaneous abortion in primary Care: A report from ASPN. J Am Board Fam Pract 1988;1:15-23 
34. Becker LA, Iverson DC, Reed FM, Calonge BN, Miller RS, Freeman WL. Patients with New Headache in Primary Care: A report from ASPN.J Fam Pract 1988;1:41-47

35. Freeman WL, Green La, and Becker LA. Pelvic inflammatory disease in primary care: A report from ASPN. Fam Med 1988;20:192-196

36. Rosser WW, Henderson R, Wood M, Green LA. An exploratory report of chest pain in primary care: A report from ASPN. J Am Board Fam Pract 1990;3:149-150

37. Calonge BN, Miller RS, Dennis LK, and Joffe LS. AIDS in primary care: A report from the Ambulatory Sentinel Practice Network.J Fam Pract 1991;32:369-372

38. Green LA, Lutz LJ. Notions about networks: Primary care practices in pursuit of improved primary care. In: Mayfield J, Grady ML, eds. Proceedings of the Second Annual Meeting of the Agency for Health Care Policy and Research. Colorado Springs, CO: Primary Care Research: An Agenda for the 90s. Rockville: DHHS, 1990:125-132

39. Culpepper L, Froom J. The International Primary Care Network: Purpose, methods, and policies: A report from ASPN. Fam Med 1988;20:197-201

40. Froom J, Culpepper L, Grob P, et al. Diagnosis and antibiotic treatment of acute otitis media: A report from the International Primary Care Network. Br Med J 1990;300:582-586

41. Jick H, Jick SS and Derby L.E. Validation of information recorded on general practitioner based computerised data resource in the United Kingdom. Br Med J 1991; 302:766-768

42. Pringle M, Hobbs R. Large computer databases in general practice. Br Med J 1991;302:741-742

43. Greenfield S. The state of outcome research: are we on target? $N$ Engl J Med 1989;320:1142-1143

44. Ellwood PM. Outcomes management: a technology of patient experience. N Engl J Med 1988;318:1549-1556

45. Editorial. Databases for health care outcomes. Lancet 1989;i:195-196 
Chapter 3:

\section{The Registration Network Family Practices: a computerized health information system in the Netherlands.}

Published as:

Job FM Metsemakers, Paul Hōppener, J. Andre Knottnerus, Rene J.J. Korken, Charles B.G. Limonard.

Computerized health information in the Netherlands: a registration network of family practices.

British Journal of General Practice, 1992;42:102-106 


\section{Summary}

A registration network of family practices (Registratienet Huisartspraktijken) has recently been established in the Netherlands. Forty two general practitioners in 15 practices, with a patient population of 80000 people, are using a general practice health information system to establish a central computerised anonymous database containing certain patient characteristics and all relevant health problems. By September 1990 patient characteristics and problem lists for 32072 patients had been entered and a total of 94476 health problems had been identified. The database has been set up primarily as a sampling frame, allowing researchers to identify patients with particular health problems. The database can also provide descriptive data on prevalence and incidence rates, fulfil a monitoring function and provide data for practice audit, medical education and health management. 
General practitioners possess a wealth of information on the health of their patients, and on many aspects of their medical treatment. Hence, they are in an unique position to gather information for research, education or management. Research in the primary care field is not easy, but its need and feasibility were clearly stated by Backer. ${ }^{1}$ He also addressed the paradox between large research projects which often produce statistically significant results but of low clinical significance, and small studies, which tend to produce a better quality of information but where the number of subjects involved is too small to allow generalization.

A solution to this paradox would appear to be collaborative research. ${ }^{2}$ This approach has been succesfully carried out in the United Kingdom were many health problems have been studied using data gathered in the national morbidity surveys undertaken by the Royal College of General Practitioners. ${ }^{3}$ Surveillance of connmon infectious diseases is carried out by practices participating in the weekly returns service or similar networks such as the Oxford regional sentinel practice scheme. ${ }^{4,5}$ Van Casteren recently published an inventory of sentinel health information systems involving general practitioners in the European Community revealing that sentinel networks have been established in almost all European countries. $^{6}$ There are, however, great differences between the networks in respect of organisation, purpose, registered health problems and functioning. The goal of the collaboration may be to study morbidity in general practice, to undertake surveillance of certain (communicable) diseases, or to keep track of trends in general practice. The Dutch Sentinel Practice Network is an example of such a registration network. ${ }^{7}$ Other practice networks, whether small like the Missouri Network or large like the Ambulatory Sentinel Practice Network (ASPN), collaborate to answer research questions. ${ }^{8,9}$

A registration network of family practices (Registratienet Huisartsprakijiken) was established in the Netherlands in 1988. Health problems and diagnoses in general practice are recorded and registered on a central database which can support research and educational programmes. This paper summarizes objectives of the network and the methods used, describes the data obtained and discusses the research potential of this data.

\section{General practice as a source of information.}

The general practitioner plays a vital role in the Dutch health care system. General practitioners are the only physicians working in primary health care and are, therefore, the route into the medical system. They occupy a 'gate keeper function' which implies that, in principle, all referrals to other specialists take place via them. Furthermore, nearly all patients are registered with a general practitioner, whether they are insured by sickness funds or are private patients. 
Most of the health problems presented to general practitioners are not seen by specialists and therefore general practices are important sources of information. This information is generally stored as handwritten records, and is not always easily accessible for research purposes. The use of computerized records in general practice facilitates the accessibility of this health information.

\section{Registration network of family practices}

The chief goal of the registration network of family practices is to establish a computerized anonymous database containing certain patient characteristics and all relevant health problems. The database has been set up primarily as a sampling frame, allowing researchers to identify patients with particular health problems or combinations of problems. This means that there are distinctive differences between the design of this registration network and that of morbidity studies, as the latter include only morbidity. On 1 September 1990, the registration network of family practices consisted of 42 participating general practitioners in 15 practices. Thirteen practices are located in the southern part of the province of Limburg, within 30 kilometres of the University of Limburg, while the remaining two practices are situated further to the north, 70 kilometres from the university.

The population covered by these 42 general practitioners is approximately 80000 patients.

In all participating practices computerized health information systems were installed, replacing the handwritten records. Data on patient encounters and other health information are stored on the computer. On a daily basis, the general practitioners complete the records of several patients, by adding patient characteristics and revising the problem list. It was stipulated that the general practitioners should not develop a specific pattern such as first completing the records of elderly patients or patients with asthma, but should 'randomly' select patients. Once completed, the data for a patient is kept up to date. Every three months these data are made anonymous and transferred by floppy disc to the Medical and Social Information Center at the University of Limburg, where they are fed into a database.

The following patient characteristics are transferred to the database: practice code (unique code identifying the practice); physician code (unique code identifying the physician); patient identification (unique internal code of the health information system); household identification (identifies all persons belonging to the same household); sex; date and place of birth; marital status; type of household couple, family, and so on; place of residence and postal code; date of entry in the practice; date of update; insurance status; date and reason for leaving the practice; and level of education.

All relevant health problems must be included on the problem list, as it is an essential part of the medical record. A health problem is thereby defined as 'anything that has required, does or may require health care management and has 
affected or could significantly affect a person's physical or emotional wellbeing. ${ }^{10,11}$ This definition requires the following types of problems to to be included: diagnoses, such as diabetes mellitus; patterns of complaints, such as chronic low back pain; abnormal findings, such as abnormal electrocardiograph; risk factors, such as alcohol abuse; and other problems, such as adverse effects of medical agent.

Problems are recorded if they affect the present functional status of patients and/or their future functioning. Thus, only permanent problems (no recovery expected), chronic problems (duration longer than six months), and recurrent problems (more than three recurrencies within a six month period), are included on the problem list. Problems are stated at the highest level of refinement which can be reasonably defended, that is, a condition cannot be given two problem definitions at the same time, such as low back symptoms and osteoarthritis of the spine. All problems are coded using the International Classification of Primary Care $(I C P C){ }^{12}$ The recording of a recently established diagnosis is justified if the inclusion criteria of the International Classification of Health Problems in Primary Care (ICHPPC-2 Defined) $^{13}$ are met, but criteria are only available for a limited number of ICPC codes and mainly for diagnoses. Otherwise, the complaint or syndrome is recorded. Past diagnoses recorded in the patient's notes are accepted without checking ICHPPC criteria, since details of the medical history are no longer avalaible in many cases.

Problems are characterized as 'active' or 'inactive'. A problem is considered to be active if it has the attention of the general practitioner or the patient at that moment, as shown by present treatment (diet, medication or specific therapy), further diagnostic investigations, regular checks for that problem or a known progressive course of a disease.

The following data are transferred to the data base for all problems: health problems (ICPC code); problem status (active or inactive; and date the problem became active or inactive.

More detailed instructions have been formulated for the general practitioners. These are given in a registration handbook which is regularly updated.

\section{Quality Control}

The health information software provides the general practitioner with an automated thesaurus for the International classification of primary care and displays ICHPPC criteria for the ICPC code, when available. The quality of the data recorded should thus be enhanced by this software. The software also checks for erroneous or missing entries before the data is transferred to the central database. Moreover, the age and sex distribution of the patients registered on the network are compared with that of the whole practice, in order to check the representativeness of the database.

Aspects of problem definition and coding are discussed in 'consensus groups'. Five such groups, of about eight general practitioners each, have been formed, 
meeting four or five times a year. In addition to this process of peer review, which is highly appreciated by the participating practitioners, the staff of the network use these meetings to determine the consistency with which general practitioners define and code problems.

Feedback from the Medical and Social Information Center is also part of the quality control programme. Ommisions, inconsistenties and mistakes are reported to the general practitioners and staff of the network. The updates to the instructions for the general practitioners cover these quality control efforts.

\section{General data held on the database}

On 1 september 1990 patient characteristics and problem lists for 32072 patients had been entered in the database. Approximately 4500 patients are added every three months, whichs means that the register should be complete by the end of 1993. The patient characteristics of the registered patients are given in Table 1 . The patient population of the network resembles the general population of the Netherlands with respect to age, sex, marital status, types of household, insurance status and level of education.

A total of 94476 problems have been identified for these patients; 50488 (53.4\%) active and 43988 (46.6\%) inactive. The distribution of male and female patients in the data base is almost equal ( $48.2 \%$ versus $51.8 \%$ ), but only $44.8 \%$ of the problems are experienced by male patients. Thus, overall women have more problems per person than men ( 3.1 versus 2.7) (Table 2). This table also shows that below the age of 15 years male patients have more problems per person than female patients, but that from the age of 25 and over that trend is reversed. This is also true for active problems. Furthermore, only 17.3 percent of the patients have no health problems on their problem list ( $18.1 \%$ of male patients and $16.6 \%$ of female patients).

The distribution of problems between ICPC chapters is shown in Table 3. Health problems and diagnoses related to the musculoskeletal system rank highest, followed by the respiratory, circulatory and digestive systems problems. These four chapters include almost $50 \%$ of all registered health problems and diagnoses. The 20 most frequent active and inactive problems, for male and female patients, are given in Table 4. The general picture which arises from the most common active problems is not surprising: hypertension; diabetes mellitus; lung problems such as asthma and chronic bronchitis; back problems; and risk factors such as smoking and obesity. Striking is the position of adverse effects of medication in a proper dose; health care itself apparently produces frequent problems. The inactive problems listed may not appear very interesting but these problems account for $46.6 \%$ of all problems and therefore provide researchers with an opportinity to define patient groups with particular health problems that have already been treated. 


\section{Table 1.}

Characteristics of the 32072 patients registered on the database on 1 September 1990

\% of patients

\section{Sex}

Male

48.2

Female

51.8

Age (years)

0-4

5-14

11.8

15-24

14.1

25-44

33.5

45-64

20.7

65-74

8.4

$75+$

\section{1}

Marital status

Married

48.5

Divorced

2.7

Single

38.7

Cohabitating

Widow(er)

Other

Unknown

Type of household

Couple

Family

One parent family

Single person

Family/couple with lodger(s)

One parent family with lodger(s)

Single person with lodger(s)

Home for the eldery

Commune

Other

Unknown

Insurance status

Sickness fund

Private insurance

\section{Level of education "}

Low (primary education/lower vocational training)

${ }^{2}$ For the 21679 patients aged 25 years and over 
Table 2. Mean number of problems and of active problems per person by sex and age group

\begin{tabular}{lllll}
\hline & \multicolumn{2}{c}{$\begin{array}{c}\text { Mean no. of problems } \\
\text { per person }\end{array}$} & \multicolumn{2}{c}{$\begin{array}{c}\text { Mean no. of active } \\
\text { problems per person }\end{array}$} \\
\cline { 2 - 5 } Age (years) & $\begin{array}{c}\text { Male } \\
\text { patients }\end{array}$ & $\begin{array}{c}\text { Female } \\
\text { patients }\end{array}$ & $\begin{array}{c}\text { Male } \\
\text { patients }\end{array}$ & $\begin{array}{c}\text { Female } \\
\text { patients }\end{array}$ \\
\hline & & & & \\
$0-4$ & 0.8 & 0.6 & 0.5 & 0.4 \\
$5-14$ & 1.6 & 1.4 & 0.7 & 0.6 \\
$15-24$ & 1.9 & 1.9 & 0.8 & 0.9 \\
$25-44$ & 2.4 & 2.9 & 1.2 & 1.4 \\
$45-64$ & 3.8 & 4.3 & 2.1 & 2.3 \\
$65-74$ & 5.0 & 5.2 & 3.0 & 3.2 \\
$75+$ & 5.7 & 6.2 & 3.5 & 4.1 \\
\hline Total & 2.7 & 3.1 & 1.4 & 1.7 \\
\hline
\end{tabular}

Table 3. Distribution of problems between the ICPC chapters

\begin{tabular}{ll}
\hline ICPC chapter & $\begin{array}{c}\text { \% of problems } \\
\text { (n=94 457) }\end{array}$ \\
\hline A $\quad$ General and unspecified & 6.5 \\
B Blood, blood-forming organs, lymphatics, spleen & 0.7 \\
D Digestive & 9.8 \\
F Eye & 2.5 \\
H $\quad$ Car & 3.6 \\
K Circulatory & 9.9 \\
L Musculoskeletal & 17.1 \\
N Neurological & 4.0 \\
P Psychological & 6.1 \\
R $\quad$ Respiratory & 11.6 \\
S Skin & 6.0 \\
T Endocrine, metabolic and nutritional & 4.5 \\
U Urology & 2.6 \\
W Pregnancy, childbearing, family planning & 4.0 \\
X Female genital system (including breast) & 5.5 \\
Y Male genital system & 2.8 \\
Z Social problems & 2.9 \\
n=total number of problems. Data missing or inadequately coded for 19 & problems
\end{tabular}




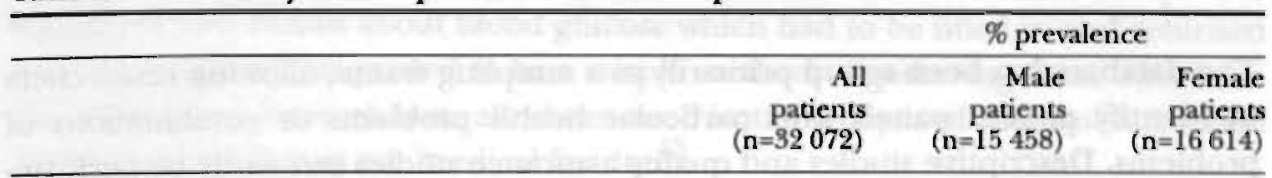

ICPC code

Active problems

P17 Tobacco abuse

9.2

8.3

5.4

K86 Uncomplicated hypertension

R96 Asthma

R97 Hayfever, allergic rhinitis

T90 Diabetes mellitus

T82 Obesity (BMI 30)

P01 Feeling anxious/nervous/tense/inadequate

L03 Low back symptoms/complaints without radiation

S87 Atopic dermatitis/eczema

L86 Lumbar disc lesion, back pain with radiating symptoms

A12 Allergy/allergic reaction not otherwise specified

L84 Osteoarthritis of spine (any region)

K95 Varicose veins of leg

T83 Overweight (BMI)

H86 Deafness/partial or complete not elsewhere classified

L90 Osteoarthritis of knee

R91 Chronic bronchitis/bronchiectasis

L98 Acquired deformities of limbs

S88 Contact dermatitis/other eczema

\section{Inactive problems}

R90 Hypertrophy/chronic infection tonsils/adenoids

D88 Appendicitis

D89 Inguinal hernia

L76 Fracture: other

Y13 Family planning/sterilization

W92 Complicated delivery liveborn(s)

D98 Cholecystitis/cholelithiasis

W13 Family planning/sterilization/referral for

L99 Other disease musculoskeletal system/connective tissue

L86 Lumbar disc lesion, back pain with radiating symptoms

L72 Fracture: radius/ulna

X78 Fibroid/myoma (uterus/cervic)

U95 Urinary calculus all types/sites

L96 Acute damage meniscus/ligament of knec

D99 Other diseases digestive system

X99 other diseases female genital system

L73 Fracture:tibia/fibula

W82 Abortion, spontaneous

K95 Varicose veins of leg

R99 Other diseases respiratory system

D85 Duodenal ulcer

H71 Acute otitis media/myringitis
3.7

3.5

2.7

2.6

2.4

2.3

2.2

2.0

2.0

1.9

1.9

1.8

1.8

1.7

1.7

1.7

1.5

7.1

3.3

2.5

2.4

2.3

2.3

2.2

2.2

g. 0

1.9

1.8

1.7

1.6

1.5

1.4

1.4

1.4

1.3

1.1

1.1

1.1

1.1
10.8

5.3

4.0

4.1

3.7

2.2

2.0

1.7

2.8

2.1

2.3

1.9

1.7

0.7

1.6

2.0

1.2

2.0

1.5

1.1

7.2

2.8

4.2

2.7

4.8

0

0.9

2.1

2.3

1.6

21

2.3

1.4

8

1.8

0.6

1.4

1.7

1.2
7.7

11.1

6.7

3.3

3.3

3.2

3.2

3.1

1.9

2.4

1.7

2.0

2.1

3.0

2.0

1.6

2.2

1.4

1.8

2.0

7.0

3.7

$\mathrm{n}=$ total number of patients 
The database has been set up primarily as a sampling frame, allowing researchers to identify patient panels with particular health problems or combinations of problems. Descriptive studies and quality assurance studies can easily be performed and study and control groups can be assembled for various study designs, such as clinical trials, cohort studies, and case control studies. The following projects have used the network database for the identification of a study population: studies of blood glucose regulation of patients with non-insulin dependent diabetes mellitus; ${ }^{14}$ diagnoses of cancer in the registration network of family practices and at the district cancer service of the Limburg Integrated Cancer Centre; use of diuretics in elderly patients with oedema of the ankle in general practice; somatization in daily life; adverse effect of medical agents used in the proper dose; and relationship between sterilization and vaginal extirpation of the uterus. The data base can provide descriptive data on prevalence and incidence rates. Since problem lists are entered with patient characteristics, all variables can be used as the nominator or denominator. The point prevalence of a problem is the frequency of that problem in the registered patient population at a certain date. The incidence of a problem can be calculated as the frequency of new entries for a certain problem per 1000 patients per year. Incidence and prevalence should, however, not be confused with active and inactive. When calculating the incidence, only problems which have been both new and active in a certain year will be counted. For the prevalence rate it is not relevant whether the problem is active or inactive. Comparison of this data with data from morbidity studies should be carried out very carefully as the registration network family practices has not been set up as a morbidity study. The problem definition used in the network excludes minor self limiting diseases. Hence, the top 20 of active problems give no indication of what general practitioners see most commonly in their daily practice nor how often they see certain patients. However, the database does indicate how many patients have one or more serious health problems which influence their well being. Differences between the prevalence rates for particular diseases such as hypertension and asthma, determined from the database and from morbidity studies are partly the result of the problem definition used for the database, which states that problems are only to be registered if they have or may have consequences for the functional status of the patient and if the problem is permanent, chronic or recurrent. Another reason for the difference may be that diagnoses established in the past were accepted for the database problem list without checking that the ICHPPC criteria were fulfilled.

The database can provide a monitoring function for particular health problems. Furthermore, the data can be used for practice audit, medical education and health management. The feasibility of using the database for practice audit has recently been studied. ${ }^{14}$ All non-insulin dependent diabetes mellitus were identified. Fach practice received a floppy disc listing the patients in their practice that 
had been identified. The practice health information system was used to print a data-sheet with details about blood glucose which had to be filled in and returned for each patient. This proved to be a simple method of gathering data. Data from the registration network have also been used in the analysis of the problem-based medical curriculum at our medical faculty. ${ }^{15}$

A steering committee of the network ensures that the research projects are scientifically relevant to the field of general practice and that the information needs of the project can be fulfilled by data from the database. Furthermore, the committee assesses the workload for the general practitioners involved and the possible inconvenience to patients before deciding upon collaboration with a particular research project.

\section{Discussion}

The registration network of family practices differs from other sentinel networks in several respects. It is not a register of morbidity in general practice, since it does not include minor intercurrent diseases such as influenza, gastroenteritis, pruritus or urinary tract infections. The network focuses on chronic health problems, including risk faktors such as smoking. The general practitioners do not gather data for three or four network studies but instead continuously update the patient characteristics and problem lists of all their registered patients. Hence, the database at the Medical and Social Information Center is an up to date index from which selections based on personal and health characteristics can easily be made.

A computerized health information system which supports the general practitioners during the process of problem definition and coding is absolutely necessary. However, it is the general practitioners who have to adapt to a strict discipline of making and then updating the problem lists of their patients. They have to do this not only when they have seen a patient but also when they receive a letter from a specialist. To enable practitioners to incorporate this process into his normal work, the definition of what constitutes a problem has to fit in with their daily work; it also has to suit the purpose of the registration network. The working definition of Sandlow and Bashook is neither too open nor too strict. ${ }^{10,11}$ It provides general practitioners with some freedom in determining whether or not to put something on the problem list. This freedom, although limited, results in some inter-doctor variance, which will be low for clearly defined diseases such as cancer or diabetes mellitus which meet quite specific ICHPPC criteria. When dealing with other health problems such as low back problems or psychosocial distress, this inter-doctor variance is likely to be higher since the criteria leave the general practitioner more room for interpretation. Minimizing this inter- and even intradoctor variance is one of the goals of the quality control programme. However, there is another factor which influences variation. In writing a problem list, general practitioners have to rely on their own records, and sometimes on letters and notes from their predecessor. This information is not always available, complete, 
understandable or accurate. Formulation of problems in retrospect is therefore, sometimes difficult in view of the rules of problem definition. In most of these cases, verifying the ICHCPPC criteria is impossible. Clear diagnoses from the past are therefore accepted without further verification. In future the correct use of ICHPPC criteria will be investigated, when these become available for a particular disease.

The chief goal of the registration network of family practice - to establish a computerized anonymous database with certain patient characteristics and all relevant health problems - has not yet been fully accomplished. Selection bias does not appear to be a problem, but this cannot be excluded until all patients have been added to the data base. Users of the database have to be aware of these problems when using it as a sampling frame or as a starting point for further research. Nevertheless, several researchers are already making use of the database for their projects.

Although most general practitioners are still entering new patients into the data base, many of them have already discovered the possibilities of the health information system for daily patient care and practice audit. All kinds of selections can be easily made, such as selecting patients who have an indication for vaccination against influenza, or patients with hypertension, diabetes mellitus or any other health problem, which is stated on the problem list. The registration network of family practices stimulates not only research in general practice but also enables generai pracuuoners to engage in piacuce auch.

\section{References}

1. Backer P. Research in and on primary health care. Scand J Prim Health Care 1983; 1:10-11.

2. Wood M. Collaborative research: a sentinel practice system. J Fam Pract 1982; 14:451-452.

3. Royal College of General Practitioners, Office of Population Censuses and Surveys and Department of Health and Social Security. Morbidity statistics from general practice. Third national study 1981-1982. London: HMSO, 1986.

4. Fleming DM. Crombie DL. The incidence of common infectious diseases: the weekly returns service of the Royal College of General Practitioners. Health Trends 1985; 17:13-16.

5. Fleming DM, Crombie DL, Mayor-White RT, Fowler GN. Comparison between the weekly returns service and the Oxford regional sentinel practice scheme for monitoring communicable diseases. J R Coll Gen Pract 1988; 38:461-464.

6. Van Casteren V. An inventory of sentinel health information systems with GPs in the European Community. Brussels: Instituut voor Hygiene en Epidemiologic, 1991.

7. Bartelds A, Fracheboud J, van der Zee J (eds). The Dutch sentinel practice network; relevance for public health policy. Utrecht: Netherlands Institute of Primary Health Care, 1989.

8. Williamson HA, Hector MG, LeFevre M, White RD. Establishing a rural family practice research network. Fam Med 1988; 20:51-54

9. Iverson DC, Calonge BN, Miller RS, Niebauer LJ, Reed FM. The development and management of a primary care research network, 1978-1987. Fam Med 1988; 20:177-181 
10. Sandlow LJ, Bashook PG. Problem Oriented Medical Records: self instruction for practitioners. Chicago: Michael Reese Hospital and Medical Center, 1978

11. Metsemakers JFM, Plagge MWM, de Kanter J. De probleemlijst. Huisarts Wet 1988; 31:379-381

12. Lamberts H, Wood M (eds). ICPC. International Classification of Primary Care. Oxford: Oxford University Press, 1987

13. Classification committee of Wonca. ICHPPC-2 defined International Classification of Health Problems In Primary Care. Oxford: Oxford University Press, 1983

14. Höppener P, Knottnerus JA, Grol R. Praktijk automatisering en kwaliteitsbewaking. De bloedsuikerregulatie bij patienten met diabetes mellitus type II onderzocht in het Registratienet Huisartspraktijken. Huisarts Wet 1990; 33: 390-39-3

15. Metsemakers JFM, Bouhuijs PAJ, Snellen-Balendong HAM. Do we teach what we preach? Comparing the content of a problem-based medical curriculum with primary health care data. Fam Pract 1991; 8:195-201 
Chapter 4:

\section{The problem list: an essential tool in the Registration Network Family Practices}

Updated and extended version of:

Metsemakers JFM, Plagge H, Kanter J de.

De probleemlijst, suggesties voor de huisarts.

Huisarts en Wetenschap 1988;31:379-381 


\section{Summary}

The Registration Network Family Practices is a recently established network in the Netherlands. Forty-two general practitioners in 15 practices, with a patient population of 80000 persons, use a general practice health information system to establish a central computerized anonymous data base with all relevant health problems and a limited set of patient characteristics. 110017 health problems have been identified on the problem lists of 35740 patients.

Diagnoses make up the greatest proportion of problems $(67 \%)$, followed by complaints or patterns of complaints (14,3\%). Risk factors, congenital or social problems are also included on the problem lists.

The problem list, as part of a general practice health information system, can become an important tool for research. It provides access to the wealth of information residing with general practitioners.

The central data base of the Registration Network Family Practices has been set up primarily as a sampling frame but can also provide descriptive data, fulfil a sentinel/monitoring function or provide data for practice audit, medical education and health management. 
The problem list is an essential part of the problem oriented medical record (POMR) developed by Weed around 1970 for use in the hospital setting. ${ }^{1}$ Others showed that the problem oriented record could also be used in ambulatory settings such as general practice. ${ }^{2-4}$ In 1979 a special issue of Huisarts en Wetenschap (the Dutch Scientific General Practice Journal) was devoted entirely to this new way of record keeping. ${ }^{5}$ The Dutch College of General Practitioners developed special problem oriented charts, but only 3-10 percent of the Dutch general practitioners have adopted the problem oriented record system. Many agree that, in principle, the system has several advantages, but they believe that the conversion from their old charts to problem oriented charts is too time consuming. In the Netherlands problem oriented record keeping, and especially the use of the problem list, will probably increase in the near future as a result of two developments. Firstly, the professional standard of medical record keeping, as issued by the Dutch College of General Practitioners, calls for a problem list as an essential part of the medical record. ${ }^{6}$ Secondly, the Working Group on Coordination of Automation (WCIA) requires computerized general practice health information systems to have at least a problem list and progress notes as part of the medical module. Seventy percent of the Dutch General Practitioners use a health information system, half of them at this moment (spring 1993) for their financial administration but in the near future also for their medical record keeping. ${ }^{7}$

The use of computerized records in general practice will facilitate the accessibility of the health information data which are normally stored in handwritten records and are therefore not always easily accessible for research purposes.

This point is proven by the Registration Network Family Practices, a recently (1988) established Network in the Netherlands which involves the registration of health problems and diagnoses in general practice. ${ }^{8}$ All general practitioners who participate in this network use a computerized general practice health information system.

This article gives guidelines for the use of the problem list in general practice and shows results of the use of the problem list.

\section{The problem list}

\subsection{Basic principles}

The basic principles of the problem list have been described in the literature but mainly in general terms. ${ }^{1-5,9,10}$ Metcalfe states that the problem list shuuld providc: the general practitioner with an overview of all relevant health problems. He describes several types of problems, such as medical diagnoses, medical problems, non-medical problems and risk factors. He acknowledges that it is not easy to 
determine which problems should be included on the problem list and which should not. And what constitutes a problem? According to the International Glossary for Primary Care a problem is : "A provider-determined assessment of anything that concerns a patient, the provider (in relation to the health of the patient), or both". ${ }^{11}$ This is a concise but global definition. Sandlow uses a more detailed description:" A health problem is anything that has required, does or may require health care management and has affected or could significantly affect a person's physical or emotional well-being."12

According to this definition the problem list should contain not only diagnoses but also complaints, symptoms, abnormal findings of physical examination or diagnostic investigation, relational and social problems, and risk factors. Problems should always be stated at the highest level of refinement which can be reasonably defended, that is:" recording at a true level of understanding" and "at the highest level of specificity." 12

\subsection{Time as a factor.}

In General Practice patients often have illnesses which affect their well-being and require medical treatment but resolve within a short period of time. Inclusion of these temporary problems, such as pharyngitis or urinary tract infection, on the problem list would make it an endless list. Minor ailments will be noted in the progress notes. Hence, the problem list should only contain problems which, over a longer period or to a serious degree, have consequences for the present or future functional status of the patient. This implies that permanent problems (no recovery expected), chronic problems (duration longer than six month), and recurrent problems (more than three recurrencies within a six month period) have to be included on the problem list.

\subsection{Active or inactive.}

A problem can be characterized as "Active" or "Inactive" ("Blind"). It is difficult to make an exact distinction between active and inactive, but the following guidelines may be helpful. A problem is considered to be Active if it has the attention of the general practitioner or the patient at that moment, as shown by present treatment (meaning a diet, medication or specific therapy), further diagnostic investigations, regular checks for that problem or a known progressive course of a disease. A patient with epilepsy who takes his medication on a daily basis and has not had an epileptic attack for many years, still has an active problem. Multiple sclerosis is known to have a slow progressive course and therefore has to be considered as an active problem. An inguinal hernia on the other hand, will become an inactive problem after corrective surgery, since the problem has been corrected and regular checks are not necessary. 


\section{Other relevant medical data.}

The blood group of a patient, vaccinations received, and results of diagnostic or preventive procedures are all relevant medical data in view of the present or future well-being of a patient. Nevertheless, these data should not be included on the problem list, but be recorded elsewhere in the medical record.

\section{Problem types}

Several kinds of problems can be distinguished, following Sandlow's definition of a problem:

medical problems

psychosocial problems

risk factors

other problems

\section{Medical problems}

Diagnoses. These clinical entities are clearly defined and criteria have been established in the International Classification of Health Problems in Primary Care (ICHPPC - 2 Defined) ${ }^{13}$ Examples are: iron deficiency anemia; duodenal ulcer.

Diagnoses followed by surgery. In some cases the result of an operation can be viewed as a new problem which has to be placed on the problem list. For example: arthrosis of the hip (inactive after surgical intervention) and the hip prosthesis (active).

Congenital Anomalies. This is a diagnosis of a special kind. Examples are: a clubfoot; a hemangioma. These problems of course, have to comply with the definition of a problem. In other words: not every clubfoot or hemangioma will have to be placed on the problem list.

Allergic reactions for instance to penicillin or other drugs.

Abnormal results. These come from a physical examination or diagnostic procedure when a diagnosis has yet to be made. The abnormal result should be important in order to comply with the definition of a problem. Examples are: systolic murmur grade II; cervical smear PAP IV.

Patterns of complaints. It is not always possible to come to a diagnosis for a particular problem. It is nevertheless possible to put a complaint or pattern of complaints on the problem list if its meets the requirements of the problem definition. Examples are: recurrent headaches; abdominal pains.

\section{Psychosocial problems}

In a number of cases it will be clear to the general practitioner and the patient that certain complaints result from psychological and/or social problems. Both problems should be included on the problem list separately. 
Example: stomach complaints resulting from relational problems. Problem 1: relational problem; Problem 2: stomach complaints.

Many psychological problems have a social origin. Both problems should be included separately on the problem list if they comply with the definition of a problem. Example: Depression as a consequence of unemployment.

Problem 1: unemployment; problem 2 : depression.

\section{Risk factors}

Tobacce. alcohol and other substances. The use of tobacco should always be considered as a problem, regardless of the number of cigarettes, cigars or pipes smoked, since it clearly threatens a person's (future) health status. The use of alcohol should be included on the problem list if there is evidence of alcohol dependence or alcohol abuse as described in the Diagnostic and Statistical Manual of Mental disorders (DSM III R ). ${ }^{14}$ This classification is preferred, since the ICHPPC only states criteria for alcohol abuse. In general practice alcohol dependency is seen more frequently and often leads to health problems. Use of other substances such as cannabis, opioids, cocaine should be stated if the pattern of use brings them within the definition of a problem.

Eamily history It is known that the chance of getting a particular disease also depends on the presence of that disease in the family. Some diseases are clearly inherited and probabilities of getting that disease can be estimated. The knowledge in this field is rapidly expanding. Examples are : breast cancer; Duchenne's disease.

\section{Other problems}

Somatisation disorder. Every general practitioner is familiar with patients who have the tendency to express their lack of well-being always in terms of somatic complaints. Inclusion on the problem list of this somatisation disorder can make the general practitioner more aware of this tendency.

Eunctional disturbances/ handicaps. These do not always have to be regarded as diseases but can have serious implications for a person's health. Examples are: deafness; limping. Once again: not every functional disturbance has to be regarded as an item for the problem list.

\section{The Registration Network Family Practices.}

The chief goal of the Registration Network Family Practices is to establish a computerized anonymous data base with all relevant health problems and a limited set of patient characteristics. In all participating practices computerized health information systems were installed replacing the handwritten records.

All relevant health problems have to be included on the problem list, which is an essential part of the medical record. The general practitioners have to follow the guidelines for a problem list described above. The recording of a diagnosis is only 
justified if the criteria of the International Classification of Health Problems in Primary Care are met (ICHPPC-2 Defined). Otherwise, the complaint or syndrome has to be recorded. All problems are coded using the International Classification of Primary Care (ICPC). ${ }^{15}$

The recorded health problems have been grouped according to the different types of problems. Appendix 1 contains a detailed description of these groups with the corresponding ICPC codes.

\section{Results}

\subsection{General data.}

Patient characteristics and problem lists of 35740 patients had been entered in the database on December 1, 1990. On the problem lists 110017 problems have been identified. Table 1 shows several characteristics of these problems. The distribution of men and women in the data base is almost equal (48.2\% versus $51.8 \%$ ), but women have more problems per person than men (3.3 versus 2.9 ). This explains why, 54.9 percent of the problems are found on women's problem lists. Table 1 also shows that below the age of 15 men have more problems per person than women, but above the age of 25 that trend is reversed. Furthermore, the data show that only 15.9 percent of the patients have no health problems on their problem list.

Table 1. Some characteristics of the problems of the Registration Network Family Practices

Distribution of problems by gender

$\begin{array}{lrr} & \mathrm{N} & \% \\ \text { men } & 49625 & 45.1 \\ \text { women } & 60392 & 54.9\end{array}$

Mean number of problems per person per age group

\begin{tabular}{lcccccccc} 
& $0-4$ & $5-14$ & $15-24$ & $25-44$ & $45-64$ & $65-74$ & $75+$ & Total \\
\hline men & 0.8 & 1.7 & 2.0 & 2.6 & 4.0 & 5.2 & 5.8 & 2.9 \\
women & 0.6 & 1.4 & 2.0 & 3.1 & 4.5 & 5.4 & 6.2 & 3.3 \\
\hline Total & 0.7 & 1.5 & 2.0 & 2.8 & 4.3 & 5.4 & 6.1 & 3.1 \\
\hline
\end{tabular}

Number of persons with filled and empty problem list

\begin{tabular}{lrrrrrr} 
& \multicolumn{2}{c}{ Men: } & \multicolumn{2}{c}{ Women: } & \multicolumn{2}{c}{ Total: } \\
& $\mathrm{N}$ & $\%$ & $\mathrm{~N}$ & $\%$ & $\mathrm{~N}$ & $\%$ \\
\hline empty problem list & 2832 & 16.4 & 2840 & 15.4 & 5672 & 15.9 \\
problem list with problems & 14986 & 83.6 & 15652 & 84.6 & 30038 & 84.1 \\
\hline & 17218 & 100.0 & 18492 & 100.0 & 35710 & 100.0 \\
\hline
\end{tabular}




\subsection{Health problems and diagnoses}

The distribution of problems over the ICPC chapters is depicted in figure 1. Health problems and diagnoses related to the musculoskeletal system rank highest, followed by the respiratory, circulatory and digestive systems. These four chapters include almost $50 \%$ of all registered health problems and diagnoses. The twenty most frequent problems are listed in table 2. These data cannot be com-

Table 2. Twenty most frequent problems in the Registration Network Family Practices

\begin{tabular}{|c|c|c|c|c|c|c|}
\hline rank & ICPC & $\begin{array}{l}\text { label } \\
\text { code }\end{array}$ & active & inactive & total & prevalence \\
\hline 1 & P17 & tobacco abuse & 3392 & 315 & 3707 & $10.4 \%$ \\
\hline 2 & A85 & adverse effect medical agent proper dose & 2967 & 80 & 3047 & $8.5 \%$ \\
\hline 3 & R90 & $\begin{array}{l}\text { hypertrophy/chronic infection tonsils/ } \\
\text { adenoids }\end{array}$ & 176 & 2551 & 2727 & $7.6 \%$ \\
\hline 4 & K86 & uncomplicated hypertension & 1910 & 162 & 2072 & $5.8 \%$ \\
\hline 5 & R96 & asthma & 1294 & 259 & 1553 & $4.3 \%$ \\
\hline 6 & L86 & $\begin{array}{l}\text { lumbar disc lesion, back pain with radiating } \\
\text { symptoms }\end{array}$ & 742 & 680 & 1422 & $4.0 \%$ \\
\hline 7 & D88 & appendicitis & 109 & 1233 & 1342 & $3.8 \%$ \\
\hline 8 & R97 & hayfever, allergic rhinitis & 1258 & 72 & 1330 & $3.7 \%$ \\
\hline 9 & L03 & $\begin{array}{l}\text { low back symptoms/complaints without } \\
\text { radiation }\end{array}$ & 854 & 363 & 1217 & $3.4 \%$ \\
\hline 10 & Y13 & family planning/sterilization & 338 & 854 & 1192 & $3.3 \%$ \\
\hline 11 & L99 & $\begin{array}{l}\text { other disease musculoskeletal/connective } \\
\text { tissue }\end{array}$ & 427 & 733 & 1160 & $3.2 \%$ \\
\hline 12 & W13 & family planning/sterilization/referral for & 340 & 801 & 1141 & $3.2 \%$ \\
\hline 13 & K95 & varicose veins of leg & 677 & 447 & 1124 & $3.1 \%$ \\
\hline 14 & P01 & feeling anxious/nervous/tense/inadequate & 846 & 258 & 1104 & $3.1 \%$ \\
\hline 15 & T90 & diabetes mellitus & 959 & 110 & 1069 & $3.0 \%$ \\
\hline 16 & L76 & fracture: other & 142 & 909 & 1051 & $2.9 \%$ \\
\hline 17 & D98 & cholecystitis/cholelithiasis & 249 & 795 & 1044 & $2.9 \%$ \\
\hline 18 & D89 & inguinal hernia & 123 & 917 & 1040 & $2.9 \%$ \\
\hline 19 & T82 & obesity (BMI > 30) & 981 & 43 & 1024 & $2.9 \%$ \\
\hline 20 & 587 & atopic dermatitis/eczema & 783 & 211 & 994 & $2.8 \%$ \\
\hline
\end{tabular}

pared directly with data from morbidity studies, since the problem definition used in our Registration Network excludes minor self-limiting diseases. The reason is that the research program for which it was developed focusses on chronic health prob-lems, so that, a common cold, a headache or a gastroenteritis will not be registered. Hence, the top twenty of active problems will not give a complete picture of all health problems seen by the general practitioner in his daily practice, nor how often he sees certain patients. It does, however, indicate how many patients (in terms of point prevalence) have one or more serious health problems which influence their well-being. The general picture which arises from this table is, of course, not surprising: hypertension; diabetes mellitus; lung problems such as asthma, chronic bronchitis, emphysema, COPD; back problems, often based on arthrosis deformans or disc degeneration; and risk factors such as smoking and obesity. A suriking feature is the high position of adverse effects of medication in a 


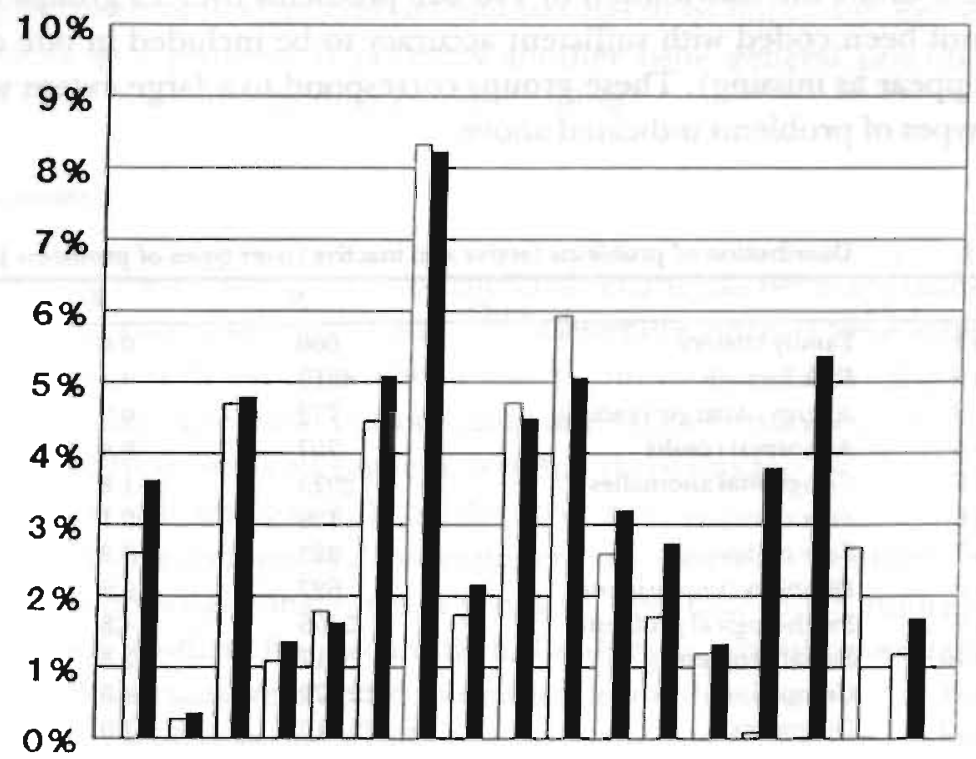

A B D F H K L N P R S T U W X Y Z

ICPC CHAPTERS

$\square$ MEN $\mathrm{N}=49625$ WOMEN $\mathrm{N}=60392$

Legenda : ICPC chapter, $\mathrm{N}$ of problems by men, $\mathrm{N}$ of problems by women, Total number of problems.

A: General and unspecified, 2879, 3983, 6862; B: Blood, bloodforming organs, lymph, spleen, 292, 388, 680; D: Digestive, 5172, 5267, 10439; F: Eye, 1196,1 492, 2688; H: Ear, 1971, 1790, 3761; K. Circulatory, 4898, 5603, 10501; L. Musculoskeletal, 9164, 9055, 18219; N:Neurological, 1906,2371,4277; P:Psychological, 5178, 4931, 10109; R: Respiratory, 6534, 5573, 12107; S: Skin, 2861, 3519, 6380; T: Endocrine, metabolic and nutritional, 1885, 3009, 4894; U: Urological, 1319, 1464, 2783; W: Pregnancy, childbearing, family planning, 94, 4176, 4270; $X$. Female genital system (including breast), 17, 5908, 5925; Y: male genital system, 2955, 21, 2976; Z: social problems, 1304, 1842, 3146. 
proper dose ( many of these concern penicillin allergy). Health care itself seems to produce a very frequent problem.

Table 3 shows the distribution of 110003 problems over 13 groups (14 problems had not been coded with sufficient accuracy to be included in one of the groups and appear as missing). These groups correspond to a large extent with the different types of problems indicated above.

Table 3. Distribution of problems (active and inactive) over types of problems (N; percentages)

\begin{tabular}{llrr}
\hline & & $\mathrm{N}$ & $\%$ \\
\hline Group 1 & Family History & 666 & 0.6 \\
Group 2 & Risk Factors & 4619 & 4.1 \\
Group 3 & Allergy/Allergic reaction & 772 & 0.7 \\
Group 4 & Abnormal results & 707 & 0.6 \\
Group 5 & Congenital anomalies & 2025 & 1.8 \\
Group 6 & Fear of cancer & 159 & 0.1 \\
Group 7 & Fear of disease & 223 & 0.2 \\
Group 8 & Disability/impairment & 627 & 0.6 \\
Group 9 & Psychological problems & 5406 & 4.8 \\
Group 10 & Social problems & 3117 & 2.8 \\
Group 11 & Complaints & 16172 & 14.3 \\
Group 12 & Diagnoses & 75510 & 67.0 \\
Group 13 & Other problems & 0 & 0 \\
Missing & & 14 & 0 \\
\hline
\end{tabular}

All but one group contain problems. Group 13 (other problems) consisted of one ICPC code ( A20 Euthanasia request/Discussion) which either had not been encountered or had not been experienced as a problem by general practitioners. Diagnoses make up the greatest proportion of problems $(67 \%)$. The most frequently encountered (active and inactive) diagnoses are: adverse effect medical agent proper dose; hypertrophy/chronic infection tonsils/adenoids; uncomplicated hypertension; asthma; lumbar back lesion, back pain with radiating symptoms. Complaints or patterns of complaints is the second largest group (14.3\%), although not all ICPC codes within this category are real complaints. ( Y13 and W13 (family planning/sterilisation)) Back problems, headaches and abdominal complaints are recorded most frequently.

Psychological problems (group 9), social problems (group 10), fear of cancer (group 6) and fear of disease (group 7) can be regarded as psychosocial problems. Together, they account for 8905 problem codes or 8 percent of the total number of problems. Fear of cancer or other diseases appears to have been present for a long time and in a severe form in 382 cases, since they were put on the problem list. Eleven persons had fear of AIDS (B25) while only one person in the database was actually diagnosed as having an HIV Infection (B90). Congenital anomalies (group 5) and disabilities/impairments (group 8) make up a small percentage $(2.4 \%)$ of all problems. Musculoskeletal problems are prominent in both these groups. Smoking has been considered a problem in 3707 persons or 10.4 
percent of the patient population. Data from other studies indicate that 33 percent of the Dutch population over the age of 15 years smokes. ${ }^{16}$ This implies that the recording behavior of the General practitioner has to be improved. Recording the family history as a problem is probably another issue general practitioners have to incorporate more fully in their record keeping.

\section{Discussion}

The introduction of the problem oriented medical record has been applauded by many but also has attracted some criticism. ${ }^{17-19}$ Generally, doctors were willing to accept the fact that records were inadequate due to omission of essential information, poor retrievability of recorded information and lack of uniformity. The criticism, even from believers of Weed's system, was that there was too much emphasis on the structure and style and too little on the substance. Sheldon found that there was disagreement between general practitioners, who used the problem oriented record system on what constituted a problem, and how much information should be put on the problem list. According to Goldfinger, workshop exercises in which competent physicians were asked to develop a problem list from an identical data base always yielded as many different problem lists as there were participants. The guidelines given in this article are intended to help the general practitioner in the process of making and maintaining a problem list. In practising medicine, doctors deal with individual patients and have to decide whether a particular condition constitutes a problem for that individual or not. There should be no inter-and intra-doctor variation in considering Diabetes Mellitus as a problem, but it must be understood that variation will clearly be present when low back pain is dealt with. To put only established diagnoses on the problem list would deny the reality of general practice, where a large number of the problems seen by general practitioners cannot be regarded as definite diagnoses. Both the ICHPPC and the ICPC have been specially developed to help general practitioners in dealing with " complaints" or other "health problems".

The data from the Registration Network Family Practices clearly show that general practitioners use the problem list the way they were supposed to. This means that $30 \%$ of all relevant health problems would not have recorded if a diagnosis based morbidity registration had been used. Furthermore, risk factors, positive fatmily history and fear of cancer or other diseases are normally not recorded in these registrations. Our data also indicate that the general practitioners need to get used to these guidelines, especially with regard to risk factors. Special effort has to be made to minimise inter- and even intra-doctor variability. This is one of the goals of the quality control program that has been set up in the Registration Network Family Practices.

The problem list, as part of a general practice health information system, can become an important tool for research. It provides access to the wealth of information on the health situation of patients residing with the general practitioners. 
The users of the Registration Network data base have to be aware of possible interand intra-doctor variability in the use of the problem definition when using the data base as a sampling frame or as a starting point for further research. This inter-doctor variability will be low for clearly defined diseases such as cancer, diabetes mellitus, asthma, eczema, hypertension or ischemic heart disease, meeting quite specific ICHPPC-2 criteria. When dealing with other health problems such as low back problems, psychosocial distress or a club-foot, this inter-doctor variability might be expected to be higher, since they leave the general practitioner with more room for interpretation.

The problem list set up according to our guidelines is an essential tool for the Registration Network Family Practices.

\section{References}

1. Weed IL. Medical education and patient care. Cleveland: Case Western Reserve University Press, 1969

2. Bjorn JC, Cross HD. The Problem-Oriented Practice. A system for comprehensive health care.. Chicago: Modern Hospital Press, 1970

3. Petrie JC, Mclntyre N. The problem orientated medical record. Edinburgh: Churchill Livingstone, 1979.

4. Tait I, Stevens ]. The problem-orientated medical record in general practice.J R Col Gen Pract $1979 ; 23 ; 311-315$

5. Probleemgeorienteerde registratie [Problem oriented Medical Registration] (Themanummer). Huisarts Wet 1979;22:3-47

6. Nederlands Huisartsen Genootschap. Standaard Medische Verslaglegging. [Professional Standard of Medical Record Keeping] Huisarts Wet 1990;33(3):114-117

7. Westerhof HP, Berden HIIM. De meerwaarde van het elektronisch medisch dossier. Tussenresultaten van het Nut-II project. Huisarts Wet 1993;36(11):380-383

8. Metsemakers JFM, Hōppener P, Knounenus JA, Kocken RJ, Limonard ChBG. Computerized health information in the Netherlands: a registration network of family practices. $\mathrm{Br} \mathrm{J}$ Gen Prac, 1992;42:102-106

9. Easton, RE. Problem-oriented medical records concept. New York: Appleton Century Grofts, 1974.

10. Hurst JW, Walker HK. The problem oriented system. New York: Medcom Press, 1970.

11. Anonymous. An international glossary for primary care. Huisarts Wet 1981; 24:342-946

12. Sandlow LJ, Bashook PG. Problem oriented medical records: self instruction for practitioners. Chicago: Michael Reese Hospital and Medical Center, 1978.

13. Anonymous. ICHPPC-2-defined (inclusion criteria for the use of the rubrics of the International Classification of Health Problems in Primary Care). Oxford: Oxford University Press, 1983.

14. American Psychiatric Association: Diagnostic and Statistical manual of mental Disorders. Third Edition, Revised. Washington DC: American Psychiatric Association, 1987.

15. Lamberts $H$, Wood $M$. The International Classification of Primary Care. Oxford: Oxford Uiniversity Press, 1987. 
16. Vademecum of health Statistics of the Netherlands. The Hague: Netherlands Central Bureau of Statistics, 1991

17. Sheldon MG. The problems of problem - orientated records. J R Coll Gen Pract 1976; 26:437-446

18. Goldfinger SE. The problem - oriented record: a critique from a believer. The N Engl J Med $1973 ; 288(12): 606-608$

19. Feinstein AR. The problems of the problem oriented medical record. Ann Intern Med 1973;78:751-762 
Problem groups with ICPC codes.

Group 1 Family History

$\alpha 00$ (Additional code in Registration Network Family Practices)

\begin{tabular}{ll} 
Group 2 & Risk Factors \\
\hline P15 & Chronic alcohol abuse \\
P16 & Acute alcohol abuse \\
P17 & Tobacco abuse \\
P18 & Medicinal abuse \\
P19 & Drug abuse
\end{tabular}

\begin{tabular}{ll} 
Group 3 & Allergy/allergic reaction \\
\hline A12 & Allergy/allergic reaction nos
\end{tabular}

\begin{tabular}{ll} 
Group 4 & Abnormal results \\
\cline { 1 - 1 } A91 & Investigation with abnormal results nos \\
B84 & Abnormal white cells \\
B85 & Abnormal unexplained blood test \\
B86 & Other hematological abnormality \\
T87 & Hypoglycemia \\
U98 & Abnormal urine test finding, nos \\
X86 & Abnormal pap smear
\end{tabular}

\begin{tabular}{ll} 
Group 5 & Congenital anomalies \\
\hline A90 & Multiple congenital syndromes/congenital anomalies \\
B78 & Hereditary hemolytic anemia \\
B79 & Other congenital anomalies \\
D81 & Congenital anomalies digestive system \\
F80 & Blocked lacrimal duct of infant \\
F81 & Other congenital anomalies eye \\
H80 & Congenital anomalies of ear \\
K73 & Congenital anomalies heart/circ.system \\
L82 & Congenital anomalies musculoskeletal \\
N85 & Congenital anomalies neurological system \\
R89 & Congenital anomalies respiratory system \\
S81 & Hernangioma/lymphangioma \\
S82 & Nevus/mole \\
S83 & Other congenital lesions \\
U85 & Congenital anomalies urinary tract \\
W76 & Congenital anomalies of mother complicating pregnancy \\
X83 & Congenital anomalies female genital \\
Y81 & Phimosis/redundant prepuce \\
Y82 & Hypospadia
\end{tabular}




\begin{tabular}{ll} 
Group 6 & Fear of cancer \\
\hline A26 & Fear of cancer, nos, nec \\
B26 & Fear of cancer of blood/blood-forming organs/lymphatics/spleen \\
D26 & Fear of cancer of digestive system/organ \\
L26 & Fear of cancer of musculoskeletal system \\
N26 & Fear of cancer of neurological disease \\
R26 & Fear of cancer of respiratory system \\
S26 & Fear of cancer of skin \\
T26 & Fear of cancer of endocrine system \\
U26 & Fear of cancer of urinary system \\
X25 & Fear of genital cancer \\
X26 & Fear of breast cancer \\
Y26 & Fear of cancer of male genital organs
\end{tabular}

\section{Group 7}

A25

\section{Fear of disease}

Fear of death

Fear of other disease nos, nec

$$
\text { Fear of AIDS }
$$

Fear of other blood/lymph disease

Fear of other digestive disease

Fear of eye disease

Fear of ear disease

Fear of heart attack

Fear of hypertension

Fear of other disease circulatory system

Fear of other musculoskeletal disease

Fear of other neurological disease

Fear of mental disorder

Fear of other respiratory disease

Fear of having other skin disease

Fear of other endocr.metab.nutr.dis.

Fear of other urinary disease

Fear of complications of preg./delivery

Fear of venereal disease

Fear of sexual dysfunction

Fear other genital/breast disease

Fear of sexual dysfunction

Fear of veneral disease

Fear of other genital disease

Fear of having a social problem

\begin{tabular}{ll} 
Group 8 & Disability/Impairment \\
\hline$\alpha 28$ & Disability/impairment
\end{tabular}




\begin{tabular}{ll} 
Group 9 & Other problern \\
\hline A20 & Euthanasia request/discussion
\end{tabular}

Group $10 \quad$ Psychological problems

All $\mathbf{P}$ codes Exclusive $\mathbf{P}$ codes already selected in other groups

Group 11 Social problems

All $\mathrm{Z}$ codes Exclusive $\mathrm{Z}$ codes already selected in other groups

Group 12 (Pattern of) complaints

a 01 - $29 \quad$ Exclusive codes already selected in other groups

Group 13 Diagnoses

$\alpha$ 70-99 Exclusive codes already selected in other groups 
Chapter 5:

\section{Doctors, patients and data of the Registration Network Family Practices}

Job FM Metsemakers 
The Registration Network Family Practices has been set up primarily as a sampling frame, allowing researchers to identify patients with particular health problems. In this chapter characteristics of general practitioners and patients of the Registration Network are compared with those of the general practitioners in general and the population in general. Furthermore, the process of quality control of the data is described including instruction and training sessions, a registration handbook, regional consensus groups and special software for data control. The accuracy of the data collected, registered and classified is evaluated on the basis of a special software control program and two quality control experiments.

The general practitioners of the Registration Network Family Practices are found to be only partly comparable with the entire group of Dutch general practitioners. The practice population resembles the Dutch general population very much as regards gender, age, type of health insurance and level of education. Minor differences were only found in household composition. The special software program for data control detected less than 1.0 percent incorrect entries in the database and made it possible to identify the most frequent mistakes. One of the quality control experiments shows that important and essential problems are placed on the problem list by the majority of general practitioners. Evaluation of the database looking for possible incorrect problems, also shows that problems have been indicated in the database which do not comply with the problem definition.

On the basis of this approach of continuous quality assurance we conclude that the Registration Network Family Practices can serve as a reliable dynamic sampling frame. 
The Registration Network Family Practices is a computerized health information network in the Netherlands. ${ }^{1}$ The chief goal is to establish a computerized anonymous data base with a limited set of patient characteristics and all relevant health problems. This database can serve as a sampling frame for researchers wishing to study (combinations of) particular health problems. These researchers base their studies on the data available in the database of the Medical and Social Information Center (MEMIC - Medisch en Maatschappelijk Informatie Centrum). The quality of these data has to be guaranteed by the Registration Network Family Practices.

One of the difficulties of multipractice studies is the interpractice variability, as was observed by Crombie in the data of the Second National Morbidity Survey. ${ }^{2}$ This phenomenon has also been described for the Dutch Sentinel Practice Network. ${ }^{3}$ One of the implications of this consistent variability is that data for descriptive studies aiming at generalisability, such as morbidity studies, must be derived from samples which are representative not only of patients but of doctors as well. Another difficulty is the accuracy of data collection, especially when dealing with multiple, often geographically dispersed practices. Green et al. studied the feasibility of a retrospective audit as a way to verify inclusion criteria and to asses the frequency of reporting errors. ${ }^{4}$ This audit was feasible since it was a chart audit of a rather small number of cases.

It has been thought that computers would bring the solution to all registration problems, but by now the expression: "Garbage in, Garbage out" is well known. Recently Jick et al. studied the extent of agreement between clinical information recorded on surgery computers of selected general practitioners and similar information in manual records. ${ }^{5}$ They concluded that the information available on the computer records was satisfactory for many clinical studies. Pringle and Hobbs however, point out that only a small proportion of the practices participating in the computer scheme had reached an acceptable standard of recording after one year. ${ }^{6}$

Lamberts reported that in the Transition project only 0.8 percent of all datat ficlds had been entered incorrectly by the data typist. ${ }^{7}$

The Registration Network Family Practices has been set up primarily as a dynamic population sampling frame and not as a morbidity study which in itself aims at generalisation of data. Therefore, there is no direct need for representativity of doctors and patients of the Registration Network. On the other hand, a good profile of doctor and patient samples and a comparison with the general population will be an added value to the database. 
Since the Registration Network Family Practices serves as a sampling frame of health problems and diagnoses the accuracy of collection, registration and coding of these data is much more important than the "external validity". These clinical data serve researchers as a starting point for further studies.

In this context the following three questions were relevant:

- To what extent are the general practitioners of the Registration Network Family Practices comparable with the entire group of Dutch general practitioners?

- To what extent is the practice population of the Regi-stration Network Family Practices comparable with the Dutch general population?

Are the data on health problems and diagnoses collected by the participating general practitioners reliable ?

These three questions will each be dealt with in turn in the following sections.

\section{General Practitioners}

This section discusses the following question: to what extent are the general practitioners of the Registration Network Family Practices comparable with the entire group of Dutch general practitioners?

\section{Methods}

The following characteristics of general practitioners have been collected:

- $\quad$ age and gender

- number of years of experience as general practitioner

- type of practice

- degree of urbanisation of practice location

- dispensing/non-dispensing

- $\quad$ membership of the Dutch College of General Practitioners

- computerized/non computerized

Most of these characteristics are known for the population of Dutch general practitioners from the register of the Netherlands Institute of Primary Health Care (NIVEL). ${ }^{8}$ Several characteristics of the Registration Network physicians were already known. The remaining data were gathered by questionnaire, with a 100 percent response rate. All data are valid for September 1, 1991. 
The 42 general practitioners who participate in the Registration Network Family Practices have been studied as one group, although there are differences in registration and computer experience.

A small number of general practitioners ( 7 GP's) were part of the project group that started the registration project in the early 1980's. They had participated in the development of the registration instrument, i.e. the concept of the problem list. Furthermore, they had participated in a trial of the Reason for Encounter Classification (RFE-C), the predecessor of the International Classification of Primary Care. ${ }^{9}$ Their experience with practice computers was limited.

Another group (nine general practitioners) was among the first general practitioners in the Netherlands to computerize their practices. This made them ideal participants for the Registration Network Family Practices. Most of them did have some previous experience with registration.

The remaining 26 general practitioners joined for various reasons. Several practitioners worked in group practices. Their colleagues joined the Registration Network as a result of the process of affiliation between the Department of General Practice and general practices. Most of them did not have much experience with registration or practice computers. Other practices spontaneously indicated interest in participation in the Registration Network Family Practices. Some of these general practitioners had some experience with the use of practice computers but not with registration activities.

Furthermore, new general practitioners joined already participating practices, sometimes for a part-time position. Only a few of them had any experience with practice computers. None of them had experience with registration.

\section{Results}

Comparing the age of the general practitioners participating in the Registration Network with that of Dutch general practitioners in general, it is obvious that most. general practitioners were in the age range of $30-49$. The Registration Network included fewer general practitioners in the older age groups and more in the youngest age group. The percentage of women participating in the Registration Network was 16 percent, which is slightly higher than in the total population of Dutch general practitioners. (Table 1) There were no great differences in the number of years of experience between the two groups, as is shown in table 2.

With regard to the type of practice, there was a distinct difference between the two groups: only a few solo general practitioners participate in the Registration Network, while many more general practitioners work in group practices and health centers.(Table 3) This is not surprising when one looks at the degree of urbanisa- 
tion of the practice locations. The province of Limburg, and certainly the southern part, where most participating general practices are located, is a densely populated area. The differences between the two groups shown in table 4, are therefore not surprising. Five percent of the general practitioners of the Registration Network had a dispensary attached to the practice, versus 12 percent of the general population of general practitioners. The difference is understandable, on the basis of the practice type and urbanisation grade, since dispensaries are usually found in rural solo or duo practices.

Almost all general practitioners of the Registration Network were members of the Dutch College of General Practitioners, compared to 60\% of the total Dutch GP population. The greatest difference was of course in the degree of computerisation, since that is the basis of the Registration Network. While the proportion of general practitioners who have computerized their practices is increasing steadily and now stands at 70 percent, only 10 to 15 percent are actually using the computerized medical record. ${ }^{10}$ (Table 5 )

Table 1. Comparison of age and gender between the general practitioners of the Registration Network Family Practices and the population of Dutch general practitioners. (column percentages)

\begin{tabular}{|c|c|c|c|c|c|c|}
\hline & \multicolumn{3}{|c|}{$\begin{array}{l}\text { Registration Network } \\
\text { Family Practices }\end{array}$} & \multicolumn{3}{|c|}{ Netherlands } \\
\hline & male & female & total & male & female & total \\
\hline & $\mathrm{N}=35$ & $\mathrm{~N}=7$ & $\mathrm{~N}=42$ & $\mathrm{~N}=5619$ & $\mathrm{~N}=852$ & $\mathrm{~N}=6471$ \\
\hline age & $83 \%$ & $17 \%$ & $100 \%$ & $86.8 \%$ & $13.2 \%$ & $100 \%$ \\
\hline$<30$ & 0 & 14 & 2 & 0.1 & 0.2 & 0.2 \\
\hline $30-34$ & 14 & 14 & 14 & 7.6 & 24.2 & 9.8 \\
\hline $35 \cdot 39$ & 29 & 43 & 31 & 23.6 & 41.1 & 25.9 \\
\hline $40-44$ & 29 & 29 & 29 & 29.2 & 21.9 & 28.2 \\
\hline $45-49$ & 14 & 0 & 12 & 6.1 & 6.6 & 14.9 \\
\hline $50-54$ & 6 & 0 & 5 & 8.5 & 2.7 & 7.8 \\
\hline $55 \cdot 59$ & 6 & 0 & 5 & 6.8 & 2.2 & 6.2 \\
\hline $60-64$ & 3 & 0 & 2 & 6.9 & 1.1 & 6.2 \\
\hline $65-69$ & 0 & 0 & 0 & 0.8 & - & 0.8 \\
\hline$>70$ & 0 & 0 & 0 & 0.2 & - & 0.1 \\
\hline Source: & \multicolumn{6}{|c|}{$\begin{array}{l}\text { Netherlands Institute of Primary Health Care (NIVEL). Statistical data on general } \\
\text { practitioners and midwives. } 1 \text { January } 1991 .\end{array}$} \\
\hline
\end{tabular}


Registration Network

Family Practices Netherlands

years of experience

$$
N=42
$$$$
N=6471
$$

0 - 5

$6-10$

$11-15$

16 - 20

2I - 25

$26-30$

$>30$

unknown

Source:

\section{$26 \%$}

23

26

14

2

7

0

\section{$25.6 \%$}

21.1

22.1

14.4

7.3

4.6

4.7

0.3

Netherlands Institute of Primary Health Care (NIVEL). Statistical data on general practitioners and midwives. 1 January 1991.

Table 3. Type of practice (column percentages)

\begin{tabular}{lcc}
\hline & $\begin{array}{c}\text { Registration Network } \\
\text { Family Practices }\end{array}$ & Netherlands \\
type of practice & $\mathrm{N}=42$ & $\mathrm{~N}=6471$ \\
\hline solo practice & 14 & 53.4 \\
duo practice & 5 & 29.1 \\
group practice & 36 & 9.1 \\
health center & 45 & 8.4 \\
Source: & Netherlands Institute of Primary Health Care (NTVEL). Statistical data on general \\
& practitioners and midwives. 1 January 1991. \\
\hline
\end{tabular}

Table 4. Degree of urbanisation of practice location (column percentages)

Registration Network

Family Practices Netherlands

\begin{tabular}{lrc} 
practice location & $\mathrm{N}=42$ & $\mathrm{~N}=6471$ \\
\hline rural municipalities & 0 & 10.8 \\
urbanised rural municipalities & 28 & 22.6 \\
commuter municipalities & 0 & 14.6 \\
urban municipalities & & \\
$\quad$ - small $10000-30000$ & 0 & 10.8 \\
- medium sized $30000-100000$ & 55 & 15.8 \\
- large $>100000$ & 17 & 25.3
\end{tabular}

Source: $\quad$ Netherlands Institute of Primary Health Care (NIVEL). Sutistical data on general practicioners and midwives. 1 January 1991. 
Registration Network

Family Practices

Netherlands

\begin{tabular}{lll}
\hline dispensing practitioners $^{1}$ & $\mathrm{~N}=42$ & $\mathrm{~N}=647 \mathrm{I}$ \\
& $5 \%$ & $11.4 \%$ \\
membership Dutch College $^{\text {of General Practitioners }^{2}}$ & $\mathrm{~N}=42$ & $\mathrm{~N}=6500$ \\
& $88 \%$ & $60 \%$ \\
computerized medical record $^{3}$ & $\mathrm{~N}=42$ & $\mathrm{~N}=6500$ \\
& $100 \%$ & $10-15 \%$
\end{tabular}

Sources: $\quad{ }^{1}$ NIVEL Netherlands Institute of Primary Health Care. Statistical data on general practitioners and midwives. 1 January 1991.

${ }^{2}$ Dutch College of General Practitioners

${ }^{3}$ Westerhof HP, Berden HJJM. De meerwaarde van het elektronisch medisch dossier.

Tussenresultaten van het NUT II projekt Huisarts en Wetenschap 1993;36(11):380-3

\title{
3. Population
}

This section discusses the extent to which the practice population of the Registration Network Family Practices is comparable with the Dutch general population.

\section{Methods}

The following patient characteristics are recorded in the Registration Network Familiy Practices:

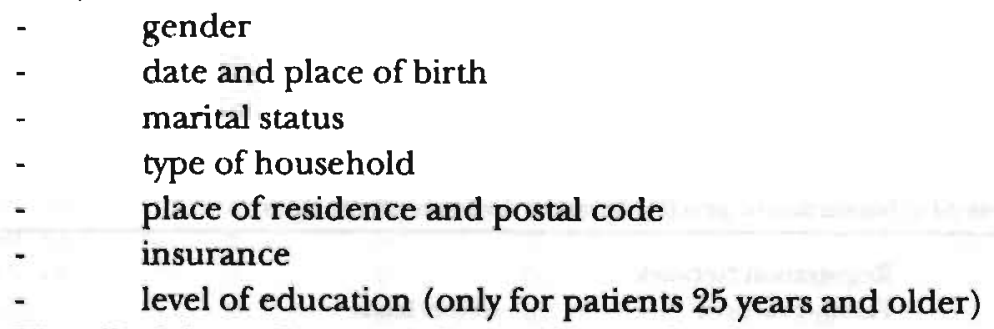

Not all of these characteristics are known for the general population. Hence, it is not possible to compare the patient population of the Registration Network with the population of the Netherlands as a whole in all respects. The comparison has therefore been limited to the following characteristics:

\author{
gender \\ age \\ type of household \\ insurance \\ level of education
}




\section{Results}

The comparison of age and gender between the Registration Network Family Practices population and the general population shows no clear differences between the two groups. (Table 6)

Comparing the household situation in the two groups is difficult, because the data of the general population are presented on the basis of combinations of household types which do not fully match those used in the Registration Network Family Practices. The difference between the two populations with regard to the household type: "couple with/without lodger(s)" and "family/couple with children with/without lodger(s)" is partly due to the fact that the Registration Network combines the households with lodgers in one small category $(1.3 \%$ of the household distribution in the Registration Network). The conclusion therefore is that there are more households with children in the Registration Network population.(Table 7) Two thirds of the persons in the Registration Network population are insured by the Sickness Fund Act, versus just over 60 percent of the general population. These are minor differences.(Table 8 ) The level of education in the population of the Registration Network Family Practices is lower than in the general population. Once again, the differences are minor and may be partly due to differences in the categories used in the two databases.(Table 9)

Table 6. Comparison of age and gender between the Registration Network Family Practices population and the general population (column percentages)

\begin{tabular}{|c|c|c|c|c|c|c|}
\hline \multirow[b]{3}{*}{ age group } & \multicolumn{3}{|c|}{$\begin{array}{l}\text { Registration Network } \\
\text { Family Practices }\end{array}$} & \multicolumn{3}{|c|}{ General Population } \\
\hline & \multicolumn{3}{|c|}{$N=42942 \quad(1 / 9 / 91)$} & \multicolumn{3}{|c|}{$N=14892574 \quad(1990)$} \\
\hline & male & female & total & male & female & total \\
\hline $00-04$ & 7.2 & 6.0 & 6.6 & 6.4 & 6.0 & 6.2 \\
\hline $05-14$ & 12.0 & 10.9 & 11.5 & 12,4 & 11.6 & 12.0 \\
\hline $15-24$ & 13.5 & 13.6 & 13.5 & 16.4 & 15.4 & 15.9 \\
\hline $25-44$ & 39.8 & 32.9 & 33.4 & 33.5 & 31.3 & 32.4 \\
\hline $45-64$ & 22.0 & 20.8 & 21.4 & 20.9 & 20.4 & 20.7 \\
\hline $65-74$ & 7.9 & 9.3 & 8.6 & 6.6 & 8.2 & 7.4 \\
\hline+75 & 3.5 & 6.4 & 5.0 & 3.8 & 7.1 & 5.4 \\
\hline total & 48.3 & 51.7 & $100 \%$ & 49.4 & 50.6 & $100 \%$ \\
\hline Source: & \multicolumn{6}{|c|}{ Central Bureau of Statistics (CBS); edited by MEMIC } \\
\hline
\end{tabular}




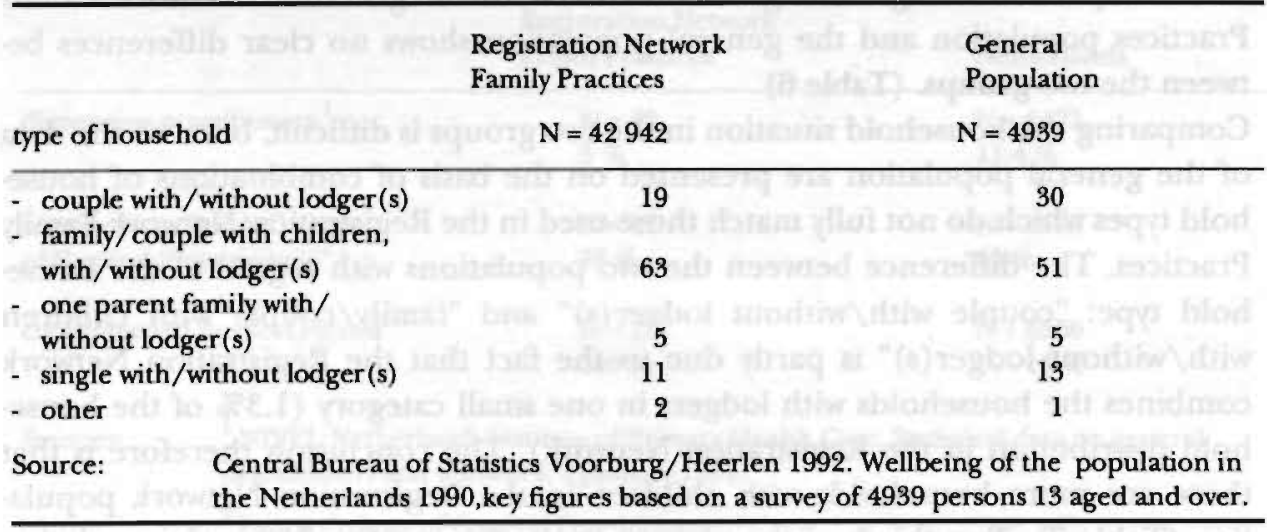

Table 8. Comparison of insurance status between the Registration Network Family Practices and the general population (column percentages)

\begin{tabular}{|c|c|c|}
\hline \multirow[b]{2}{*}{ insurance } & $\begin{array}{l}\text { Registration Network } \\
\text { Family Practices }\end{array}$ & \multirow{2}{*}{$\begin{array}{l}\text { General } \\
\text { Population } \\
N=15010495 \quad(1 / 1 / 1991)\end{array}$} \\
\hline & $\mathrm{N}=42942 \quad(1 / 9 / 1991)$ & \\
\hline sickness fund & $67.5 \%$ & $61.4 \%$ \\
\hline private insurance & 32.5 & 38.6 \\
\hline Source: & \multicolumn{2}{|c|}{ Statistical Yearbook; Central Bureau of Statistics 1992} \\
\hline
\end{tabular}

Table 9. Comparison of educational levels between the Registration Network Family Practices and the general population (column percentages)

\begin{tabular}{|c|c|c|c|c|}
\hline \multirow{2}{*}{\multicolumn{2}{|c|}{ level of education }} & \multirow{2}{*}{$\begin{array}{l}\text { Registration Network } \\
\text { Family Practice }^{\text {a) }} \\
\mathrm{N}=29391 \quad(1 / 9 / 91)\end{array}$} & \multirow{2}{*}{$\begin{array}{l}\text { General } \\
\text { Population }{ }^{\text {b) }} \\
N=4171\end{array}$} & \\
\hline & & & & \\
\hline \multicolumn{5}{|c|}{ low (primary education/ } \\
\hline \multicolumn{2}{|c|}{ lower vocational training) } & 56.3 & 43.8 & \\
\hline \multicolumn{2}{|c|}{ medium (secondary education) } & 33.6 & 39.5 & \\
\hline \multicolumn{2}{|c|}{ high (higher education) } & 10.1 & 16.7 & \\
\hline a) & \multicolumn{4}{|c|}{ only for patients aged 25 and over } \\
\hline b) source: & \multicolumn{4}{|c|}{$\begin{array}{l}\text { Central Bureau of Statistics. Voorburg/Heerlen } 1992 \text {. Wellbeing of the population in } \\
\text { the Netherlands } 1990 \text {. Based on a survey of } 4171 \text { persons } 25 \text { aged and over. }\end{array}$} \\
\hline
\end{tabular}


This section discusses the following question: are the data on health problems and diagnoses collected by the participating general practitioners reliable ?

\subsection{Introduction}

The general practitioners participating in the Registration Network Family Practices have to include all relevant health problems on the problem list. A health problem is defined as "Anything thas has required, or does or may require health care management and has affected or could significantly affect a person's physical or emotional well-being." 11,12

This definition requires the following types of problems to be included: diagnoses, patterns of complaints, abnormal fin-dings, risk faktors and other problems.

Problems should be recorded only if they have consequences for the present and/or future functional status of the patient. This operationalisation implies that permanent problems (no recovery expected), chronic problems (duration longer than six months), and recurrent problems (more than three recurrences within a six month period) have to be included on the problem list.

Problems should always be stated at the highest level of refinement which can reasonably be defended. Recording a recently established diagnosis is justified if the criteria of the International Classification of Health Problems in Primary Care (ICHPPC-2 defined) are met. ${ }^{13}$ If not, then the complaint or syndrome is recorded without a diagnostic label.

Since there is no gold standard for inclusion of health problems on the problem list, and thereby in the database, general practitioners have to decide for each separate health problem or diagnosis whether it meets the problem definition and additional criteria.

Clearly, diabetes mellitus will be put on the problem list by all general practitioners, but some degree of inter-doctor variance will be present for other health problems such as low back pain.

Several mechanisms have been set up to minimise this inter-doctor variance and to guarantee the quality of the data in the Registration Network Family Practices:

instruction and training sessions

registration handbook

regional consensus groups

special software for data control in the health information system used by the general practitioners 
special software for data control in the database of the Medical and Social Information Center

quality control experiments

\subsection{Instruction and training sessions}

All general practitioners participated in the instruction and training session, which was given several times. In addition, more detailed written instructions were provided, illustrated with examples based on an article on the problem list. ${ }^{12}$ This material was sent to the general practitioners approximately two to three weeks before the session. The general practitioners attended these sessions in groups of 8 to 12 persons.

After an introduction, the basic principles and instructions of the registration were reiterated and clarified. In the second part of the session the general practitioners had to prepare a problem list on the basis of three specialist letters. The problem list of one of the general practitioners was used in the discussion, in which the group had to come to a consensus based on the problem definition. It was pointed repeatedly out that there was no gold standard list of health problems or diagnoses to be included on the problem list, but that the general practitioners had to decide on each health problem or diagnosis.

At the cnd of the session attention was paid to the use of the ICPC and the criteria of the ICHPPC-2 defined.

The sessions lasted two to three hours and were regarded as very valuable.

\subsection{Registration Handbook}

All general practitioners were provided with a Registration Handbook, which is updated regularly. The problem list concept, the problem definition, all additional guidelines and criteria are described in this handbook. Furthermore, technical instructions with regard to data entry, data control and data exit are given. Examples are used to clarify the instructions.

\subsection{Regional consensus groups}

Although all general practitioners had followed the instruction and training session and possessed the Registration Handbook, it was clear that continuing training in the application of the problem definition was needed.

For this purpose four regional consensus groups were organised in 1990, convening at least four times a year. A problem list task force oversees and plans the activities of these consensus groups. This task force meets several times a year, at least four times with the coordinators of the regional consensus groups.

The most important aim is for the general practitioners to come together and discuss their registration difficulties, using the problem definition as a guideline. This leads to greater consensus in relation to the problem definition. In addition, the problem list task force provides the regional consensus groups with other 
tasks, such as screening certain ICPC codes. This process can be used for several purposes. It is possible to choose an ICPC code whose presence on the problem list seems odd. Chickenpox, for instance, cannot be regarded as a chronic disease and should therefore in principle not appear on a problem list. In this way the problem lists have been screened for this type of problem. Some ICPC codes, especially the alpha99 codes, are last resort codes containing all kinds of health problems and diagnoses within the same ICPC code. Screening these ICPC codes can be very rewarding, since it may turn out that diagnoses have been labeled with the wrong ICPC code.

Sometimes the groups have to formulate a problem definition on the basis of letters of medical specialists to general practitioners or a medical record. The goal of such exercises is, once again, to practice the use of the problem definition and the additional criteria.

The coordinators of the regional consensus groups have to report both in writing and orally. Their reports are used in the process of ongoing refinement of instructions and guidelines. The general practitioners regard these meetings as very useful and in some groups a process of medical audit has evolved from these meetings.

\subsection{Special software for data control in the health information system used by the general practitioner.}

All practices use microHIS, a commercially developed general practice health information software program containing a basic module, a medical module and a pharmacy module. Several general practitioners of the Registration Network Family Practices have participated in the development of the microHIS program and still participate in the regular update process. Additional software has been developed and installed to achieve data control and data collection. The software for data control checks all items which contain information for the central database. Most of the items are patient background characteristics and the program checks whether or not the field is filled with a permitted code. All health problems and diagnoses for example have to have an ICPC code, but the program cannot check whether it is the correct ICPC code.

If the data control program detects erronous or missing entries, it notifies the general practitioner and he then has to correct these items before the data collection program will accept the data for transfer to the central database at the Medical and Social Information Center.

\subsection{Special software for data control in the database of the Medical and Social Information Center}

The central data base is stored in a VAX Mainframe computer. This allows for a more extensive data control program. 
It is possible to check for impossible values such as age over 115 years; married at the age of 5; non-existing ICPC codes such as C25; impossible combinations such as W80 ectopic pregnancy if the person is male; or unlikely values such as age more than 100 years; education level 3 at age of 15 , living in a home for the elderly and being younger than 50; L95 osteoporosis at age 30; H84 presbyacusis at age 40.

It has as yet not been possible to develop a data control program which completely covers all impossible, unlikely, and often unpredictable combinations of values. The current data control program checks for the items listed in table 10. The program includes patient characteristics controls (type 1 items) and several data controls on health problems (type 2 items).

Table 10. Items of the MEMIC data control programme

\begin{tabular}{|c|c|}
\hline Type 1 & patient characteristics \\
\hline$\overline{1 a}$ & marital status \\
\hline $1 b$ & code of residence \\
\hline 1c & type of household \\
\hline ld & level of education \\
\hline le & place of birth \\
\hline If & postal code \\
\hline Type 2 & health problems \\
\hline $2 a$ & problem list without problem \\
\hline $2 b$ & incorrect entry active date health problem \\
\hline $2 c$ & incorrect entry inactive date health problem \\
\hline $2 \mathrm{~d}$ & ICPC code \\
\hline $2 e$ & problem number, active date and health problem \\
\hline $2 f$ & ommision of appropriate inactive date \\
\hline $2 g$ & incorrect active date in relation to inactive date \\
\hline
\end{tabular}

\section{Studies of the database}

The database of June 1, 1991 was used for the analysis presented here, using the data control program. For the sake of privacy, a random character was assigned to identify each practice.

\section{Results}

Table 11 shows the distribution of the 9305 incorrect entries in the database. It becomes clear that the items $2 \mathrm{f}, \mathrm{le}, 2 \mathrm{~g}$, and $2 \mathrm{c}$ together account for the greatest number of incorrect entries ( 8626 or 92.7 percent). When entering the place of birth (item le) general practitioners have to enter the city of birth if the person is born in the Netherlands and the country of birth if he or she was born in a foreign country. Several general practitioners always stated the city of birth, regardless of the country where the person was born. Item $2 \mathrm{f}$ is another source of mista- 
kes where general practitioners either forgot to enter the date on which an active health problem became inactive or labeled an already inactive health problem as inactive while entering the inactive date in the space intended for the active date. The control program then finds an inactive health problem without an inactive date.

Table 11. Distribution of incorrect entries in the database of 1-6-1991. Detected by the MEMIC data control program

\begin{tabular}{llrr}
\hline item & patient characteristics & $\mathrm{N}$ & percentage \\
la & marital status & 6 & 0.1 \\
1b & code of residence & 51 & 0.5 \\
Ic & type of household & 1 & 0.0 \\
Id & level of education & 36 & 0.4 \\
le & place of birth & 1934 & 20.8 \\
If & postal code & 278 & 3.0 \\
\hline total type 1 & & 2306 & 24.8 \\
& & & \\
item & health problems & $\mathrm{N}$ & percentage \\
2a & problem list without problem & 0 & 0.0 \\
2b & incorrect entry active date health problem & 10 & 81.2 \\
2c & incorrect entry inactive date health problem & 88 & 39.5 \\
2d & ICPC code & 38 & 0.4 \\
2e & problem number, active date and health problem & 16 & 11.7 \\
2f & omission of appropriate inactive date & 4724 & 50.8 \\
2g & incorrect active date in relation to inactive date & 1085 & 11.7 \\
\hline total type 2 & & 6999 & 75.2 \\
\hline total & & & \\
\hline
\end{tabular}

The number of type 1 incorrect entries was 2306 on a total of 243594 entries ( 6 items x 40899 registered persons), or 0.9 percent. A very low percentage of errors is also found for type 2 entries. On a total of 861154 entries ( 7 items x 123022 registered problems) the number of incorrect entries was 6999 or 0.8 percent.

Table 12 shows that some practices need to look very carefully at the entry of patient characteristics, since they have a large number of incorrect entries. In particular practices $T, N$ and to a lesser degree practices $R$ and $C$ should review their procedures.

Practices T, N and R made 1741 mistakes (590; 950; 201) on 7706 registered patients (22.6 percent) for the patient characteristic place of birth. Practice $\mathrm{C}$ entered 79 wrong postal codes on 1997 registered patients ( 3.9 percent). 
Table 12. Incorrect entries of patient characteristics (type 1 items) in relation to the number of patients per practice in the database of 1-6-1991

\begin{tabular}{lrrr}
\hline & incorrect entries & number of patients & $\begin{array}{l}\text { incorrect entries/ } \\
\text { number of patients } \\
\text { (percentage) }\end{array}$ \\
total & $N$ & $N$ & $5.6 \%$ \\
\hline practice & 2306 & 40899 & \\
B & & & 1.7 \\
C & 9 & 519 & 5.8 \\
D & 117 & 1997 & 0.2 \\
F & 4 & 2187 & 0.5 \\
G & 24 & 4455 & 1.6 \\
H & 31 & 1902 & 0.3 \\
K & 3 & 1105 & 0.4 \\
L. & 14 & 3384 & 1.1 \\
N & 22 & 1924 & 22.0 \\
O & 986 & 4476 & 1.1 \\
P & 12 & 1108 & 0.7 \\
R & 26 & 3780 & 9.1 \\
S & 226 & 2492 & 4.8 \\
T & 141 & 2904 & 80.9 \\
V & 597 & 738 & 0.7 \\
W & 23 & 3319 & 1.8 \\
X & 47 & 2630 & 1.2 \\
\hline
\end{tabular}

Table 13. Incorrect entries of health problems (type 2 items) in relation to the number of problems per practice in the database of 1-6-1991

\begin{tabular}{lrrr}
\hline & incorrect entries & number of problems & $\begin{array}{l}\text { incorrect entries/ } \\
\text { number of problems } \\
\text { (percentage) }\end{array}$ \\
total & $\mathrm{N}$ & $\mathrm{N}$ & $5.7 \%$ \\
\hline practice & 6999 & 123022 & \\
B & & & 7.7 \\
C & 112 & 1456 & 3.4 \\
D & 147 & 4339 & 17.2 \\
F & 1831 & 10620 & 6.9 \\
G & 736 & 10685 & 5.7 \\
H & 222 & 3874 & 0.7 \\
K & 25 & 3436 & 4.5 \\
L & 598 & 13426 & 11.6 \\
N & 740 & 6382 & 4.9 \\
O & 780 & 15968 & 4.8 \\
P & 108 & 2243 & 3.1 \\
R & 399 & 13039 & 6.9 \\
S & 301 & 4964 & 4.9 \\
T & 409 & 8321 & 8.2 \\
V & 151 & 1839 & 1.9 \\
W & 175 & 9080 & 1.5 \\
X & 138 & 9414 & 2.8 \\
\hline & 127 & 4536 &
\end{tabular}


How practices registered health problems is shown in table 13. Practices D, L and, to a lesser degree, practices T, B and F had a greater proportion of incorrect entries than other practices. Item $2 \mathrm{f}$ : "omission of inactive date in relation to active date when appropriate" is by far the largest source of incorrect entries in all these practices. Item $2 \mathrm{~g}$ : "incorrect active date in relation to inactive date" is another problem for practice $D$.

\section{Conclusion}

The number of incorrect entries as detected by the MEMIC data control program is very low. In relation to the total number of entries 0.8 percent and 0.9 percent incorrect entries were found for patient characteristics and health problems respectively. Furthermore, the program only discovers technical mistakes. No definitive judgment can be made on the reliability of the health problems formulated by the general practitioners of practices $\mathrm{D}, \mathrm{L}, \mathrm{T}, \mathrm{B}$ and $\mathrm{F}$.

Several practices should review their registration procedures, but no practice can be identified as doing a poor job in general.

Furthermore it can be concluded that the guidelines for several items should be reviewed by the project group, especially with respect to: place of birth (1e), "omission of inactive date in relation to active date when appropriate" (2f), and "incorrect active date in relation to inactive date" $(2 \mathrm{~g})$.

\subsection{Quality control experiments}

\subsubsection{Experiment 1: Patient Dummy}

The goal of the instruction and training session was to establish a common registration behaviour which would minimise inter-doctor variance.

The problem list task force decided to test the registration behaviour of the general practitioners in June 1990, approximately one year after the first instruction and training sessions.

\section{Methods}

All 35 participating general practitioners received the typed medical notes of patient Dummy with the instruction to construct a list with al definite and tentative problems, and to code the problems using the ICPC. Appendix 1 contains an excerpt of the medical notes.

Three experienced members of the problem list task force were given the task to formulate the gold standard problem list after completing their own problem lists. After a short discussion they reached consensus on the gold standard problem list. 


\section{Results}

Problem lists were returned by all 35 general practitioners. Table 14 shows that the items of the gold standard problem list were identified by most general practitioners. Problem 6 (status post extirpation of spleen) was stated as a separate problem by 15 general practitioners but was included in problem 5 by 18 other general practitioners. In other words, 33 (or 94\%) of the general practitioners put this condition on the problem list, although not all of them did this in the correct way. Ten general practitioners concluded that the patient had nervous stomach complaints, as stated in problem 8 of the gold standard problem list. If the problem had been labeled "stomach complaints", 34 general practitioners (or 97\%) would have complied with the proposed problem label. Review of the medical notes revealed that there were arguments for each of these problem definitions but that nervous stomach complaints had been used explicitly.

Table 14. Gold standard problem list in relation to the results of the general practitioners $(n=35)$

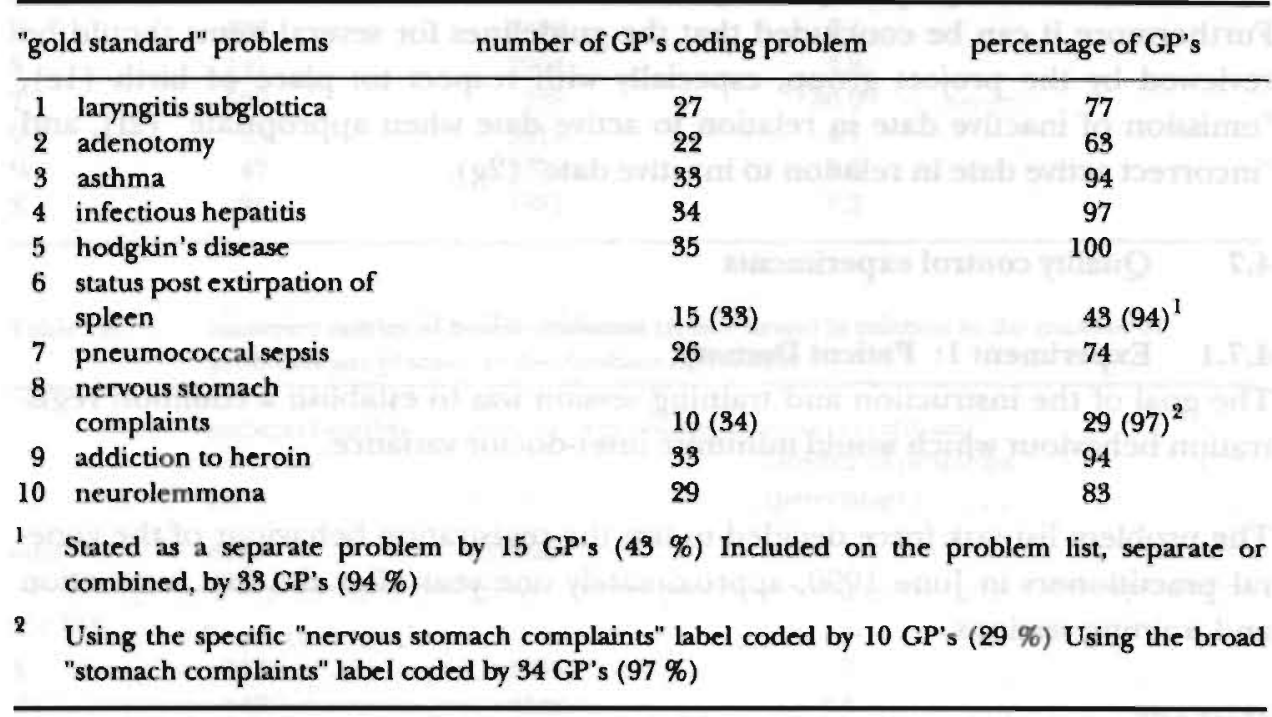

Of course the problem lists of the general practitioners contained more than just the ten items of the gold standard problem list. Some general practitioners listed only a few problems, others named many more problems, as shown in table 15. While the gold standard problem list consisted of ten items, the mean number of problems per general practitioners, on the basis of their own lists was 13.1. Eleven general practitioners formulated less than 10 problems, 23 formulated more, even up to 25 . One should, however, take into account the fact that they were instructed to formulate a list with all definite and tentative problems. The gold standard problem list only contained definite problems. 
Number of problems on the problem list number of general practitioners formulating that number of problems on the problem list ( $\mathrm{N}=35$ )

\begin{tabular}{lll}
\hline 4 & 1 \\
5 & 1 \\
6 & 7 & 2 \\
8 & 2 \\
9 & 5 \\
10 & 1 \\
11 & 3 \\
12 & 2 \\
13 & 2 \\
14 & 3 \\
15 & 3 \\
16 & 2 \\
17 & 1 \\
18 & 2 \\
19 & 2 \\
20 & 1 \\
21 & 1 \\
22 & 1 \\
\hline 23 & 23 & \\
\hline
\end{tabular}

\section{Discussion}

Paper exercises cannot match real practice situations, where it is possible to question the patient about information in his medical record.

On the other hand it is a useful instrument to use in a quality control programme like that implemented in the Registration Network Family Practices. The fact that all 35 general practitioners of the network participated in this experiment indicates their commitment to the quality control programme.

This experiment demonstrates that important and essential problems are placed on the problem list by the majority of general practitioners, justifying the use of the data base as a sampling frame for revelant health problems and diagnoses.

At the same time, the experiment also shows that some general practitioners use a very narrow interpretation of the concept, while others have a rather broad "problem" concept, although they may have included tentative problems on their list. This means that the data base will contain a number of health problems and diagnoses which do not fully comply with the problem definition. Therefore, further instructions and discussions in the regional consensus groups will be necessary on a regular and continual basis. 


\subsubsection{Experiment 2: Data base evaluation}

Since one of the suggestions from experiment 1 (patient Dummy) was that some general practitioners did not fully comply with the problem definition and included minor self limiting problems on their problem lists, we decided to evaluate the data base of December 1, 1990.

\section{Methods}

First, we identified four ICPC codes which should not have been included on the problem list, either on the basis of their label ( A96: death (excl. perinatal); A97: no disease) or on the basis of an agreement in the Registration Network ( W78: pregnancy:confirmed; W90: normal delivery liveborn(s)). These ICPC codes have always been excluded from the Registration Network data base. Furthermore we found 3 ICPC codes (W84: pregnancy requiring special care (high risk); W91: normal delivery deadborn(s); W92: complicated delivery liveborn(s)) to be included on the problem list of either the mother, the father or the child. We decided to exclude these ICPC codes from our analysis and to formulate further instructions for the use of these ICPC codes.

Next we asked two general practitioners with experience in registration and use of the ICPC to screen the ICPC for codes which would probably not comply with the problem definition due to the nature of the complaint or disease, such as cough (R05), head cold (R74), nausea (D09) and others. We considered these to be: unlikely problems. GP A indicated 43 ICPC codes, while GP B concluded that 39 ICPC , codes would be unlikely problems. They agreed on 11 ICPC codes. The ICPC codes they did not agree on where reviewed by the author. 18 ICPC codes were added to the list of eleven, 12 indicated by GP A, 6 of GP B. In all, 29 ICPC codes were labeled as unlikely problems and were identified in the database of December 1, 1990. (Appendix 2)

The special software for data control in the database of the MEMIC has been described above. Although the data controlprogram does not include all impossible or unlikely values or combinations of values, we studied the combination of gender and gender specific ICPC chapters $\mathrm{W}, \mathrm{X}$ and $\mathrm{Y}$ in the database of December 1 , 1990. All persons labeled as male and having an ICPC code from chapters X or W, and all persons labeled female and having an ICPC code from chapter Y were identified. The mistake in these cases was either the gender or the ICPC code.

Since it was our purpose to let the general practitioners review and correct their own material we decided to add as "control codes" those ICPC codes which were probably correct. This was done to avoid correction bias by the general practitioners who might think that every ICPC code should be corrected. The frequency of these probably correct ICPC codes was 10 percent of the unlikely problems, with a minimum of three ICPC codes per general practitioner. 
Thus, in February 1991 each general practitioner received a set of ICPC codes with patient data allowing identification in their own general practice health information system. They were requested to review their ICPC codes and to indicate whether the problem and its ICPC code should be left unchanged, should be removed or should be given another ICPC code. The instruction clearly indicated that unlikely problems, probably correct problems and impossible gender-specific ICPC codes were present in the data set they had received.

\section{Results}

The data base of December 1, 1990 contained 110017 problems, of which 14 had been insufficiently coded. 1175 problem codes were removed because they should not have been included or required the addition of further instructions. 635 unlikely problems (sample A) were identified while the data control program located a further 47 incorrect gender-specific ICPC codings (sample B). Furthermore, 213 problems presumed to have been correctly coded were selected (sample C).

This means that $682(0.6 \%)$ possible errors were identified on a total of 110017 health problems. The design of this database analysis is summarised in table 16.

health problems excluded

- on the basis of ICPC label

- on the basis of agreement

in the Registration Network

- on the basis of insufficient

insuruction for use

\begin{tabular}{rr} 
A96 & 2 \\
A97 & 73 \\
W78 & 397 \\
W90 & 621 \\
W84 & 2 \\
W91 & 2 \\
W92 & 78 \\
& \\
\cline { 2 - 2 } & 1175
\end{tabular}

1175

Remaining number of health problems

avalaible for evaluation

sample A

- unlikely problems

sample B

- gender specific ICPC code

incortectly coded

sample $C$

- probably correct problems 
886 of the 895 ICPC codes were returned after review by the general practitioners. Nine ICPC codes could no longer be linked to a patient, because the patient had left the practice or had died.

The overall results of this review process, are given in table 17, which shows that of the 886 problems reviewed $564(63,7 \%)$ were unaltered, $240(27,1 \%)$ had been removed, and $82(9.3 \%)$ had been corrected. There is a clear difference between the erroneous problems (sample $\mathrm{A}$ ) and the correct problems (sample $\mathrm{C}$ ). In sample A 229 (36.3\%) health problems were removed, in sample C only 7 (3.4\%). This indicates that many unlikely problems (sample A) proved indeed not to be a problem according to the problem definition used within the Registration Network Family Practices, although the general practitioners decided that more than half of the unlikely problems were correctly labeled as a problem.

Sample B consisted of 47 gender specific ICPC problems, detected by the quality control programme, in which either the gender or the ICPC code was wrong. During the review process the general practitioners removed four problems and changed the ICPC code in 24 cases. Two gender changes were reported in the category of ICPC code unaltered. We asked the general practitioners to review the remaining 17 gender specific ICPC codes again. The result is that eight more gender corrections were made and nine more ICPC changes. The review process of 47 gender specific ICPC codes therefore resulted in four ICPC removed (8.5\%), 33 ICPC codes changed at chapter level $(70.2 \%)$ and 10 gender changes $(21.3 \%)$. Furthermore it illustrates that even when specifically asked to review possible errors, the general practitioners at first miss a number of errors.

In a further analysis, a comparison was made between the different general practitioner groups mentioned in the first part of this chapter. No differences in review results were found between general practitioners with more registration experience and those with less experience.

Table 17. Results of review of samples A (unlikely problems), B (incorrectly coded gender specific icpc problems) and C (probably correct problems)

\begin{tabular}{|c|c|c|c|c|c|c|c|c|}
\hline \multirow[b]{2}{*}{ sample } & \multicolumn{2}{|c|}{ unaltered } & \multicolumn{2}{|c|}{ removed } & \multicolumn{2}{|c|}{ ICPC changed } & \multicolumn{2}{|r|}{ total } \\
\hline & $\mathbf{N}$ & $\%$ & $\mathbf{N}$ & $\%$ & $N$ & $\%$ & $\mathbf{N}$ & $\%$ \\
\hline A & 365 & 57.8 & 229 & 36.3 & 37 & 5.9 & 631 & 100.0 \\
\hline B & 19 & 40.4 & 4 & 8.5 & 24 & 51.1 & 47 & 100.0 \\
\hline C & 180 & 86.5 & 7 & 3.4 & 21 & 10.1 & 208 & 100.0 \\
\hline & 564 & 63.7 & 240 & 27.1 & 82 & 9.8 & 886 & 100.0 \\
\hline
\end{tabular}




\section{Discussion}

The results of the data base analysis allow several conclusions. First of all it will be necessary to refine the instructions with regard to several ICPC codes which should not have been present in the problem list data base.

Furthermore, it seems necessary to achieve greater consensus about ICPC codes labeled as "unlikely problems" and then to monitor these in the data base. The automatic quality control program should be expanded with other unlikely values or combination of values, since the gender specific ICPC codes detected by the program had to be altered in all cases.

The number of possible errors is very low $(0,6 \%)$, while the number of actual errors recognized and corrected in the review process was 341 , or 0,3 percent of the total data base of 110017 problems. Unlikely problems were removed in 27,1 percent of the cases, while probably correct problems were left unaltered in 86,5 percent. Although the review process proved useful, it also made it clear that even in such a process errors may go undetected, as was shown by the review of the gender specific ICPC problems.

There were no great differences between general practitioner groups with regard to their review behaviour, which means that there is no need for group specific instructions.

\section{General conclusions}

At the beginning of this chapter three questions were posed.

To what extent are the general practitioners of the Registration Network Family Practices comparable with the entire group of Dutch general practitioners?

To what extent is the practice population of the Regi-stration Network Family Practices comparable with the Dutch general population?

Are the data on health problems and diagnoses collected by the participating general practitioners reliable?

Although the differences in age, gender and years of practice experience are minimal, the general practitioners of the Registration Network Family Practices differ distinctly with regard to other characteristics such as type of practice; degree of urbanisation of practice location; dispensary attached to the practice; membership of the Dutch College of General Practitioners and degree of computerisation of the practice. The general practitioners of the Registration Network Family Practices are therefore only partly comparable with the entire group of Dutch general practitioners. This conclusion does not diminish the value of the Registration Network data. The representativeness of the general practitioners has never been an issue, since the Registration Network, being a sampling frame for research, was looking for general practitioners who were interested in research and in using a 
practice computer for that purpose. Furthermore, the Registration Network has been set up in the region around the University of Limburg were the degree of urbanisation, and hence the practice type, are unlikely to be comparable with the general practice situation in the country as a whole. Since the Registration Network does not aim primarily at demographical generalisability, as many other morbidity studies do, there is no direct need for representativeness of the general practitioners participating in it. The practice population of the Registration Network Family Practices resembles the Dutch general population very much as regards at gender, age, type of health insurance and level of education. Minor differences were only found in household composition.

The third question, about the reliability of the data, is very important but also the most difficult one to answer in a database with 123022 registered health problems. An attractive way to monitor the quality of the health problems registered would be to repeatedly select a sample of health problems from each of the participating general practitioners and to verify the problem definition on the basis of data available either in their practice computer or in old paper records. Also simulated patients could be used to evaluate the quality and inter doctor variability of the patient data. Since such monitoring routines would be very time consuming and expensive, we took a different approach, focusing on careful instruction and training. A registration handbook was provided and regional consensus groups were established as part of the continuing quality control programme. Special software was developed for data control both for the practice health information system and for the database of the Medical and Social Information Center. This special software program detected less than 1.0 percent incorrect entries in the database and made it possible to identify the most frequent mistakes. Several quality control experiments were undertaken to provide more insight into the process of problem definition. One of the experiments shows that important and essential problems are placed on the problem list by the majority of general practitioners. Analysis of the database looking for possible incorrect problems, also shows that problems have been indicated in the database which do not comply with the problem definition.

On the basis of this approach of continuous quality assurance we conclude that the Registration Network Family Practices can serve as a reliable dynamic sampling frame. Of course, additional checks on relevant items may be required in specific studies using the sampling frame.

\section{References}

1. Metsemakers JFM, Hōppener P, Knottnerus JA, Kocken RJ, Limonard ChBG. Computerized health information in the Netherlands: a registration network of family practices. $\mathrm{Br} J$ Gen Pract 1992;42:102-106.

2. Crombie DL. Inter-Practice Variability in Multipractice Studies. Scand J Prim Health Care 1983;2:51-53. 
3. Bartelds AIM, van der Zee J. The Dutch sentinel practices: origin, objectives and organization. In: The Dutch sentinel practice network; relevance for public health policy. Aad IM Bartelds, Jacques Fracheboud, Jouke van der Zee (eds); Utrecht: Netherlands Institute of Primary Health Care, 1989

4. Green LA, Reed FM, Miller RS, Iverson DC. Verification of Data Reported by Practices for a Study of Spontaneous Abortion. Fam Med 1988;20:189-191.

5. Jick H, Jick SS, Derby LE. Validation of information recorded on general practitioner based computerised data resource in the United Kingdom. Br Med J 1991;302:766-768.

6. Pringle $\mathrm{M}$, Hobbs R. Large computer databases in general practice: of little use unless high quality data are collected. Br Med J 1991;302:741-742.

7. Lamberts $\mathrm{H}$, Brouwer $\mathrm{H}$, Groen ASM, Huisman H. Het transitiemodel in de huisartspraktijk: praktisch gebruik van de ICPC tijdens 28.000 contacten. Huisarts Wet 1987;30: 105-113.

8. Pool JB, Hingsman L. Netherlands Institute of Primary Health Care. Statistical data on general practitioners and midwifes. Utrecht: Netherlands Institute of Primary Health Care, 1 january 1991

9. Lamberts H, Wood M (eds). ICPC. International Classification of Primary Care. Oxford: Oxford University Press, 1987.

10. Westerhof HP, Berden HIJM. De meerwaarde van het elektronisch medisch dossier. Tussenresultaten van het NUT II project. Huisarts Wet 1993;36(11):380-383

11. Sandlow LJ, Bashook PG. Problem oriented medical records: self instruction for practitioners. Chicago: Michael Reese Hospital and Medical Center, 1978

12. Metsemakers JFM, Plagge HWM, de Kanter J. De probleemlijst. Huisarts Wet 1988;31:379-581. 
Excerpt of medical notes Dummy

date : 170270

letter : pediatrician

Infectious hepatitis; Bilirubin and Transaminases (SGOT; SGPT) greatly elevated ; Furthermore slight lung problem ; hospital admission

date : $17 / 03 / 73$

Imipramin $10 \mathrm{mg}$ at night

date : $17 / 08 / 73$

letter : dermatologist

Uricaria due to cocci

date : $11 / 02 / 75$

Bronchitis, medication : Amoxicillin (ClamoxylR)

date : $12 / 03 / 75$

Abrasion ; toxoid $1 / 2 \mathrm{cc}$

date : $21 / 05 / 76$

Flu ; medication : Feneticillin (BroxilR)

date : $23 / 08 / 76$

Lynnph node enlargement neck ; 260876 Mantoux : negative

date : $13 / 09 / 76$

letter : pediatrician

Lymph node enlargement neck ; negative investigation; ; mother reassured

date : $11 / 10 / 76$

Imipramin $10 \mathrm{mg}$ at night

date : $19 / 01 / 77$

letter : radiotherapist

Nodular sclerosis Hodgkin's disease ; Grade 2, Irradiation of mediastine, neck and axillae. No lymph nodes palpable after therapy

date : $13 / 09 / 76$

letter : pediatrician

Hodgkin's disease

date : $25 / 03 / 77$

letter : surgeon

Extirpation of the spleen : lymph nodes positive 


\section{Appendix 2}

Unlikely problems according to the Registration Network Family Practices criteria, as reviewed by three experienced general practitioners

ICPC ICPC

code text

A02 chills

A03 fever

A10 bleeding, site nos

A13 concern about drug reaction

A14 infancile colic

A15 excessive crying infant

A16 irritable/fidgety infant

A20 euthanasia request/discussion

A71 measles

A72 chickenpox

A74 rubella

A76 other viral diseases with exanthems

A77 other viral diseases, nos

B04 sympt.blood/blood-forming organs

B70 acute lymphadenitis

D08 flatulence,gas pain, belching,windy

D09 nausea

D10 vomiting (excl.blood D14/pregnancy W06)

D18 change in feces/bowel movements

D22 worms/pinworms/other parasites

D24 abdominal mass nos

F02 red eye

F15 abnormal appearance of eyes

F17 sympt./complt.glasses

F75 contusion/abrasions/blackeye

H01 ear pain/earache

H78 superficial injury of ear

H79 other injuries

R01 pain: attributed to respirat.system

(excl.sinuspain R09)

R05 cough

R06 nose bleed/epistaxis

R71 whooping cough

R72 strep-throat/scarlet fever

R76 tonsillitis acute

R77 acule laryngitis/trancheitis/croup

R80 influenza (proven) without pneumonia

S01 pain, tenderness of skin

S03 warts

S04 localized swelling/papules/lump/

mass/skin/subcut.tissue

S05 generalized multiple swelling/

papules/lumps/skin/subcut.tissue

S06 localized redness/erythema/rash of skin

S07 generalized/multiple redness/

erythema/rash of skin

S08 other changes in skin color

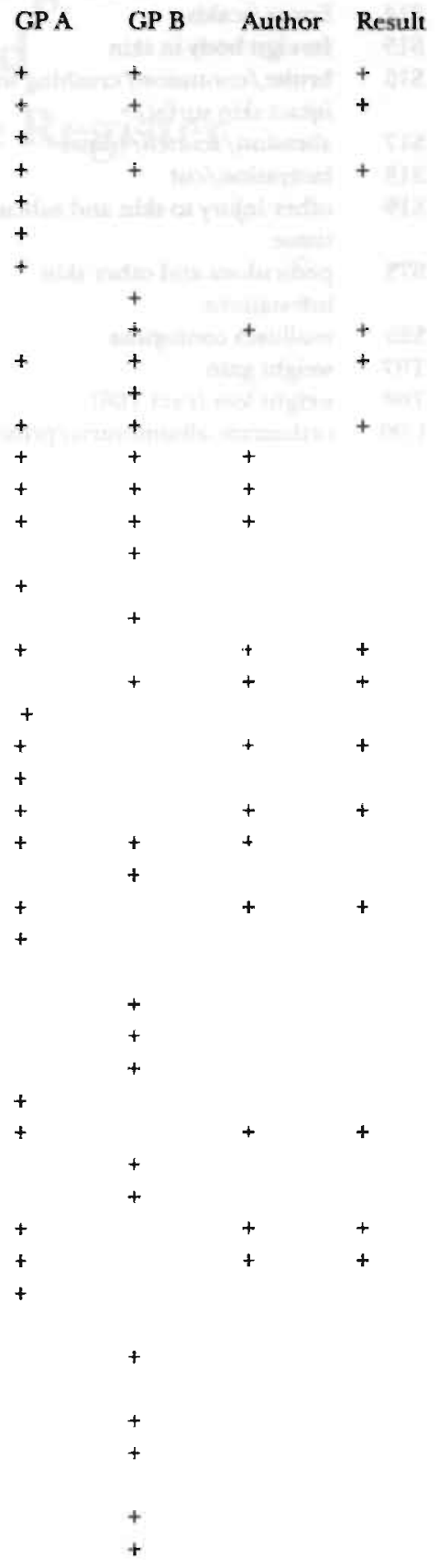


S10 boil/carbuncle/cellulitis localized

S11 other localized skin infection

S12 insect bite

S13 animal/human bite

S14 burns/scalds

S15 foreign body in skin

S16 bruise/contusion/crushing with intact skin surface abrasion/scratch/blister

S18 laceration/cut

S19 other injury to skin and subcutaneous tissue

S73 pediculosis and other skin infestations

\$95

T07 mollusca contagiosa

weight gain

T08 weight loss (excl.T06)

U90 orthostatic albuminuria/proteinuria

U98 abnormal urine test finding, nos

W01 question of pregnancy (excl. fear of being pregnant)

W03 antepartum bleeding

W05 vomiting/nausea of pregnancy

WI0 morning after pill, postcoital contraception

W15 complaints of infertility

W19 symptoms/complaints of lactation

W20 other symptoms/complaints of breast (during pregnancy)

W79 unwanted pregnancy: confirmed

W95 other disorders of breast in puerperium/disorders of lactation postponement (selected) of menstruation problems food and water

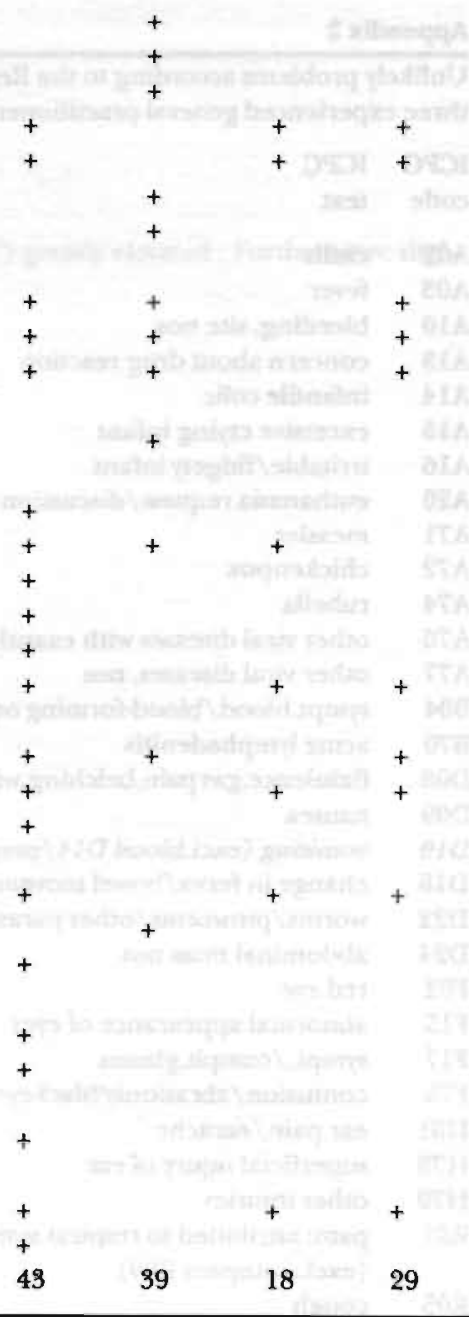


Chapter 6:

\section{A comparison between the Registration Network Family Practices and the Maastricht Epilepsy Case Register}




\section{Summary}

The Maastricht Epilepsy Case Register was set up to gather data on epileptic patients seen in the 6 hospitals of the southern Limburg region. General practitioners participating in the Registration Network Family Practices are to include epilepsy on the problem list and hence also in the database of the network. A comparison between these two registers was therefore expected to provide information on the completeness and reliability of each register.

The two databases were matched using a matching key consisting of date of birth, gender and four digits of the postal code. The general practitioners of the Registration Network received a questionaire for patients in the discordant groups and for a control group, asking for more detailed information on these patients.

The results show that 75 of the 116 epilepsy cases which should have been included in both registers, were indeed found in both. 38 patients under specialist treatment and receiving medication were found in the Registration Network but were missing from the MECR. Only 3 patients had been missed by the Registration Network Family Practices. Furthermore, it was found that at least 72 epileptic patients were being treated by general practitioners only.

The analysis shows that the matching process is difficult and may have led to incorrect matches, resulting in unjustified inclusion of patients in the discordant groups. The Registration Network Family Practices is more complete than the Maastricht Epilepsy Case Register. The guidelines for registering a problem in the Registration Network will have to be followed by general practitioners more precisely, since 23 patients had been included with a diagnosis of epilepsy, even though the GP had serious doubts about the diagnosis.

Collaboration between the registers could prove beneficial to both. 
Epilepsy is regarded as a serious disease with a permanent influence on the daily activities of most epileptic patients. International epidemiological studies estimate prevalence rates of 3 to 10 per 1000 in western populations. ${ }^{1,2}$ Figures from Dutch morbidity studies have indicated a prevalence of 5.0 per 1000 (Continuous Morbidity Registration Nijmegen) and 3.5 per 1000 (Dutch National Morbidity Survey). ${ }^{3,4}$ Both studies showed an increased prevalence in more advanced age groups. Epilepsy patients living in institutions for mentally handicapped persons are not included in these general practice based morbidity studies. Therefore, a prevalence of 6.6 per 1000 (or 96000 epileptic patients) can be considered a more complete estimate for the Dutch population. ${ }^{5}$

The care of epileptic patients is the joint responsibility of the general practitioner and the specialist, with the latter normally confirming the diagnosis and initiating treatment. However, Stokx found that general practitioners and specialists differed about the responsibility for follow up treatment, repeat prescriptions and coordination of care. ${ }^{6}$ Not all epileptic patients are regularly seen by specialists, especially if seizures have been absent for some years or their condition does not require medication. Therefore, studies based on special groups of epileptic patients such as mentally retarded patients or psychiatric patients may give a biased view. In order to gather data on all epileptic patients in the southern Limburg region, the Maastricht Epilepsy Case Register was established. ${ }^{7}$ Epilepsy is also to be included on the problem lists of patients of the Registration Network Family Practices. 8

It was studied whether epileptic patients of general practitioners participating in the Registration Network Family Practices would be included in both case registers or whether one case register would contain epileptic patients not known in the other. A comparison between these two registers was expected to provide information on the completeness and reliability of each register. Furthermore, it could indicate whether the Registration Network Family Practices could be a valid sampling frame for studies on epilepsy. In addition, the comparison might shed light on the "iceberg phenomenon" of epilepsy cases in primary care.

\section{General Background}

\subsection{The Maastricht Epilepsy Case Register}

In order to study epilepsy and related issues in a broader perspective the Maastricht Epilepsy Case Register was established in April 19837, in the southern I.imburg region, with a population of 600000 inhabitants served by 6 hospitals: Brunssum, Heerlen, Geleen, Kerkrade, Maastricht, and Sittard. The aim is to include data on all epileptic patients seen by neurologists, pediatricians, psychiatrists and neuro-surgeons in this region as well as doctors in institutions for mentally handicapped patients. All patients are asked for their consent before data are entered 
into the register. Some demographic data such as date of birth, gender, and socioeconomic data are registered, together with medical data on diagnosis, type of epilepsy and type of seizure, cause of epilepsy, medication, frequency of seizures and details of the electroencephalogram (EEG). All follow up contacts with patients included in the register are also added to the relational database, which is managed by the Medical and Social Information Center (MEMIC) of the University of Limburg. When completed, the Maastricht Epilepsy Case Register will provide insight into the prevalence and incidence of epilepsy in southern Limburg. Furthermore, it can serve as a sampling frame, allowing researchers to study specific aspects of epilepsy such as the relation between epilepsy and professional activities or between epilepsy and sports. 9,10

\subsection{The Registration Network Family Practices}

The Medical and Social Information Center (MEMIC) also manages the database of the Registration Network Family Practices. ${ }^{10}$ This network of general practices, most of them also located in the southern part of Limburg, was set up as a case register. Computerized health information systems have been installed, in all participating practices replacing the handwritten records. Data on patient encounters and other health information are stored in the computer. The general practitioners record all relevant health problems on a problem list, a health problem being defined as "anything that has required, does or may require health care management and has affected or could significantly affect a person's physical and emotional well-being". ${ }^{11,12}$ These health problems are to be recorded if they affect the (present) functional status of patients (and their future functioning). Together with some patient characteristics such as gender, date and place of birth, marital status, type of houschold, insurance status and level of education these health problems are transferred to the database of the Medical and Social Information Center (MEMIC).Updating of the database is achieved by entering data on newly enlisted patients, migration, death, and changes in problem status every 3 months. Evidently, epilepsy is a health problem relevant enough for general practitioners to be included on their problem lists.

\section{Patients and methods}

\subsection{Patients}

Data on the patients were derived from the two case registers:

\section{The Maastricht Epilepsy Case Register}

The registration of epileptic patients in the Maastricht Epilepsy Case Register started on 1 April, 1983. The region served by the register has approximately 600000 inhabitants. Based on a prevalence rate of around 6 per 1000 it would mean that a complete register should contain around 3500 cases. The register has grown stea- 
dily, including almost $30 \%$ of the expected number of cases in 1985 and $50 \%$ in 1988. On 1 December 1990 the Maastricht Epilepsy Case Register contained data on 2088 patients with epilepsy who had agreed to their data being entered into the register. Data on these patients were used in this study.

\section{The Registration Network Family Practices}

Registration within the Registration Network Family Practices started in May 1988. The patient lists of the general practitioners of the 15 participating practices (which can be seen as the general population registered in the practices) include approximately 80000 persons. Data on 35000 registered patients (43\%) had been included by the end of 1990 . The patient population of the Registration Network resembles the general population of the Netherlands with respect to age, sex, marital status, type of household, insurance status and level of education. Since two of the practices are located in the north of the province of Limburg, a region not covered by the Maastricht Epilepsy Case Register, the patients of these practices were excluded from the comparison. Hence, the database of the Registration Network Family Practices for this study contained, on 1 December 1990, data on 30583 patients, of whom 259 had been given the ICPC code N88="Epilepsy, all types". ${ }^{13}$ Registration of both active and inactive (a health problem from the past) cases resulted in the database of the Registration Network Family Practices showing a prevalence of epilepsy of 8.5 per 1000 .

\subsection{Methods}

The comparison between the two case registers was made in several stages.

\subsubsection{Stage 1: Matching the databases}

Linking disease registers for follow up studies has become increasingly important and methods for record linkage have been proposed and studied. The use of combinations of identifiers for the linkage of the Dutch Cancer Registry with other data bases has been described by van der Brandt et al. ${ }^{14}$ An optimal linkage can be made by using: date of birth, gender and the first four letters of the family name. ${ }^{14}$ The family name, however, is not present in the anonymous databases of the Maastricht Epilepsy Case Register and the Registration Network Family Practices. We therefore used a matching key consisting of date of birth, gender and four digits of the postal code, which had also proved to be powerful, even though the postal code may change over time. ${ }^{14,15}$ This key had already been used in a comparison between the regional cancer register (IKL) and the Registration Network Family Practices. ${ }^{16}$ The postal code is updated every 3 months in the database of the Registration Network Family Practices, but in the Maastricht Epilepsy Case Register it depends on the frequency of follow up contacts.

General descriptive data for the databases to be matched were: 
- 1 December 1990

- $\quad 2088$ cases

Registration Network Family Practices:

- 1 December 1990

- $\quad 30583$ patients in 13 general practices (excluding two practices in the North of Limburg )

- $\quad 259$ patients with epilepsy

Matching was done in May 1991, using the databases as they were on 1 December 1990.

\subsubsection{Stage 2: Classification in groups and verification of the data}

Four groups were made by matching the two databases (Table 1). The matching cases of the two databases constituted group A. The cases of the registers without a match were included groups $B$ and $C$. To ensure a blinded review by the general practitioners of cases from groups $\mathrm{B}$ and $\mathrm{C}$, a number of patients not registered as epilepsy patients in either database were added (group D). For practical purposes, group D was composed from the discordant groups found in a comparison between the databases of the Cancer Registry and the Registration Network Family Practices, so that the GP could review this group for both studies at the same time. ${ }^{16}$ General practitioners were provided with labels showing data by which the patients could be identified in the general practices (patient number; date of birth; gender; postal code). They were asked to retrieve the patients of groups B,

Table 1. Groups formed by matching the databases of the Maastricht Epilepsy Case Register and the Registration Network Family Practices.

Maastricht Epilepsy Case Register

$\begin{aligned} & \text { Registration Network } \\ & \text { Family Practices }\end{aligned}$
+ :
known with epilepsy in the Registration Network or included in the Maastricht Epilepsy
Case Register
unknown with epilepsy in the Registration Network or not included in the Maastrict
Epilepsy Case Register


C and D from their general practice health information system, verify the identifying data and answer the question whether the patient had ever been diagnosed with epilepsy, was certainly not known with epilepsy or was a doubtful case of epilepsy. Further questions where asked about diagnosis, treatment, medication and the label of the disease on the problem list. (Appendix 1) These questionnaires were mailed in June 1991.

\subsubsection{Stage 3: Arranging the results and analysis}

Returned questionnaires were checked for unclarities and entered into a database for further analysis. During the process two general practitioners reviewed a subset of their questionnaires again as part of a follow up control programme.

\section{Results}

\subsection{Group classification and verification of the data}

The results of the matching procedure can be arranged in the four groups described above. Figure 1 shows these groups and the further process.

Figure 1. Results of matching the Masstricht Epilepsy Case Register with the Registration Network Family Practices: the different subgroups and the further process.

$\begin{array}{ll}\begin{array}{l}\text { Registration Network } \\ \text { Family Practices }\end{array} & \begin{array}{l}\text { Maastricht Epilepsy } \\ \text { Case Register }\end{array} \\ \begin{array}{l}\text { Database } \\ \text { 1 December } 1990\end{array} & \text { Database } \\ \text { P:30 } 483 \quad \text { E }: 259 & 1 \text { December } 1990 \\ \end{array}$

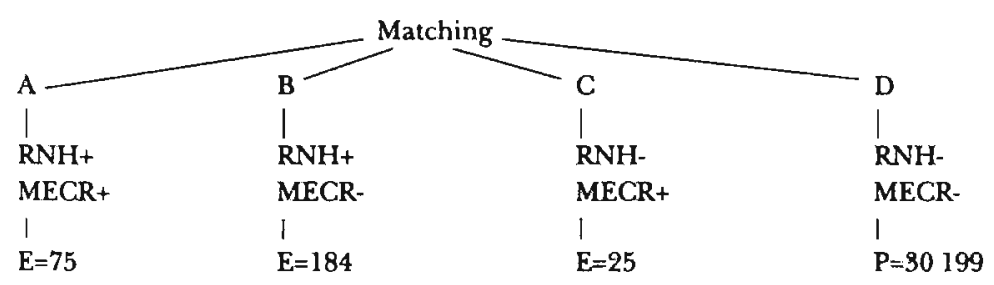

Verification in the practices of the Registration Network

Family Practices by 444 questionnaires

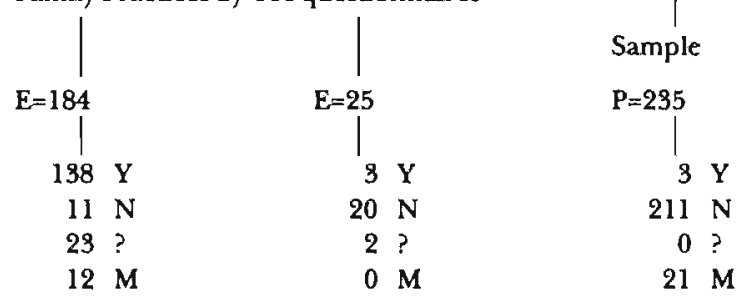

Legenda: $P=$ number of patients; $E=$ number of patients with epilepsy; $Y=$ Yes epilepsy $N=N o$ epilepsy ; ? doubtul case; $\mathbf{M}=$ Missing 
Group A is a group of patients included in both registers as having epilepsy. Matching for date of birth, gender and 4 digits of the postal code resulted in 59 matches. Another 16 matches were found with date of birth, gender and epilepsy as identifiers. These were included in group A, making this a concordant group of 75 patients with epilepsy, which will not be discussed in more detail.

Groups B (184) and C (25) are discordant groups, with patients labelled as epileptic in only one of the two registers.

Group D contains the non-matching patients, meaning all patients of the Registration Network Family Practices not known with epilepsy in either register. For blinding purposes, a sample of 235 patients of "control" group D was added in the verification process to those of groups $B$ and $C$, resulting in a number of 444 patients about whom further information was gathered.

\subsection{Processing the results and analysis}

\subsubsection{General results}

The 444 questionnaires were sent to the 13 general practices of the Registration Network Family Practices located in the south of Limburg. The response rate was $100 \%$. Thirty three questionnaires could not be used in the analysis because the patient could not or no longer be retrieved from the general practice health information system. In some cases the general practitioner indicated the reason: died (1x), moved $(2 x)$ or a computer test patient $(1 \mathbf{x})$. We presume that such reasons apply also to the other 29 patients.

\subsubsection{Results of group B}

Group B consisted of 184 patients known with epilepsy in the Registration Network Family Practices but not included in the Maastricht Epilepsy Case Register. Figure 1 shows that after review by the general practitioners 138 patients were still labelled as epileptic, 11 cases were regarded as not having epilepsy, while 23 cases were doubtful according to the general practitioners. In group B 12 patients could not be retrieved.

\subsubsection{Patients of group B with epilepsy after verification}

Figure 2 shows how many patients were being treated by a specialist and how many were on antiepileptic drugs. 56 patients $(41 \%)$ were under specialist care, while 72 patients (52\%) were being treated by the general practitioner. For 10 patients $(7 \%)$ the general practitioners had failed to indicate which doctor was responsible for treatment. 64 patients were using medication, predominantly in the group seen by the specialist: 47 patients $(34 \%)$, versus $17(12 \%)$ who were treated by the general practitioner. The 47 cases seen regularly by the specialist and receiving medication prescribed by the specialist were reviewed to determine whether they should have been included in the Maastricht Epilepsy Case Register (Table 2). The hospital actually providing care was taken as the measure for inclusion. 
Two cases could not be assessed: in 1 case two hospitals were involved, while in the other case it was not known which hospital was providing care. In 8 cases (17\%) specialist care was provided by specialists not reporting to the Maas-tricht Epilepsy Case Register. Thirty-seven (79\%) of the cases of group B were assessed as missing from the Epilepsy Case Register. For the 7 cases under specialist treatment according to the general practitioners' questionnaire but not receiving medication, as well as the 2 cases where the use of medication was unknown, it is difficult to determine whether they should have been included in the Maastricht Epilepsy Case Register. Of these 9 , those cases (7) for which the hospital providing treatment is reporting to the register, were assessed as doubtful.

Figure 2. Patients from group B labelled as epileptic after verification by the general practitioners: different subgroups according to treatment

Patients of group B labelled epileptic after verification by the general practitioners

At present treatment by specialist?

At present medication?
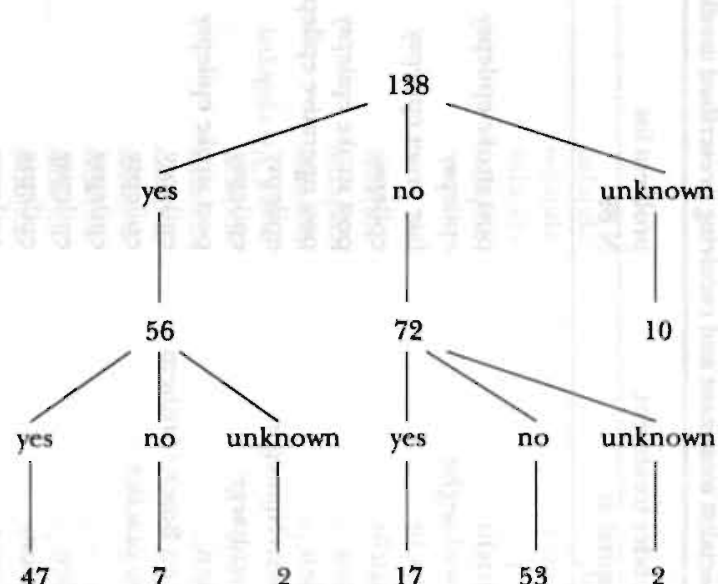

47

7

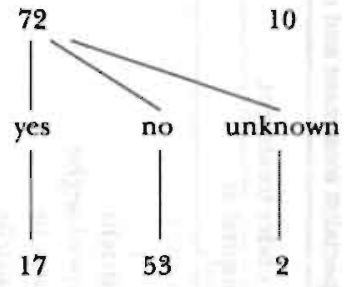

\subsubsection{Patients of group B not having epilepsy after verification}

In 11 cases the general practitioners could identify the patient as belonging to their practice, but could not confirm the diagnosis of epilepsy, although these: cases came from the register of the Registration Network Family Practice itself.

\subsubsection{Patients of group $B$ in which the diagnosis of epilepsy was regarded as doubtful after verification}

In $23(13 \%)$ of the original 184 epileptic cases the general practitioners had second thoughts about the diagnosis of epilepsy, even though they themselves had labelled the problem as such on the problem list. Eight of these patients had never received any anti-epileptic medication. Changes in the electroencephalogram (EEG) suggestive of epilepsy had been labelled as epilepsy in 7 cases, while patients with one seizure had received anti-epileptic medication in several cases 
Table 2.

Overview of 47 cases (from group B) under specialist treatment and receiving prescribed medication

epilepsy diagnosed

diagnosis

date of

now under treatment

problem list

real miss

in hospital at

in

birth

in hospital at

N 88

CRE

a) medication prescribed by the specialist

\begin{tabular}{|c|c|c|c|c|}
\hline Maastricht & 1989 & $20 / 01 / 27$ & Maastricht & post stroke epilepsy \\
\hline Maastricht & 1967 & $03 / 06 / 28$ & Kempenhaeghe & epilepsy \\
\hline Maastricht & 1983 & $16 / 12 / 11$ & Maastricht & late onset epilepsy \\
\hline Maastricht & 1985 & $20 / 10 / 55$ & Maastricht & epilepsy \\
\hline Heerlen & 1988 & $23 / 07 / 33$ & Hecrlen & post stroke epilepsy \\
\hline Heerlen & 1984 & $24 / 04 / 50$ & Heerlen & post operative epilepsy \\
\hline Heerlen & 1987 & $29 / 01 / 84$ & Heerlen+Nijmegen & epilepsy \\
\hline Heerlen & 1986 & $27 / 04 / 59$ & Kempenhaege & epilepsy \\
\hline Heerlen & 1987 & $01 / 07 / 30$ & Heerlen & post stroke epilepsy \\
\hline Heerlen & 1952 & $29 / 01 / 44$ & Meer en Bosch/Arnhem & epilepsy \\
\hline Heerlen & 1957 & $10 / 05 / 13$ & Private practice & epilepsy \\
\hline Heerlen & 1977 & $31 / 01 / 76$ & $?$ & epilepsy \\
\hline Heerlen & 1990 & $07 / 01 / 21$ & Heerlen & epilepsy \\
\hline Brunssum & $?$ & $03 / 12 / 57$ & Brunssum & epilepsy \\
\hline Brunssum & 1988 & $12 / 06 / 83$ & Brunssum & epilepsy \\
\hline Kerkrade & 1988 & $17 / 05 / 60$ & Heerlen & epilepsy \\
\hline Kerkrade & 1984 & $13 / 09 / 54$ & Kerkrade & epilepsy \\
\hline Sittard & 1970 & $25 / 10 / 65$ & Sittard & epilepsy \\
\hline Sittard & 1984 & $25 / 10 / 78$ & Sittard & epilepsy \\
\hline Sittard & 1967 & $12 / 04 / 67$ & Brunssum & epilepsy \\
\hline Sittard & 1985 & $29 / 11 / 52$ & Sittard & epilepsy \\
\hline Geleen & 1975 & $25 / 01 / 73$ & Geleen & epilepsy \\
\hline Nijmegen & 1976 & $29 / 06 / 72$ & Kempenhaeghe & epilepsy \\
\hline Heemstede & 1969 & $24 / 05 / 42$ & Kempenhaeghe & epilepsy \\
\hline Kempenhaeghe & 1989 & $20 / 02 / 74$ & Kempenhaeghe & epilepsy \\
\hline
\end{tabular}




$\begin{array}{lll}\text { Dublin } & 1987 & 15 / 08 / 87 \\ \text { Den Haag } & 1963 & 27 / 06 / 50 \\ \text { Unknown } & 1972 & 02 / 04 / 47 \\ \text { Unknown } & 1980 & 21 / 07 / 53 \\ \text { Unknown } & 1970 & 20 / 10 / 49 \\ \text { Unknown } & ? & 06 / 07 / 31 \\ \text { Unknown } & 1990 & 29 / 07 / 23\end{array}$

Heerlen

Heerlen

congenital epilepsy

nocturnal epilepsy

Sittard

Kerkrade

post traumatic epilepsy

epilepsy

Heerlen

Kerkrade

epilepsy

epilepsy

Heerlen

epilepsy

b) medication prescribed by the general practitioner

$\begin{array}{lll}\text { Maastricht } & 1970 & 19 / 10 / 37 \\ \text { Maastricht } & 1979 & 11 / 03 / 50 \\ \text { Maastricht } & 1968 & 22 / 12 / 30 \\ \text { Heerlen } & 1976 & 01 / 12 / 50 \\ \text { Heerlen } & 1963 & 24 / 04 / 49 \\ \text { Kerkrade } & 1988 & 10 / 08 / 66 \\ \text { Kerkrade } & 1989 & 29 / 12 / 87 \\ \text { Sittard } & 1979 & 25 / 05 / 15 \\ \text { Unknown } & 1986 & 10 / 01 / 73 \\ \text { Unknown } & 1950 & 21 / 12 / 28 \\ \text { Unknown } & 1960 & 09 / 01 / 58\end{array}$

Maastricht

Maastricht

Maastricht

Kempenhaeghe

Heerlen

Kerkrade

Kerkrade

Sittard

Maastricht

Maastricht

Brunssum

c) medication prescribed by both

$\begin{array}{llll}\text { Heerlen } & 1967 & 13 / 04 / 36 & \text { Heerlen } \\ \text { Heerlen } & 1984 & 15 / 05 / 46 & \text { Sittard } \\ \text { Brunssum } & 1989 & 17 / 10 / 70 & \text { Brunssum } \\ \text { Geleen } & 1979 & 17 / 11 / 77 & \text { Sittard }\end{array}$

epilepsy

epilepsy

epilepsy

epilepsy

epilepsy

epilepsy

epilepsy

post CVA epilepsy

epilepsy

epilepsy

epilepsy 


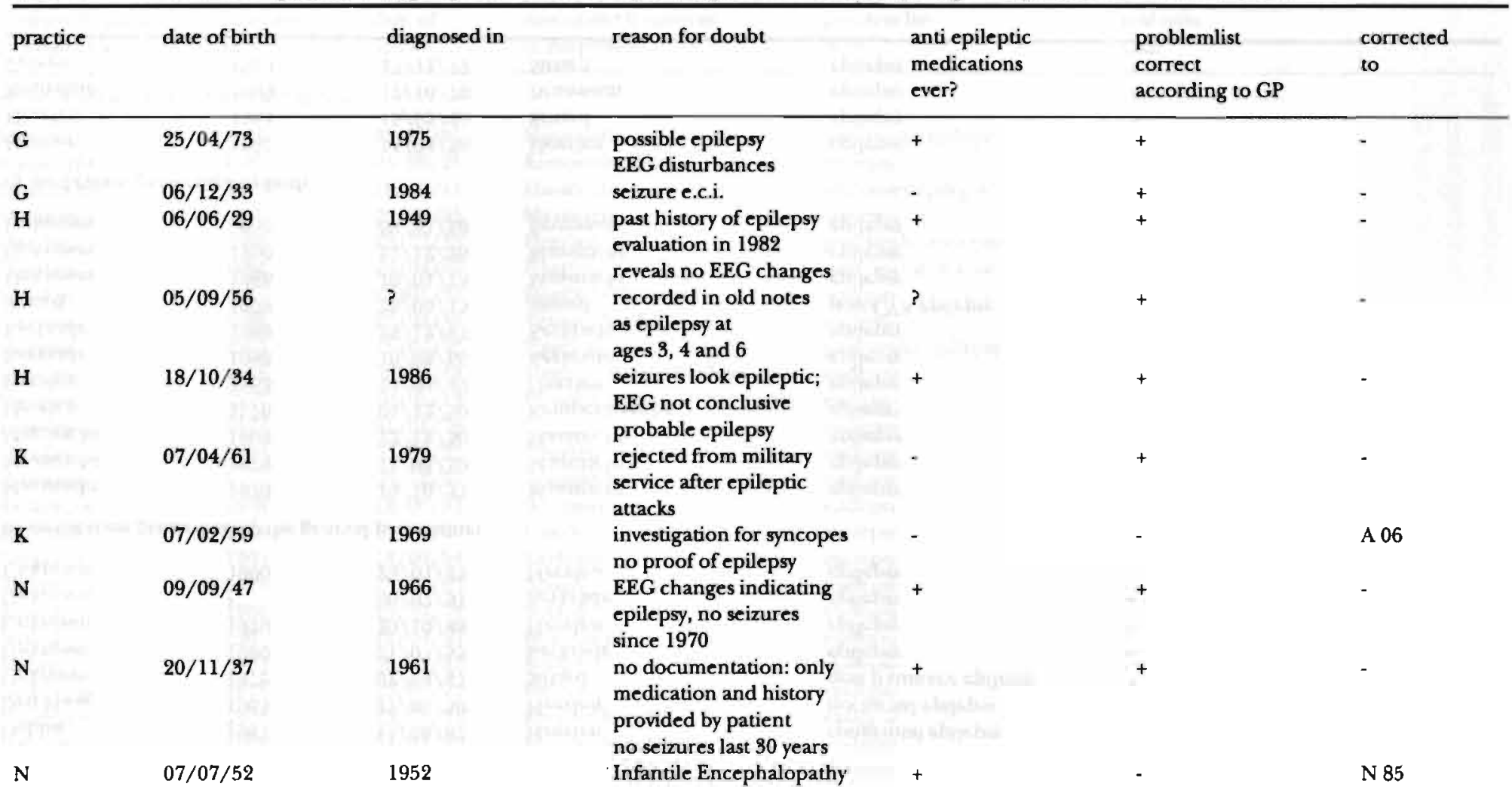


post traumatic epilepsy

$12 / 11 / 66$

\section{EEG charges}

Epileptic predispostion unreliable neurologist no documentation; only record notation from predecessor

one seizure

suspected epilepsy

one seizure

suspected epilepsy according to EEG

possible epilepsy

in past history

epilepsy recorded

in past history

unproven epileptic

seizure

epileptic seizure;

mental retardation

no proven epilepsy

$\begin{array}{ccc}\mathrm{X} & 18 / 01 / 59 & 1978 \\ \mathrm{X} & 22 / 07 / 54 & 1992 \\ \mathrm{X} & 01 / 10 / 81 & 1982\end{array}$

EEG changes suggestive

of epilepsy

EEG changes suggestive

of epilepsy

EEG minor non specific changes after seizure 
where the definitive proof of epilepsy seemed to be lacking. In 2 cases the general practitioners actually changed the initial label of epilepsy. In all other cases they still labelled the patient as epileptic, even though they had doubt about these cases. Table 3 gives an overview of these patients, indicating that this phenomenon is not restricted to one practice but occured in 8 of the 13 general practices participating in this study.

\subsubsection{Results of group C}

This group consisted of 25 patients who had been included in both registers but had not been labelled as having epilepsy in the Registration Network Family Practices. After review, the general practitioners concluded that they had no recording of epilepsy or other evidence of epilepsy in 20 patients $(80 \%)$. Three patients were recognised as being epileptic. In one of these the general practitioner presumed that the patient was being seen regularly by a specialist. The patient was not receiving any medication and the general practitioner had not labelled epilepsy as a problem on the problem list. An incorrect ICPC code had been used in a second case, where the patient was no longer being seen by the specialist but was receiving anti-epileptic medication prescribed by his general practitioner. In the third case the general practitioner reported that he had identified 2 patients with the same date of birth, gender and postal code in his practice computer, one of them with epilepsy stated on the problem list. In 2 cases included in the Maastricht Epilepsy Case Register the general practitioners expressed doubts on the diagnosis: one had been labelled as suffering from Korsakow's syndrome, while in the second case the general practitioner did not feel that the diagnosis had been satisfactorily confirmed and therefore had not recorded it as such on the problem list.

\subsubsection{Results of group D}

In 21 cases the patient could no longer be found in the practice computer. The majority of cases in this group (211) were reviewed as not having epilepsy. Three cases $(0.8 \%)$ were identified with epilepsy. One of these had been diagnosed in 1981 and the patient was still under specialist care. The diagnosis had not been indicated on the problem list. In a second case the diagnosis had been established in 1982 but the patient was no longer under specialist care. The third case was a patient who had recently died of a Grawitz tumor, with brain metastases and symptomatic seizures. This diagnosis had been made in 1991 , i.e after the inclusion date for the comparison ( 1 December 1990). 


\subsection{The study process}

The comparison between the Maastricht Epilepsy Case Register and the Registration Network Family Practices was made possible by the automatisation of the easily accessible databases. Matching these databases with a key consisting of date of birth, gender and 4 digits of the postal code was considered to be powerful. ${ }^{14}$ Some of the results, however, indicate that this key is not perfect. One general practitioner found 2 patients with the same date of birth, gender and 4 digits of the postal code in his practice. One of them had epilepsy, so the matching will have resulted in a RNH+/MECR+ and a RNH-/MECR+ match. Furthermore, it was found out that the total database of the Registration Network Family Practices provided several examples of patients with the same date of birth, gender, and 4 digits of the postal code. This means that a patient with epilepsy according to the Maastricht Epilepsy Case Register could match with several different patients of the Registration Network Family Practices, only one of them having epilepsy. The other matches will provide RNH-/MECR+ results, while the verification process will show no evidence of epilepsy in the GP's medical records.

The response to the questionnaire was $100 \%$ and the answers proved to be very useful in analysing the cases in the groups.

\subsection{The control group D}

Of the 3 cases of epilepsy identified in this group none had been included in the Maastricht Epilepsy Case Register on 1 December 1990, which is correct for 2 of them: one case had been diagnosed before 1983 and not under specialist care anymore, the second case was diagnosed after 1 December 1990. The third case, although diagnosed in 1981, was under specialist treatment in a reporting hospital and should have been included in the database of the Maastricht Epilepsy (ase Register. This case and the first one fulfilled the criteria of a problem and should have been recorded on the problem list of the Registration Network Family Practices as epilepsy, by 1 December 1990.

\subsection{Epilepsy: yes, no, or doubtful}

The diagnosis of epilepsy is recorded in the Maastricht Epilepsy Case Register on the authority of the specialist reporting on a patient. No formal criteria such as EEG results are required. In the Registration Network Family Practices general practitioners have to rely on the information provided by specialists. In addition, the network registers retrospectively, while old records often only mention the term epileptic/epilepsy. Therefore, it is not always possible to verify the diagnosis using uniform diagnostic criteria. Furthermore, as can be concluded on the basis of the doubtul cases in group B, many general practitoners use the label epilepsy even though they themselves doubt the diagnosis. Nevertheless, the label is put on the problem list which may result in a $\mathrm{RNH}+$ / MECR- conclusion. In summary, in 
the absence of a 'gold stand-ard' diagnosis it is impossible to define the correct: number of epilepsy cases which should have been included in both databases. Nevertheless, certain conclusions can be drawn on the basis of the analyses of the groups B and C.

\subsection{Comparison between the discordant groups}

The Registration Network Family Practices contains at least 37 (79\%) of the 47 cases of epilepsy where the patient is under treatment by a specialist reporting to the Maastricht Epilepsy Case Register and assessed as missing from the Maastricht Epilepsy Case Register. In another 7 cases it was thought that inclusion in the Maastricht Epilepsy Case Register would have been justified. 20 patients in group C, recorded with epilepsy in the Maastricht Epilepsy Case Register, were not found to have epilepsy. These cases cannot be regarded as missed diagnoses, since two general practitioners reviewed their negative responses once again, without new results. The 5 identified cases proved to include one clear miss, in which the diagnosis had been made but not recorded on the problem list; one was a wrong ICPC code; one a matching problem and two were known with neurological problems but had not been labelled as epilepsy.

\section{Evaluation and conclusions}

This study was undertaken to evaluate the completeness and reliability of two registrations by linking their patient records. Goldberg et al described this method as probably the best for measuring completeness. ${ }^{15}$ Record linkage used date of birth, gender and the four digits of the postal code, which has proved to yield a sensitivity of $98.4 \%$ and a positive predictive value of $91.1 \% .{ }^{14}$

\subsection{Matching}

Mailing the questionnaires in June 1991 while using data from December 1990 may have caused a decrease in the power of the linking key, since the postal code may have changed due to migration of patients. This could also, at least partly, account for the 33 patients which could not or no longer be retrieved from the general practitioners' computers. Furthermore, one general practitioner reported that he had identified 2 patients with the same date of birth, gender and four digits of the postal code, resulting in two matches (one for group A ( $\mathrm{RNH}+/ \mathrm{MECR}+)$ and one for group C (RNH-/MECR+). It is not clear whether this phenomenon accounts for the 20 patients from group $C$ in whom the general practitioner could not find evidence of epilepsy. Matching with the described key, followed by verification of the first four letters of the family name before inclusion in the study population, can increase the sensitivity and specificity. Privacy aspects could be dealt with by performing the verification process in the general practitioner's office. 


\subsection{Completeness}

The results show that 75 of the 116 epilepsy cases (65\%) which should have been included in both registers were indeed found in both (Table 4). The Registration Network Family Practices lacked $3(2,6 \%)$, of the certified epilepsy cases which should have been included in both databases, while the Maastricht Epilepsy Case Register lacked 38 cases $(32,7 \%)$ (Table 4$)$. It must, however, be remembered that the Maastricht Epilepsy Case Register asks patients for their consent before entering data into the register. This could explain a number of missing cases, although there is no indication that many patients have refused participation to the MECR. Furthermore, not all pediatricians of the southern Limburg region refer data to the register, causing an underrepresentation of children.

72 patients with epilepsy were only being seen by their general practitioner and were not included in the Maastricht Epilepsy Case Register, as was the case with patients treated in hospitals outside the region of the register. The Registration Network Family Practices contains $213(75+138)$ certified cases, while the Maastricht Epilepsy Case Register includes $77(75+2)$ certified cases in the same region. This difference is partly due to patients diagnosed with epilepsy before the start of the Maastricht Epilepsy Case Register or again to lack of patient consent. The Maastricht Epilepsy Case Register covers a selected population: only referred patients, who have given their consent to be included in the register and whose disease is severe enough to require consultation with a specialist. Patients who have been without seizures for several years, with or without medication, often cease to consult a specialist. As a result, they are no longer registered in the MECR, while still will being included in the Registration Network Family Practices. Studies on the basis of the Maasticht Epilepsy Case Register make use of an incomplete dataset, which could result in conclusions not valid for all epilepsy patients. The Registration Network Family Practices could very well serve as a sampling frame for studies on epilepsy.

Table 4.

Epilepsy cases which should have been included in both databases.

\begin{tabular}{llrl}
\hline Group A & RNH+/MECR+ & 75 & \\
Group B & RNH+/MECR- & 37 & all missed by MECR \\
Group C & RNH-/MECR+ & 2 & 1 missed by the RNH \\
& & & $\begin{array}{l}1 \text { incorrect coded by the RNH } \\
(1 \text { incorrect math) }\end{array}$ \\
Group D & RNH-/MECR- & 2 & $\begin{array}{l}1 \text { missed by both RNH and MECR. } \\
1 \text { missed by RNH }\end{array}$
\end{tabular}

116

Missed by MECR:

Missed by RNH:

$38(32.7 \%)$

$3(2,6 \%)$ 


\subsection{Reliability}

Cases selected from the Registration Network Family Practices should, however, be checked again in the general practice health information system by the researcher, using diagnostic criteria to ascertain the correct diagnosis, since this study has also shown that 23 patients had been labelled was epileptic on their problem list, even though the general practitioner had serious doubts about the diagnosis. The registration guidelines from the Registration Network Family Practices state that the diagnostic criteria of the International Classification of Health Problems in Primary Care ( ICHPPC) should be used when available. ${ }^{10,17}$ For many patients, however, detailed information on diagnoses and health problems defined in the past is not available, and the criteria cannot be applied. This will not only be the case with epilepsy but also with other diagnoses and health problems present in database of the Registration Network Family Practices. The ongoing quality assurance programme of this register already has general practitioners checking their registered problems systematically. On the basis of this study, diagnoses which seem certain at first sight will have to be included in the quality assurance programme.

\subsection{Future actions}

The Maastricht Epilepsy Case Register will have to investigate the reasons why 38 epilepsy patients have failed to be included in the register. Furthermore, the issue of epileptic patients seen only by general practitioners will have to be studied. If the Maastricht Epilepsy Case Register wishes to strive for completeness, these patients should be included, meaning that general practitioners would have to report to the register as well. That would, however, cause enormous logistic problems for the Maastricht Epilepsy Case Register. Collaboration between the registers could prove benificial to both. This study also shows that it is possible to validate a database by comparing it with another database, which includes at least part of the same data. Such a comparison can yield much information on the completeness and the reliability of each database. Careful planning of the matching procedure and detailed evaluation of the results can lead to the detection of weak points in the structure of the registration and/or the database.

\section{References}

1. Rutgers MJ. De epidemiologie van de epilepsiēn. Epilepsie Bulletin 1988;18:3-14

2. Sander JWAS, Shorvon SD. Incidence and prevalence studies in epilepsy and their methodological problems: a review. J Neurol Neurosurg Psychiatry 1987;50:829-839

3. Lisdonk EH van (ed). Ziekten in de huisartspraktijk. Utrecht: Wetenschappelijke Uitgeverij Bunge, 1990

4. Velden J van der, Bakker DH de, Claessense AAMC, Schellevis FG. Een nationale studie naar ziekten en verrichtingen in de huisartspraktijk. Basisrapport: Morbiditeit in de huisartspraktijk. Utrecht: Netherlands Institute for Primary Health Care , 1991 
5. Becker HA. Klashorst JP van de, Schaik-Colijn HG van, Hermkens PLJ. Epilepsiezorg in Nederland 1970/2010. 1ste ed. Heemsbeck: De Christelijke Vereniging voor de verpleging van Lijders aan Epilepsie, 1987:210

6. Stokx LJ, Kersten TJJM. Aandeel van huisarts en specialist in de zorg voor de parient met epilepsie. Ned Tijdschr Geneeskd 1990;134:nr 40:1943-1946

7. Heuts-van Raak EPM, Boellaard A, De Rrom MCTFM, Lodder J. Supratentorial brain infarcts and adult-onset seizures; The Maastricht Epilepsy Case Registry. Seizure 1999;2: 221-227

8. Metsemakers JFM, Höppener P, Knottnerus JA, Kocken RJJ, Limonard CBG. Computerized health information in the Netherlands: a registration network of family practices. $\mathrm{Br} \mathrm{J}$ Gen Pract 1992;42:102-106

9. Golde A van, Lassouw G. Onderzoek epilepsie en arbeid. Epilepsie Bulletin $18 \mathrm{nr} 2$ december 1989:9-11

10. Hupperts R, Habets J. Epilepsie en Sport. Epilepsie Bul-letin $18 \mathrm{nr} 2$ december 1989:14-16

11. Metsemakers J, Plagge H, Kanter J de. De Probleemlijst, suggesties voor de huisarts. Huisarts Wet 1988;31:379-381

12. Sandlow LJ, Bashook PG. Problem oriented medical records: self instruction for practitioners. Chicago: Michael Reese Hospital and Medical Center, 1978

13. Lamberts $H$, Wood $M$ (eds). ICPC International Classification of Primary Care. Oxford: Oxford University Press, 1987

14. Van den Brandt PA, Schouten LJ, Goldbohm RA, Doran E and Hunen PMH. Development of a record linkage protocol for use by the Dutch cancer registry for epideminlogical research. Int J Epidemiol 1990;19: 553-558

15. Goldberg J, Gelfand HM, Levy PS. Registry evaluation methods: a review and a case study. Epidemiol Rev 1980; 2: 210-220

16. Schouten LJ, Höppener P, van den Brandt PA, Knottnerus JA and Jager II. Completeness of cancer registration in Limburg, the Netherlands. International Journal of Epidemiology 1993;22:369-376

17. Classification Committee of WONCA. ICHPPC-2 defined. International classification of health problems in primary care. Oxford: Oxford University Press, 1983 
Questionnaire

Registration Network Family Practices

Cancer Registry Limburg

Maastricht Epilepsy Case Register

patient number

date of birth

postal code (4 digits)

gender

MEMIC regnumber

practice code

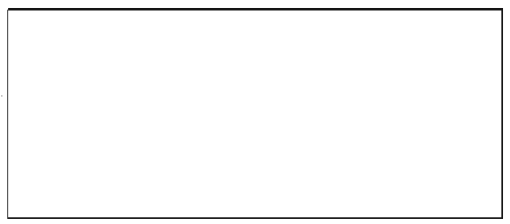

1. Please verify date of birth, gender and postal code

Correct any mistakes:

patientnumber

date of birth

postal code (4 digits)

gender

2. Has this patient ever been diagnosed with cancer?

$\square$ yes

$\square$ no

3. Has this patient ever been diagnosed with epilepsy?
$\square$ yes
$\square$ certainly not
$\square$ doubuful

If you have answered no to questions 2 and 3 , you have completed the questionnaire.

If you have answered question 2 and/or 3 otherwise, proceed to parts $A$ and/or $B$.

Part A Cancer (if you have answered yes to question 2)

- not reproduced - 1

Part B

Epilepsy (if you have answered yes or doubtful to question 3)

Question 3 - yes

- doubtful

part B1

part B2 (overleaf)

B1

If this patient has been diagnosed with epilepsy

In which year

In which hospital

$\begin{array}{ll}\text { Maastricht } & \text { Kerkrade } \\ \text { Heerlen } & \text { Sittard } \\ \text { Brunssum } & \text { Geleen } \\ \text { other ........ } & \end{array}$


Which specialist made the diagnosis: (name)

Is this patient being regularly seen by a specialist ?

$\begin{array}{llll}\square \text { yes } & \text { in which hospital } & \text { Maastricht } & \text { Kerkrade } \\ & \text { Heerlen } & \text { Sittard } \\ \text { Brunssum } & \text { Geleen } \\ \text { Other ................... } & \end{array}$

$\square$ no

Does the patient use any medication for his epilepsy?

$\square$ yes who usually prescribes these

Ospecialist

$\square$ no

Gen. practitioner

Had epilepsy been stated as a health problem on the problem list in the MicroHIS health information system on 1 December 1990 ?

$\square$ no

$\square$ yes on the problem list as

ICPC code

Describe the reason for your doubt as briefly as possible

Has the patient consulted a specialist for this condition?

$\square$ unknown

a no

$\square$ yes

$$
\begin{aligned}
& \text { which year } \\
& \text { which hospital }
\end{aligned}
$$

\section{Maastricht}

which specialist
Heerlen

Brunssum

other

\section{Kerkrade}

Sittard

Geleen (name)

Has the patient ever used medication over a longer period which can be considered as anti-epileptic medication?

no

ayes

which medication (s)

from ......... to ........... (years)
indication

Had this indication been recorded on the problem list on $1 / 12 / 1990$ ?

no

ayes

on the problem list as

ICPC code

${ }^{1}$ Part A, which was used in the comparison between the Cancer Registry and the Registration Network, has not been reproduced here. 
Chapter 7:

\section{Do we teach what we preach?} Comparing the content of a problem-based medical curriculum with primary health care data

Published as:

Metsemakers JFM, Bouhuijs PAJ and Snellen-Balendong HAM.

Do we teach what we preach? Comparing the content of a problem-based medical curriculum with primary health care data.

Family Practice 1991;8:195-201 


\section{Summary}

The content of a problem-based medical curriculum has been analysed with reference to educational and medical characteristics. The data have been compared with primary health care data obtained from the Registration Network Family Practices, a computerized health information system in the southern part of the Netherlands. The analysis reveals differences between curriculum and health care data on several aspects such as reasons for encounter/complaints, problems/diagnoses, chronic diseases, health problems of children and referrals to specialists. Although the analysed material reflects only part of the curriculum, it can be concluded that the primary care orientation of the curriculum is meagre and that a critical review of the patient cases used in the problem-based curriculum is needed. 
Medical education is the entry to one of the central health care professions in society. The undergraduate curriculum leads students in a certain direction, which influences their future professional performance. Tomorrow's doctor is in training now and the question is whether his medical training will provide sufficient opportunities for him to prepare for his future task. Vuori presented a number of shifts in focus, content, organization, and responsibility in the future development of primary health care which could affect medical education. ${ }^{1}$ Current medical curricula generally do not sufficiently reflect the knowledge, skills, and attitudes required for physicians who will work in the 21 st century: curricula are usually overloaded and often tertiary care oriented. ${ }^{2,3}$ Students in these programmes may not see a representative sample of health problems and illnesses, and face difficulties in acquiring a broad perspective on health and health care. Over the past twenty years a growing number of medical schools have responded to these criticisms and challenges by implementing curricula which emphasize primary care and community health. ${ }^{46}$ Several of these schools use problem-based learning as an educational strategy: the success of these programmes will ultimately be measured by the performance of graduates. Evaluation studies therefore tend to focus on student attitudes, learning outcomes, and performance data. ${ }^{7}$ The actual content of the programme is usually taken for granted. In this article the content of a problem-based curriculum is analysed by looking at the kind of problems which are presented to students. By comparing the content of the curriculum of the Faculty of Medicine in Maastricht with actual health care data we will try to answer the question: do we teach what we preach?

\section{Curriculum analysis}

There is a growing interest in several medical schools to provide students and teachers with short-hand information about what is taught in the various lectures and courses offered. Computer databases containing relevant descriptions of each course are being developed, and these provide powerful retrieval facilities to the users of these systems. ${ }^{8,9}$ Each lecture hour or lab session is usually described in a number of key concepts. The Medical Systems Headings (MeSH) thesaurus is frequently used for this classification task. ${ }^{10}$

In a problem-based curriculum paper problems, rather than lectures, are the main components of the programme. Students are supposed to learn the underlying mechanisms and theories using patient problems as a starting point for their learning process. When describing the content of a problem-based curriculum it is therefore necessary to analyse these patient problems. A database has been developed which contains relevant characteristics of all the problems presented in the first 4 years of the medical curriculum of our Faculty of Medicine. The pro- 
gramme consists of 21 blocks of 6 weeks each and 24 weeks of electives. During these 4 years students also work with simulated patients and occasionally with actual patients. We have not included these additional learning opportunities in this study. Neither does the analysis include the content of the clerkships in the fifth and the sixth year of the programme.

All patient problems which were offered to all students have been analysed on educational and medical characteristics. For this study the relevant items were age and gender of the patient; reasons for encounter/complaints presented; relevant problems/diagnoses; level of care provided. Reasons for encounter/complaints and problems/diagnoses have been coded using the International Classification of Primary Care (ICPC). ${ }^{11}$ This classification contains 17 chapters, of which 14 are concerned with organic (body) systems such as the digestive system (D). One chapter contains unspecified complaints and problems (A), while the two remaining chapters deal with psychological $(P)$ and social items $(Z)$.

Since the number of patient cases per block varied from 12 to 23, and some patient cases included one, some two or three diagnoses the raw data were corrected to provide a better estimate of the time a student could spend on each complaint and diagnosis presented by dividing the block period by the number of patient cases and dividing this by the number of presented complaints or diagnoses. The Spearman rank correlation between the uncorrected and corrected reasons for encounter data was 0.94 . The rank correlation between uncorrected and corrected diagnoses was 0.92 . These results reflect that a correction for assumed time spent on patient problems has a limited effect on the raw data. The corrected data have been used in the analysis.

The data were stored in a data trieve system on a VAX/VMS mainframe system, which allows multi entry analysis. Furthermore, the system has a large data storage capacity.

\section{Primary health care data}

The primary health care data were obtained from the Registration Network Family Practices, a health information system in the southern part of the Netherlands which covers 15 practices, with 42 general practitioners and 80000 patients. ${ }^{12}$ The doctors use problem lists not only for diagnoses but also for psychosocial problems, chronic complaints and risk factors. These data are coded using the ICPC, the reliability, adequacy and feasibility of which were proven. ${ }^{13}$ Data on reasons for encounter/complaints have been gathered in a field trial of the reasons for encounter mode of the ICPC. ${ }^{14}$ The problems/diagnoses come from the continuing registration by the Registration Network. ${ }^{15}$ The patient population of the Registration Network resembles the general population of the Netherlands with respect to age, gender, marital status, types of household and level of education. 
In this section we will present general data, followed by comparisons of specific topics relevant for a primary care approach.

\section{General characteristics}

The first 4 years of the curriculum contain 275 paper problems. The average number of tasks per block period was 14, but several blocks contained far more tasks. Two hundred and nineteen of these problems presented a reason for encounter/complaint; no age or gender was indicated for 24 patients. The age and gender distribution of the other 195 patients was found to generally resemble that of the general population (Table 1), although the gender distribution in some age groups was not the same as that of the general population.

In 25 cases the medical or health problem was not presented in a specified doctorpatient setting (Figure 1).

One hundred and sixty of the cases $(73 \%)$ start in a general practitioners office: $73(46 \%)$ are referred to a specialist for further investigation or treatment, while the actual referral rate in the Netherlands is less than $10 \% .^{16}$

In 34 patient cases a specialist is presented as the first provider of care: in three of these the patient is referred to another specialist and in only two cases does the specialist refer the patient to the general practitioner for continuation of care. Although there are no statistical data on this process this certainly happens more often.

Table 1. Age and gender distribution in the general population ( $N=14714948$ ) and the curriculum population ( $\mathrm{N}=195)$ (percentnges)

\begin{tabular}{lrrrrrrr}
\hline $\begin{array}{l}\text { Age group } \\
\text { (years) }\end{array}$ & \multicolumn{2}{c}{ Male population } & \multicolumn{2}{c}{ Female population } & \multicolumn{2}{c}{ Total population } \\
\hline $0-04$ & General & Curriculum & General & Curriculum & General & Curriculum \\
\hline $5-14$ & 6.3 & 5.0 & 5.9 & 10.6 & 6.1 & 7.7 \\
$15-24$ & 12.8 & 16.8 & 12.0 & 5.3 & 12.4 & 11.3 \\
$25-44$ & 17.4 & 16.8 & 16.3 & 12.8 & 16.8 & 14.9 \\
$45-64$ & 33.0 & 20.8 & 30.8 & 37.2 & 31.9 & 28.7 \\
$65-74$ & 20.4 & 28.7 & 20.3 & 19.1 & 20.3 & 24.1 \\
$>75$ & 6.4 & 7.9 & 8.0 & 7.4 & 7.2 & 7.7 \\
& 3.7 & 4.0 & 6.8 & 7.4 & 5.3 & 5.6 \\
& 100 & 100 & 100 & 100 & 100 & 100 \\
\hline
\end{tabular}




\begin{tabular}{|c|c|c|}
\hline $\begin{array}{l}\text { setting of the } \\
\text { patient case at } \\
\text { the beginning }\end{array}$ & $\begin{array}{l}\text { patient cases } \\
\text { handled by }\end{array}$ & $\begin{array}{l}\text { setting of the } \\
\text { patient case at } \\
\text { the end }\end{array}$ \\
\hline
\end{tabular}

not mentioned

general practitioner

specialist
25

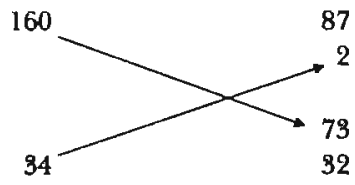

89

\section{Reasons for encounter/complaints}

Reasons for encounter/complaints from the curriculum have been compared with those of the reason for encounter study (Figure 2). In general practice most complaints are respiratory or musculoskeletal, and many others are registered as gene$\mathrm{ral} / \mathrm{unspecified.} \mathrm{The} \mathrm{distribution} \mathrm{of} \mathrm{complaints} \mathrm{in} \mathrm{the} \mathrm{curriculum} \mathrm{differs} \mathrm{in} \mathrm{sever-}$ al respects: general/unspecified, digestive and psychological are the most common. The largest difference (8.9\%) was found in the incidence of the respiratory chapter, while the average difference over all the chapters was just over $3 \%$. Table 2 shows the 10 reasons for encounter/complaints presented most frequently in specimen cases in the curriculum and in actual general practice. Only two items are present on both lists: cough and fever.

Table 2. Reasons for encounter/complaints: top ten

\begin{tabular}{|c|c|c|c|}
\hline \multicolumn{3}{|c|}{ Curriculum } & \multirow{2}{*}{$\begin{array}{l}\text { General practice } \\
\text { Cough }\end{array}$} \\
\hline A.04 & General weakness tiredness/ill feeling & R05 & \\
\hline R05 & Cough & K86 & Uncomplicated hypertension \\
\hline A09 & Fever & A03 & Fever \\
\hline D06 & Other localized abdominal pain & W11 & Family planning oral contraceptive \\
\hline D01 & Generalized abdominal pain/cramps & R21 & Symptom/Complaint throat \\
\hline R02 & Shortness of breath/dyspnoea & L02 & Back symptoms/Complaints \\
\hline A06 & Fainting (syncope)/Loss of consciousness & S06 & $\begin{array}{l}\text { Localized redness / erythema/rash } \\
\text { of skin }\end{array}$ \\
\hline W01 & Question of pregnancy & Nol & Headache \\
\hline S04 & $\begin{array}{l}\text { Localized swelling/papules/lump/mass/ } \\
\text { skin/subcutaneous tissue }\end{array}$ & D06 & $\begin{array}{l}\text { Other localized abdominal } \\
\text { pain }\end{array}$ \\
\hline L28 & Disability/impairment musculoskeletal & $\mathrm{H} 01$ & Ear pain/earache \\
\hline
\end{tabular}




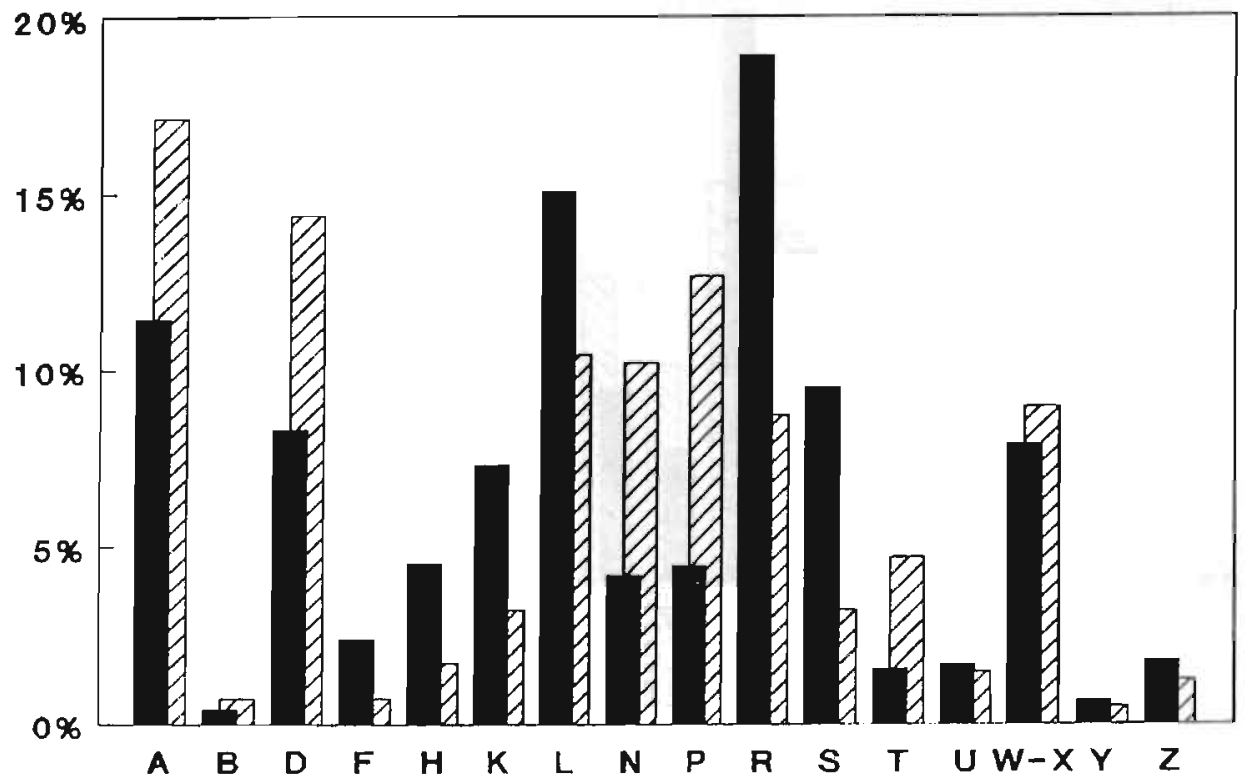

Reason for Encounter Study

(Health Care data)
General practitioner patient cases

DID (Curriculum data)

ICPC chapters:A: General and unspecified; B: Blood, bloodforming organs, lymphatics, spleen: D: Digestive; F: Eye; H: Ear; K. Circulatory; L. Musculoskeletal; N: Neurological; P: Psychological; R: Respira. tory; S: Skin; T: Endocrine, metabolic and nutritional; U: Urology; W: Pregnancy, childbearing, family planning; X: Female genital system (including breast); Y: Male genital system; Z: Social problems. 


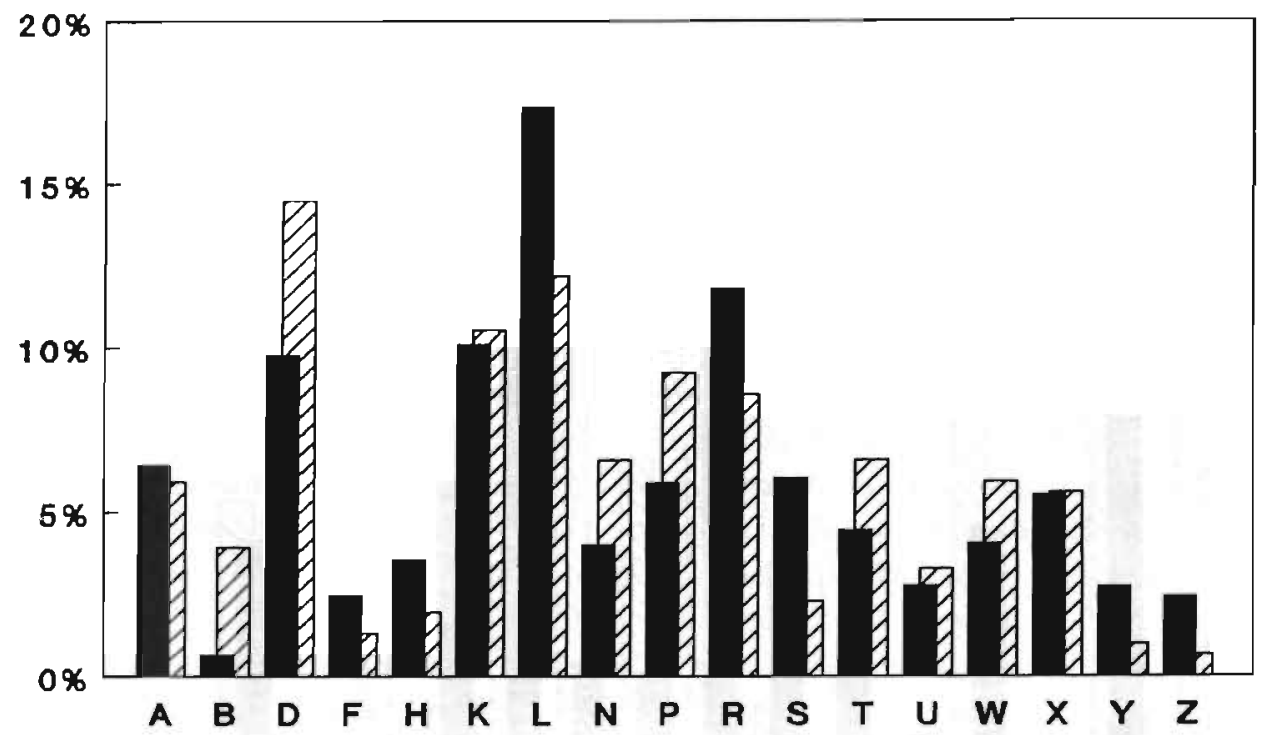

Reason for Encounter Study

(Health Care data)
General practitioner patient cases

$\square / \triangle$ (Curriculum data)

ICPC chapters:A: General and unspecified; B: Blood, bloodforming organs, lymphatics, spleen; D: Digestive: F: Eye: H: Ear; K: Circulatory: L: Musculoskeletal; N: Neurological; P: Psychological; R- Respiratory; S: Skin; T: Endocrine, metabolic and nutritional; U: Urology; W: Pregnancy, childbearing, family planning; X: Female genital system (including breast);Y: Male genital system;Z: Social problems. 
Figure 3 depicts the distribution of problems/diagnoses according to the ICPC as found in the curriculum and in general practice. Musculoskeletal problems were registered most frequently in general practice, followed by problems in the respiratory, circulatory and the digestive systems. In the curriculum, problems of the digestive system were most frequent followed by the musculoskeletal system. The average difference is only $2 \%$, with the largest difference being $5.2 \%$ for the musculoskeletal diagnoses. Analysis of more specific problems/diagnoses (Table 3) showed that only diabetes mellitus and hypertension were present on both lists.

Table 3. Problems/diagnoses : top ten

Curriculum

D99 Other disease digestive system

P76 Depressive disorder

D70 Infectious diarrhea, dysentery

T90 Diabetes mellitus

R91 Chronic bronchitis/bronchiectasis

K87 Hypertension with involvement target organs

K90 Stroke/cerebrovascular accident

K99 Other disease of circulatory system

W81 Toxemia/(pre)eclampsia

R84 Maligne neoplasm of trachea/ bronchus/lung
General practice

A85 Adverse effect medical agent proper dose

K86 Uncomplicated hypertension

R96 Asthma

R97 Hayfever, allergic rhinitis

T90 Diabetes mellitus

T82 Obesity (BM $\cdot \mathrm{I} 30$ )

L03 Low back complaints without radiation

P01 Feeling anxious/ nervous/ terise: inadequate

S87 Atopic dermatitis/eczema

L84 Osteoarthritis of spine (any region)

\section{Chronic diseases}

Four diagnoses in the top 10 of the curriculum can be regarded as chronic diseases: diabetes mellitus, stroke/cerebrovascular accident, hypertension, and cancer of the trachea, bronchus or lung. In actual practice, five of the 10 most common diagnoses can be considered as such: hypertension, asthma, diabetes mellitus, obesity and osteoarthritis of the spine.

The ICPC contains 66 specific labels for chronic diseases; 41 are dealt with in the curriculum. Several diseases are presented more than once as a patient case, including stroke/cerebrovascular accident ( 7 cases), cancer of the trachea, bronchus or lung (6 cases), chronic bronchitis or bronchiectasis (5 cases) and diabetes mellitus (6 cases). Common chronic diseases such as obesity (BMI >30), glaucoma, varicose veins, psoriasis and malignancy of the colon and rectum are not presented in the curriculum. 


\section{Children}

Eighteen of the 194 cases presented in the curriculum deal with health problems of children below the age of 6: the problems/ diagnoses presented in these cases are presented in Table 4. Although the general practitioner is the health care provider in 12 of these cases, most of the diagnoses are very serious, while children are mostly seen in the general practitioners office with minor ailments: cough, fever, ear pain, localised redness/erythema, other general infantile complaints and diarrhoea account for $50 \%$ of the encounters in that age group. Eczema, asthma, acute otitis media, serous otitis media, congenital anomalies of the musculoskeletal system, and tonsillitis are the chronic diseases most commonly diagnosed in general practice. None of them are dealt with in the cases presented in the curriculum.

Table 4. Problems/diagnoses of young children (0-5 years) in the problem-based curriculum

\begin{tabular}{|c|c|c|c|}
\hline & Age & Problem/diagnosis & ICPC code \\
\hline \multirow[t]{14}{*}{ General practitioner } & 0 & Obstruction stomach/small intestines & D99 \\
\hline & 0 & General symptoms of disease & A17 \\
\hline & 0 & Malabsorption endocrine/metabolic & T99 \\
\hline & 1 & Malabsorption & D99 \\
\hline & & Nontropical sprue & D99 \\
\hline & & Lipid metabolism disorder & T93 \\
\hline & 1 & Obstruction stomach/small intestines & D99 \\
\hline & 1 & Congenital dysplasia of the hip & L82 \\
\hline & 2 & Diseases neurological system & N99 \\
\hline & 2 & Chickenpox & A72 \\
\hline & 2 & Salmonellosis & D70 \\
\hline & 4 & Diseases neurological system & N99 \\
\hline & 5 & Genu valgus/varus & L98 \\
\hline & 5 & Trauma & $\mathrm{A} 80$ \\
\hline \multirow[t]{6}{*}{ Pediatrician } & 0 & Feeding problems in premature baby & W95 \\
\hline & & & A93 \\
\hline & 0 & 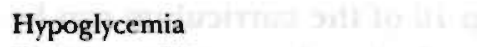 & T87 \\
\hline & & Diabetes mellitus & T90 \\
\hline & 0 & Large for date & w92 \\
\hline & & Small for date & A94 \\
\hline Surgeon & 5 & Burns & S14 \\
\hline \multirow[t]{2}{*}{ Not mentioned } & 4 & Disturbances of behaviour & P22 \\
\hline & 4 & Learning problems & P24 \\
\hline
\end{tabular}

\section{Referrals to specialists}

The general practitioner is the first provider of care in 160 patient cases, and refers $73(46 \%)$ to a specialist. As mentioned above, this is far higher than the actual referral rate in Dutch practice. Table 5 shows the number of cases referred to each specialty. It is noteworthy that no cases are referred to an ophthalmologist, a 


\section{Number of cases}

Surgery
Cardiology
Geriatrics
Gynaecology
Internal medicine*
Pediatrics
ENT
Psychiatry
Neurology
Orthopedic surgery
Pulmonology
Urology
Clinical genetics

Total 73

* Internal medicine includes subspecialities such as endocrinology; hematology; oncology; immunology; nefrology.

dermatologist or a rehabilitation physician, whereas the referral rate to ophthalmologists is most common in actual practice (101 referrals per 1000 persons).

\section{Ophthalmology and dermatology cases}

Since no patient cases were referred to an ophthamologist or a dermatologist we looked especially at problems/diagnoses presented in these fields (Table 6). Morbidity data from general practice indicate that conjunctivitis is the most common new eye problem, followed by refractive errors, sty, blepharitis, cataract and strabismus. ${ }^{17}$ Only two of these were included in the curriculum, while only one of the common skin problems such as atopic dermatitis, eczema, acne, sebaceous cyst, and psoriasis is dealt with.

Table 6. Problems/diagnoses in the fields of ophthamology and dermatology

\begin{tabular}{|c|c|c|c|}
\hline Problems/diagnoses & ICPC code & Frequency & Health care provider \\
\hline \multicolumn{4}{|l|}{ Retinopathy, diabetic and } \\
\hline hypertensive & F83 & 1 & General pracutioner \\
\hline Refractive ertor & F9l & 1 & General practitioner \\
\hline Cataract & F92 & 1 & General practitionı $r$ \\
\hline Burns/scalds & $\mathrm{Sl4}$ & 1 & General practitioner \\
\hline Abrasion/scratch/blister & S17 & 1 & Surgeon \\
\hline Laceration/cut & $\$ 18$ & 1 & Surgeon \\
\hline \multicolumn{4}{|c|}{ Moniliasis/monilia infection/ } \\
\hline candidiasis (excl.urgon.) & S75 & 1 & Internist \\
\hline Malignant neoplasms of skin & S77 & 2 & General practitioner \\
\hline Acne & S96 & $\mathbf{l}$ & General practitioner \\
\hline
\end{tabular}


Since the problem-based curriculum of the Faculty of Medicine has been designed to cover the problem areas relevant to primary health care, one would expect that the problems presented to students would reflect this emphasis. At first sight, this emphasis seems to be present: a high percentage of the problems consist of patients presenting a complaint to a general practitioner. A further analysis reveals, however, that the curriculum differs in many respects from the actual primary health care situation. An unrealistic high percentage of the curriculum patients is referred to a specialist by the general practitioner. Serious health problems are mainly presented to general practitioners, but reasons for encounter/complaints and problems/diagnoses show large differences between the curriculum and the primary care practice, as shown by their distribution over the ICPC chapters and the top 10 problems listing. Young children are supposed to present mainly with severe illness, while on the other hand few patient cases deal with problems of the eye or skin. Does this imply that the curriculum is insufficiently oriented towards primary care?

A few points should be taken into consideration when looking at these results. We have to keep in mind that the analysed material reflects only a part of the curriculum. Sonie of the parts not included, especially the skills training programme, are clearly primary care oriented. Furthermore, the curriculum content cannot be viewed only in relation to primary health care data, nor be based on the power of numbers. If, for example, a common cold is diagnosed 15 times more often than external otitis, or uncomplicated hypertension is seen 100 times more often than multiple sclerosis, these diseases should not necessarily be represented in the curriculum in the same proportions.

In order to decide which diseases should be dealt with in the curriculum, priorities should be set using a series of additional criteria such as treatability, prototype value and clinical logic. ${ }^{18-20}$ Even so, the curriculum seems to follow the principle of the "worst case scenario": common complaints are inflated with serious complications requiring specialist care. The result is that the reality value of the curriculum is low: students get a biased view of health and primary care when primary care problems are presented as specialty problems, or treated as such. Furthermore, students get an incorrect epidemiological perspective on health care problems. From an educational point of view, the strong emphasis on exceptional cases could be challenged: recent research on the development of professional expertise suggests that students in their first phase of training would benefit most from typical disease cases in which they have to relate clinical findings to pathophysiological knowledge. ${ }^{21}$ For students this task is already fairly complicated and there is no sound educational reason why students should at this stage be presented with complicated and exceptional findings: even in medicine one should first learn the rules before one learns the exceptions. Our conclusion is, therefore, that if the Faculty of Medicine in Maastricht is serious about its orientation on pri- 
mary care, a critical review of the cases is needed. 'The curriculum content is currently being revised, but it will take another year before we can report on the actual changes made in response to our findings.

\section{References}

1. Vuori $\mathrm{H}$, Health for all, primary health care and general practitioners. Krynute address WONCA 1986. J R Coll Gen Pract 1986:36: 290, \$98-402.

2. Abrahamson S, The reformation movement in medical education; nust there be marcyrs? In: Barrows H, Peters MJ, (eds), How to begin reforming the medical curriculum. Springficld: Southern Illinois University School of Medicine, 1984.

3. AAMC, Preparing physicians for the 21st century; the GPEP report. Washington: AAMC, 1984.

4. Katz FM, Fulop T, (eds), Personnel for health care. Case studies of educational programmes. Public Health Papers 70, Geneva: WHO, 1978.

5. Kaufman A, (ed), Implementing Problem-based Medical Education: lessons from successful innovations. New York: Springer Publishing Company, 1985.

6. Schmidt HG, Lipkin M, DeVries M, Greep JM (eds), New directions for medical education; problem-based learning and community-oriented medical education. New York: Springer Verlag, 1989.

7. Schmidt HG, Dauphinee WD \& Patel Vl, Comparing the effects of problem-based and conventional curricula in an international sample. J Med Educ 1987;62: 305-315.

8. Brown JS, The University of North Carolina School of Medicine Curriculum Database. (unpublished manual) University of North Carolina, 1987.

9. Baumber JS, Harasym PH, Philp JR, The quest for the definition of content. In: Bender W, Hiemstra RJ, Scherpbier AПA, Zwierstra RP, (eds) Teaching and assessing clinical competence. Groningen: Boekwerk Publications Groningen, 1990

10. National Library of Medicine, Medical Subject Headings. Bethesda: NIH Publication No. $90-265,1990$

11. Lamberts $\mathrm{H}$, Wood $\mathrm{M}$, (eds) International Classification of Primary Care (ICPC) Oxford: Oxford University Press, 1987.

12. Hōppener P, Knottnerus JA, Metsemakers JFM, Kocken RJ, Limonard ChBG. Het Registratienet Huisartspraktijken van de Rijksuniversiteit Limburg. Huisarts Wet 1990; 39(2):66-69.

13. van der Horst F, Metsemakers J, Vissers F, Saenger G, de Geus C, The Reason-for-Encounter mode of the ICPC: reliable, adequate, and feasible. Scand J Prim Health Care 1989; 7:99-103.

14. Lamberts $\mathrm{H}$, Meads $\mathrm{S}$, Wood M, Waarom gaat iemand naar de huisarts? Een internationale studie met de Reason-for-Encounter Classification. Huisarts Wet 1984;24:234-244.

15. Metsemakers JFM, Höppener P, Knottnerus JA, Limonard ChBG. Health problems and diagnoses in Family Practice. Report 3, Registration Network Family Practices. Maastricht: University of Limburg, 1990.

16. Groenewegen PP, Verrichtingen in de huisartspraktijk. Medisch Contact 1990;45:608-611.

17. van de Lisdonk EH, van den Bosch WJHM, Huygen FJA, Lagro-Janssen ALM, (eds), Ziekten in de huisartspraktijk. Utrecht: Wetenschappelijke Uitgeverij Bunge, 1990.

18. Bordage $G$, Zacks $\mathrm{R}$, The structure of medical knowledge in the memories of mediral students and general practitioners: categories and prototypes. Med Educ. 1984;18:406-416. 
19. Chong.JP, Neufeld VR, Oates MJ, Secord $M$, The selection of priority problems and conditions: an innovative approach to curriculum design in medical education. Washington, RIME Proceedings 23th Annual Conference, 1984.

20. Neufeld VR, Sitthi-Amorn C, The population health perspective: some challenges for medical education. April 1985 McMaster University (unpublished paper).

21. Boshuizen HPA, De ontwikkeling van medische expertise. [PhD thesis University of Limburg) Meppel: Krips Repro, 1989. 
Chapter 8:

\section{Chronic Illnes in the Community and the Concept of 'Social Prevalence'}

Published as:

JA Knottnerus, J Metsemakers, P Höppener and C Limonard.

Chronic illness in the community and the concept of 'social prevalence'.

Family Practice 1992;9:15-21 


\section{Summary}

General practice is an important source of information on the occurence and distribution of chronic disease in the population. In this study, the burden of chronic illness was expressed as different indices of prevalence. Data were provided by 42 general practitioners in 15 computerized practices, collaborating in the Registration Network Family Practices of the University of Limburg in the Netherlands. Morbidity data concerning the actual health status of 25357 subjects, as recorded by their GPs, were classified following the International Classification of Primary Care using the diagnostic criteria of the International Classification of Health Problems in Primary Care-2-Defined. The most frequent single disease was asthma (3.5\%), while locomotor problems represented the most prevalent category $(8.3 \%)$. The overall prevalence of chronic disease was $29.4 \%$, with a clear positive correlation with age and, to a lesser extent, with a lower educational level. The 'social prevalence'of chronic illness (including individuals related to chronically diseased patients via their households) could be measured in a subset of the database ( $n=4577)$, and amounted to $56 \%$. It is concluded that the role of the GP as a family doctor involved with chronic disease concerns the majority of the general population. 
As members of the western societies live longer, chronic diseases become increasingly common and represent a substantial part of the burden of illness in the population. General practice, providing primary and longitudinal care, is an important source of basic information on the occurrence and sociodemographic distribution of chronic disease. In describing the relevant morbidity, however, epidemiological numbers do not always adequately reflect the impact of health problems in general practice. Severe and chronic diseases, for example, are often dealt with separately and these diseases may seem to be not very frequent: general practice is often said to be a low prevalence domain of medicine.

We must consider both the difference and the relationship between incidence and prevalence. Most severe and chronic diseases have a low incidence and a low prior probability as a new diagnostic finding in the GP's office. However, they may have a very long or even a lifelong duration, and thus, can reach a considerable prevalence, since the prevalence equals the product of incidence and mean duration in a stable, dynamic population. ${ }^{1}$ Furthermore, the doctor, particularly in general practice is confronted with any chronic disease, and therefore the prevalence of 'chronic disease' or better of 'chronically diseased patients' is a combination of all single disease prevalences (not merely the sum of them, since some patients may be affected by more than one disease, which can be designated as comorbidity). This represents the prevalence of being chronically diseased, that is, of having at least one chronic disease. The occurrence of disease is not only an epidemiological-nosological phenomenon (expressed in number of cases per 1000 inhabitants), but is embedded in a social context of families and households. More persons than just the patients themselves are concerned with the disease, and in this connection, we can speak about 'social prevalence', (as opposed to nosological prevalence) a concept, which is again especially relevant for family doctors.

We can relate these concepts to another in a four-fold table, which presents four types of chronic disease prevalence (Table 1): nosological prevalence of single diseases (cases per 1000); social prevalence of single diseases (number of persons directly involved, per 1000) nosological prevalence of 'chronic disease' as a combination or pooling of all single diseases (cases per 1000); and social prevalence of 'chronic disease' (number of persons directly involved, per 1000) The latter cate-

Table 1. Four types of prevalence, in relation to the distinction of disease as a nosological or social phenomenon, and the distinction between single diseases and being chronically diseased

Nosological

Single disease

Combined disease
Social

(4) 
gory can be considered as an indicator of the social burden of severe and chronic disease in families and households.

We investigated these types of prevalence, in order to estimate the epidemiologi$\mathrm{cal} /$ nosological burden of chronic/severe diseases in a general practice population. We were also interested in the relationship between prevalence and age, gender, level of education, and type of insurance (private or sickfund). Moreover, we wanted to asses the social burden of illness, as indicated by the involvement of families and households. Since in the Netherlands members of households generally have the same family doctor, this aspect could be studied in the participating practices.

\section{Methods}

\subsection{Registration Network Family Practices}

The investigation of these topics is greatly facilitated by our computerized Registration Network Family Practices. ${ }^{2,3}$ The network consists of 15 practices and 42 general practitioners in Limburg, with a registered population of 80000 persons. Standardized patient data are collected and updated in a general practice health information system by the general practitioners and transferred on floppy disc to a central database at the university 4 times a year. These data encompass; firstly general personal characteristics such as gender, date and place of birth, marital status, type of insurance (private or sickfund), type of household, level of education (registered for persons of 25 years or above; three classes comparable with primary school, high school and academic level, respectively), dates of entry and exit. In addition three practices could provide household identification numbers, which in future will be also done by the other practices. Thus we could combine morbidity data of members of specific households. Secondly, health problems and diagnoses, coded following the International Classification of Primary Care (ICPC), using the diagnostic criteria of the International Classification of Health Problems in Primary Care (ICHPPC-2 -defined) ${ }^{5}$ The diagnosed problems are registered by the GP only if they are permanent, chronic, (duration longer than 6 months) or recurrent (more than three recurrences within a 6 -month period). Incidental problems of short duration with complete recovery such as common colds, are not listed. The problems can be indicated as active (relevant for actual care) or inactive. Thus, for every patient (each of whom has a unique identification number) a record of general personal characteristics and a complete and up-to-date problemlist, with its historical development, is available in the database. ${ }^{6}$ This database can be used as a sampling frame, and as a source of descriptive and longitudinal research. Several quality control procedures have been developed, including special software for data control, repeated data checks for representativeness, peer review of general practitioners in five consensus groups, feedback from the Medical and Social Information Center on the data provided by the practitioners, and ongoing refinement of instructions and guidelines. 
The database is being built up by reviewing and entering randomly three to five patient records per day per GP. After patients have been entered, their medical data and problem list are checked and updated whenever they visit the GP's office. Patients who have not contacted the doctor within 2 years (an estimated $10 \%$ of all registered patients) will receive a short questionnaire concerning their recent and actual health status. There is a complete listing and referral system in the Netherlands: each individual has his own GP, and all referrals and relevant medical informa-tion can be recorded by the GP.

At the moment of reporting, 25357 patients have been entered, and repeated data checks indicate that the sex-and age distribution of the entered group of patients has been stabilized and is quite comparable with the whole Dutch population (Table 2). The prevalence distribution of disease categories has also been stabilized.

Table 2. Age- and sex-distribution of the registered study population in March 1990, compared with the total Dutch population (column percentages)

\begin{tabular}{lllll}
\hline \multicolumn{2}{l}{ Study population } & \multicolumn{2}{l}{$\begin{array}{l}\text { Total Dutch population } \\
(\mathrm{x} 1000)\end{array}$} \\
\hline $\begin{array}{l}\text { Age } \\
\text { (years) }\end{array}$ & $\begin{array}{l}\text { Men } \\
(\mathrm{n}=12 \mathrm{167})\end{array}$ & $\begin{array}{l}\text { Women } \\
(\mathrm{n}=13190)\end{array}$ & $\begin{array}{l}\text { Men } \\
(\mathrm{n}=7358)\end{array}$ & $\begin{array}{l}\text { Women } \\
(\mathrm{n}=7536)\end{array}$ \\
$0-24$ & 33.7 & 32.5 & 35.2 & 33.0 \\
$25-44$ & 33.6 & 33.2 & 33.6 & 31.3 \\
$45-64$ & 21.2 & 19.5 & 20.9 & 20.4 \\
$65+$ & 11.5 & 14.9 & 10.4 & 15.3 \\
\hline
\end{tabular}

\subsection{The Analysis}

We analysed the actual contents of the database cross-sectionally, in order to study point prevalences of active chronic problems in our population on March 1st, 1990. We related patient characteristics to problem list data, for which we used certain disease-specific codes concerning severe and chronic problems such as breast cancer, ischaemic heart disease and diabetes. In order to assess the impact of disease categories, we defined categories such as cancer, cardiovascular and endocrine problems. A patient was classified in a category if he had at least onc specific disease in that category. Finally, we defined being "chronically diseased" as having at least one disease in a specified category. In the appendix the selected ICPC-codes with their point prevalences in the basic populations are listed according to the defined categories.

In the three practices which also provided household numbers, we crombined all subjects with the same household numbers in one household, studying the clustering of health problems over the households. 
For statistical testing, Pearson's 2 test for independent proportions was used, with a two-sided significance level of $5 \%$. For the analysis of the relationship between a high number (3) of chronic problems and the probability of having at least one other chronic disease, we calculated the odds ratio with Cornfield's $95 \%$ confidence interval.

\section{Results}

A total of 11144 chronic health problems within the specified categories was found among the 25357 subjects. Since a number of patients had more than one problem per category, the total number of positive scores on the categories was lower: 10147.

The most prevalent category of listed active chronic problems (Table 3) involved

Table 3. Prevalence of active chronic health problems

\begin{tabular}{lcll}
\hline Category & $\begin{array}{c}\text { Prevalence } \\
\text { of category }\end{array}$ & $\begin{array}{l}\text { Prevalence of most frequent } \\
\text { disorder per category }\end{array}$ \\
\hline Locomotor & $8.3 \%$ & Arthrosis (spine) & $1.9 \%$ \\
Respiratory & 6.4 & Asthma & 3.5 \\
Cardiovascular & 5.4 & IHD & 1.3 \\
Endocrine & 5.3 & DM & 2.8 \\
Psychological & 3.4 & Depression & 1.1 \\
Skin & 3.4 & Eczema & 2.0 \\
Sensory & 2.7 & Deafiness & 1.6 \\
Cancer & 1.7 & Breast cancer & 0.4 \\
Urogenital & 1.2 & Incontinence & 0.7 \\
Neurological & & & \\
$\quad$ Pain & 1.2 & Migraine & 1.1 \\
Disabling & 1.0 & Epilepsy & 0.6 \\
& & & \\
Combined & & & \\
prevalence & 29.4 & & \\
\hline
\end{tabular}

the locomotor system (point prevalence $8.3 \%$ ), arthrosis, especially of the spine, being the most prevalent chronic disorder within this category. Chronic respiratory disease was also quite prevalent $(6.4 \%)$, with asthma even having the highest single disease prevalence of all categories (3.5\%). Chronic psychological problems were less prevalent than we expected, but still they were not infrequent $(3.4 \%)$, depression being the highest scoring specific disorder (1.1\%). The 11144 chronic health problems were found in 7443 patients. Considering the 'combined' prevalence of being a chronically diseased patient, we can conclude that this is considerably high: $7443 / 25357$, which is about $30 \%$ of the registered population (which is of course lower than the sum of the category specific prevalences, being 40.0\%). 
As expected, the prevalence of being chronically diseased was highly correlated with age, for both sexes (Figure 1). On the basis of our problem list registration, we found overall that men and women were affected about equally at all ages. Very high prevalences ( $70-80 \%)$ were found from about 75 years of age. Not all registered health problems were serious, of course, but the picture is impressive.

Table 4 shows that those who have most problems, in general, have a somewhat higher probability of having at least one other chronic problem: $40 \%$ as opposed

Figure 1. Prevalence of being chronically diseased in relation to age, for men and women.

Prevalence of active chronic disease

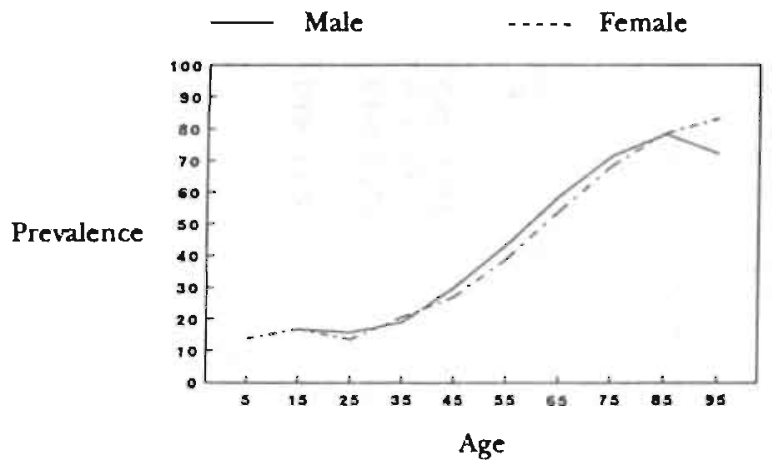

Table 4. Relationship between number of problems per patient and the probability of having at least one other chronic disease

$\begin{array}{ll}\text { (Sub)population } & \begin{array}{l}\text { Number of } \\ \text { patients }\end{array}\end{array}$

$\begin{array}{lrr}\text { All } & 25357 & 29.4 \\ \geq 1 \text { disorder } & 7449 & 31.7 \\ \geq 2 & 2360 & 34.6 \\ \geq 3^{*} & 817 & 40.6 \\ \geq 4 & 332 & 40.7\end{array}$

* Comparing the probability of at least one other chronic disease in subjects with 3 disorders as oppo. sed to those with $\leq 2$ disorders, the odds ratio is 1.68 (95\% confidence interval: $1.45,1.94 ; p<0.001$ ). 
Women

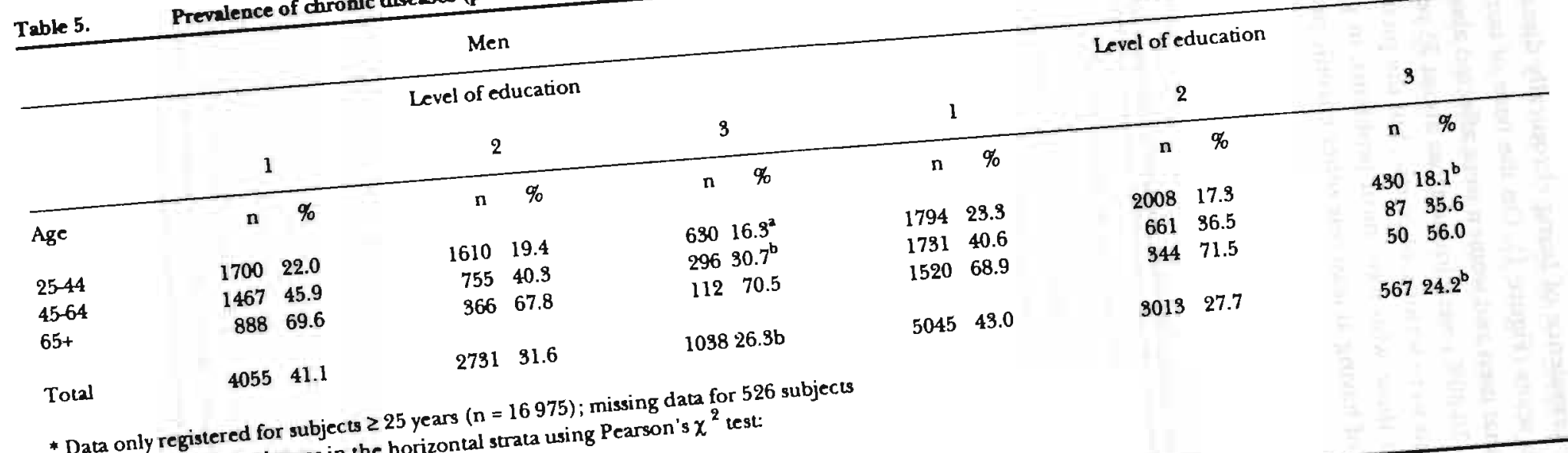

* Data only registered for subjects $\geq 25$ years ( $n=16975)$; missing

Comparing the
$0.01<p<0.05$

b $\mathrm{P}<0.01$ 
to $30 \%$ in the general population. Comparing subjects with more than three disorders with those having two or less disorders the odds ratio is 1.68 (P 0.001 ). A moderate but clear correlation is found between level of education and the prevalence of chronic health problems; this remained after stratification for age (Table 5). This is especially the case in younger men. After stratification for age, no relationship was found between overall prevalence and type of insurance.

Clustering of chronic disease over households was studied in the three practices for which household identification numbers were available, including 4577 registered subjects (Table 6). In $45.6 \%$ of the households there is no chronic health problem listed. Most of the problems were concentrated in a minor part of the households: for example $76.7 \%$ of the problems are found in $29 \%$ of the households and $45.5 \%$ of the chronically diseased patients were found in $15.1 \%$ of the households (Table 6). Our analysis revealed, not unexpectedly, that small households (couples or singles) including relatively many elderly patients had a higher prevalence of chronic problems ( 0.8 problem per subject) than larger households ( 0.3 problem per subject). Most $(2620 / 4677=56 \%)$ of the registered subjects are involved via their households with the 1523 chronically diseased patients. This 'social prevalence' almost doubles the overall nosological prevalence in these practices $(1523 / 4677=32.6 \%)$ which is about equivalent to the nosological prevalence in the total database: $29.4 \%$. Specific morbidity figures for these practices did not substantially differ from those for all practices (Table 3).

Returning to our fourfold table, we can give the following general description (Table 7). There is a clearly increasing prevalence of chronic health problems, starting from single disease (lower than $5 \%$, with asthma having the highest prevalence), and its 'social prevalence', (\%, the average number of subjects per household being 2.2.), to being chronically diseased (about $30 \%$ ) and its 'social prevalence' (56\%).

Table 6. Clustering of chronic health problems and, since patients may have more than one problem, of chronic diseased patients over 2112 households in three practices with 4677 registered subjects. (Percentages)

\begin{tabular}{lcccc}
\hline $\begin{array}{l}\text { Number per } \\
\text { household }\end{array}$ & $\begin{array}{l}\text { Problems } \\
\text { Proportion of } \\
\text { problems } \\
(\mathrm{n}=2365)\end{array}$ & $\begin{array}{l}\text { Proportion of } \\
\text { households } \\
(\mathrm{n}=2112)\end{array}$ & $\begin{array}{l}\text { Proportion of } \\
\text { diseased patients } \\
(\mathrm{n}=1529)\end{array}$ & $\begin{array}{l}\text { Proportion of } \\
\text { households } \\
(\mathrm{n}=2112)\end{array}$ \\
\hline 0 & $0 \%$ & $45.6 \%$ & $0 \%$ & $45.6 \%$ \\
1 & 100 & 54.4 & 100 & 54.4 \\
2 & 76.7 & 28.6 & 45.5 & 15.1 \\
3 & 52.2 & 15.2 & 9.9 & 2.2
\end{tabular}

Example: $76.7 \%$ of the problems are combined in the same household with at least one other problem, and are concentrated within $28.6 \%$ of the households; $45.5 \%$ of the patients are in households with at least one other patient, and are concentrated in $15.1 \%$ of the households. 


\begin{tabular}{lrr}
\hline & Nosological & Social \\
Single disease & $<5 \%$ & $<10 \%$ \\
Combined disease & $30 \%$ & $56 \%$ \\
\hline
\end{tabular}

\section{Discussion}

On the basis of the data from the Registration Network Family Practices, we had the opportunity to study the prevalent burden of chronic illness in a general practice population at March 1st, 1990 . We found, about $30 \%$ of the registered population were 'chronically diseased'. Taking families and households of patients into consideration, it appears that most people are directly involved: 'social prevalence' was $56 \%$. There was a pattern of clustering of problems among a minority of (high risk) patients and households. We found, not unexpectedly, a strong relationship with age, and some correlation with the level of education. Small, couple or single households of aged people often have a heavy burden of illness.

Considering the ICPC-codes we selected for our analysis, one might disagree in some respects about the choices made in defining chronic disease. Indeed we could have added more registered problems, and this would have enlarged prevalence. However, we deliberately focused on the more serious problems. With respect to the merits of the methods used, we must face the possibility of iatrotropic bias: patients do not present all health problems to doctors, and, in addition, patients may differ in their decision making about this. Furthermore the registration process may be influenced by the doctor themselves, in order to legitimate their management decisions retrospectively, for instance. There may be relevant interdoctor variability in several aspects, and definitions of diagnoses and chronic problems are not definitive. In studying morbidity patterns in a general practice and social context, these aspects indeed play an important role, but we think that in the morbidity sector under study here we obtained a reasonable picture: we focused on permanent, recurrent, or chronic ( 6 months) problems significantly affecting patients' well-being, which may be assumed to be reported to or detected by GPs in most cases. Moreover, we used widely accepted classifications and diagnostic criteria and the general practitioners are experienced in applying these. ${ }^{3-5}$ There is an intensive communication and feedback between the GPs about the coding and classification activities.

Another comment might be that patients who are diagnosed as having an active problem may not always come back when a problem has passed or became inactive. This could hinder the updating of the problem list, and therefore artificially enlarge prevalence. On the average, Dutch patients contact their GP three times a year and about $75 \%$ will do this at least once a year. ${ }^{7}$ Facing the type of chronic problems we studied, these numbers will even be much higher, since the duration 
of the problems is long and often lifelong. In conclusion, we do not think it is likely that our prevalences are significantly overestimated.

From our results based on standardized problem lists of general practitioners, it is evident that the role of the GP as a family doctor involved with chronic disease is intensive, concerning the majority of the registered general population. Clearly this role will become even more important, since the proportion of people aged 65 years or above will increase. In the Netherlands, for example, an increase from $12.8 \%$ to about $23 \%$ in the next four decades is expected. ${ }^{8}$ In the debate about the compression or decompression of morbidity at advanced age ${ }^{9,10}$ for the time being, we find, from our cross-sectional data, more support for the 'decompression' theory: ageing is correlated with a constantly increasing rate of chronic morbidity. This is of course important for the planning of professional and informal health care for the next decades. ${ }^{11,12}$ The same is true for the relationship between educational level, probably an appropriate indicator of social economic status, ${ }^{13}$ and the prevalence of chronic morbidity. Until now, such a relationship has been documented quite well with respect to mortality. ${ }^{13,14}$ Morbidity studies also focused on specific diagnosis groups might yield a more complete insight in the processes going on, as a basis for health policy. Prospective general practice studies will make essential contributions to the analysis and monitoring of these processes. In order to perform these studies efficiently and in a natural connection with modern GP care, computerized networks can be extremely valuable.

\section{References}

1. Armitage P, Berry G. Statistical methods in medical research, 2nd edn. Oxford: Blackwell Sientific Publications, 1987.

2. Hôppener P, Knottnerus JA, Metsemakers JFM, Kocken RJ, Limonard CBG. Het Registratienet Huisartspraktijken van de Rijksuniversiteit Limburg. Huisarts Wet 1990; 33: 66-69.

3. Metsemakers JFM, Hōppener P, Knotunerus JA, Limonard CBG. Health problems and diagnoses in Family Practice. Registration Network Family Practices. Maastricht: Report 3 University of Limburg, 1990.

4. Lamberts H, Wood M. The International Classification of Primary Care. Oxford: Oxford University Press, 1987.

5. Anonymus. ICHPPC-2 defined. Inclusion criteria for the use of the rubrics of the International Classification of Health Problems in Primary Care. Oxford: Oxford U'niversity Press, 1983.

6. Metsemakers JFM, Plagge MWM, Kanter J de. De probleemlijst. Huisarts Wet 1988; $31: 379$-381.

7. Lamberts H. Morbidity in General Practice. Diagnosis related information from the monitoring project. Utrecht: Huisartsenpers 1984.

8. Centraal Bureau voor de Statistiek. Bevolkingsprognose voor Necierland 1988-205i) 's-Gravenhage: SDU-uitgeverij/CBS-publicaties, 1989.

9. Fries JF. Aging, natural death and the compression of morbidity. N Engl J Med 1989; 303 : $190-185$.

10. Stout RW, Crawford V. Active-life expectancy and terminal dependency: Trends in longterm geriatric care over 33 years. Lancet 1988; i: 281-283. 
11. Fries JF, Green I.W, Levine. Health promotion and the compression of morbidity. Lancet 1989; 1. 181-483.

12. Winblad B, Ljunggren G. Life expectancy and planning care for the elderly. Lancet 1988; ii: 1313.

13. Doornbos (;, Rromhout D. Educational level and mortality in a 32-year follow-up study of 18-year old men in the Netherlands. Int J Epidemiol 1990; 19: 374-379.

14. Illsley R. Comparative review of sources, methodology and knowledge. Soc Sci Med 1990: 31; 229-236. 
Chronic disease and health problems, as classified by the International Classification of Primary Care 4 , selected and grouped in categories for the study.

Category ICPC
code

circumscription

codespecific

prevalence

$\%$

Locomotor

$\begin{array}{lll}\text { L84 } & \text { Osteoarthritis of spine } & 1.9 \\ \text { L85 } & \text { Acquired deformities of spine } & 1.2 \\ \text { L88 } & \begin{array}{l}\text { Rheumatoid arthritis / } \\ \text { allied conditions }\end{array} & \\ & \text { Osteoarthritis of hip } & 0.7 \\ \text { L89 } & \text { Osteoarthritis of knee } & 0.9 \\ \text { L90 } & \text { Other osteoarthritis } & 1.6 \\ \text { L91 } & \text { Osteoporosis } & 0.9 \\ \text { L95 } & \text { Acquired deformities of limbs } & 0.5 \\ \text { L98 } & & 1.6\end{array}$

Respiratory

\begin{tabular}{lll}
\hline R91 & Chronic bronchitis / & \\
& bronchiectasis & 1.7 \\
R95 & Emphysema / COPD & 1.4 \\
R96 & Asthma & 3.5
\end{tabular}

Cardiovascular

K74 Angina Pectoris

K75

K76

Acute Myocardial infarction

1.2

Other and chronic ischemic

heart disease

1.3

Heart failure

0.5

K77

Pulmonary heart disease

0.02

K87

Hypertension with involvement

of target organs

0.8

K90

Stroke/cerebrovascular accident

0.4

Atherosclerosis excl. heart/brain $\quad 0.6$

K92

Other arterial obstructive /

peripheral vascular disease $\quad 0.8$

K93

Pulmonary embolism

0.2

K94

Phebitis and thrombophlebitis

0.3

Endocrine

T85

T86

T90

T92

T93

T99
Hyperthyroidisin / thyrotoxicosis

Hypothyroidism / myxedema

Diabetes mellitus

Gout

Lipid metabolism disorder

Other endocrine / metabolic /

nutritional disease

\section{5}

0.3

2.8

0.5

1.3

0.3

Psychological 
Hysterical / hypochondriacal

Depressive disorder

Skin

S87

S91

S97
Atopic dermatitis / eczema

Psoriasis w/wo arthropathy

Chronic ulcer skin / including varicosis

\section{0}

Sensory

$\begin{array}{lll}\text { F83 } & \text { Retinopathy } & 0.3 \\ \text { F84 } & \text { Macular degeneration } & 0.1 \\ \text { F94 } & \text { Blindness, all types } & 0.6 \\ \text { H83 } & \text { Otosclerosis } & 0.2 \\ \text { H86 } & \text { Deafness / partial or complete } & 1.6\end{array}$

Cancer

A79

B72

B73

B74

D74

D75

D76

D77

N74

R84

R85

S77

T71

U75

U76

บ77

W72

$\times 75$

$\times 76$

$\times 77$

Y77
Carcinomatosis (unknown primary site) 0.00

Hodgkin's disease

0.1

Leukemia

Other malignant neoplasms blood / lymphatics

Malignant neoplasm stomach $\quad 0.05$

Malignant neoplasm colon, rectum $\quad 0.2$

Malignant neoplasm pancras $\quad 0.01$

Other gastrointestinal malignant neoplasm

Neurological malignant neoplasm $\quad 0.02$

Malignant neoplasm bronchus / lung $\quad 0.1$

Other malignant neoplasms respiratory system

Malignancies skin

Malignant neoplasıns thyroid

Malignant neoplasms kidney

Malignant neoplasms bladder

Other malignant neoplasms

Malignant neoplasms in pregnancy $\quad 0.01$

Malignant neoplasms cervix

0.1

Malignant neoplasms breast

0.4

Other g) naecological malignancies

0.1

Malignant neoplasms prostate 
Urogenital

$\begin{array}{lll}\text { U04 } & \text { Incontinence } & 0.7 \\ \text { U85 } & \text { Congenital anomalies urinary tract } & 0.2 \\ \text { U88 } & \text { Glomerulonephritis / nephrosis } & 0.1 \\ \text { Y85 } & \text { Benign prostatic hypertrophy } & 0.3\end{array}$

Neurological

\begin{tabular}{lllr}
\hline pain & N89 & Migraine & 1.1 \\
& N90 & Cluster headache & 0.02 \\
disabling & N92 & Trigeminus neuralgia & 0.1 \\
& N70 & Poliomyelitis / enterovirus & 0.1 \\
& N85 & Congenital anomalies & 0.2 \\
& N86 & Multiple sclerosis & 0.1 \\
& N87 & Parkinsonism & 0.2 \\
& N88 & Epilepsy, all types & 0.6 \\
\hline
\end{tabular}




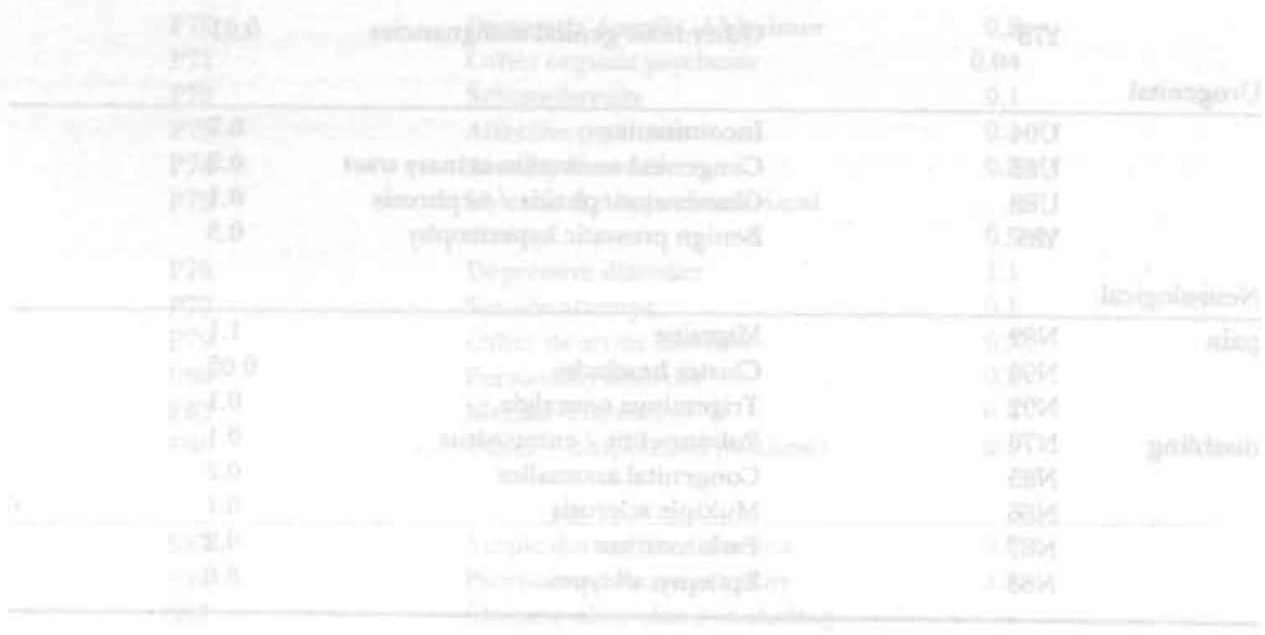


Chapter 9:

\section{A child with a health problem: more health problems in the parents?}

Published as:

FG van der Horst, JFM Metsemakers, HFJM Crebolder, GHLM Franssen. Een kind met een gezondheidsprobleem: meer gezondheidsproblemen bij de ouders?

Huisarts Wet 1992; 35(13):503-6. 


\section{Summary}

A group of 5943 families listed in 15 practices affiliated with the Registration Network Family Practices (RNH) of the University of Limburg, was examined for differences in the amount of health problems between parents of a child with a health problem and parents of a child without a health problem. In addition, the influence of socioeconomic status (SES) and family size on the amount of health problems in the parents was investigated. The amount of health problems appeared to be relatively high in parents of a child with a health problem. This also proved to be the case when controlled for SES and family size. The amount of health problems was shown to decrease as the family's SES rose and the number of children per family increased. This applied to both parents of children with a health problem and parents of children without a health problem. Problem-solving behaviour is believed to be the basic mechanism in explaining the differences found in this study. Also hereditary factors may play a role in the occurrence of health problems. Future studies are needed to examine questions which arise from this study. 
A study of Van Eijk showed that a child's long-term or chronic disease in combination with an inadequate problem-solving ability leads to an increase in complaints in the other members of the family (see figure). It was stated that adequate problem-solving ability was unevenly distributed over the various socio-economic strata and family sizes: higher strata and larger families appeared to have a greater problem-solving ability. It was suggested that the poorer problem-solving ability of lower-class families in itself may make the members of these families more susceptible to disease. Members of lower-class families, in contrast to the higher strata, tend to consider disease as "part of life". Furthermore, health problems were more frequently reported in smaller families with a child with a chronic health problem than in larger families with a child with a chronic health problem ${ }^{1}$.

The database of the Registration Network Family Practices, which contains 'chronic' health problems, provided the oportunity to study this phenomenon in our population. We did not focus on all complaints reported to the General Practitioner, which was Van Eijk's approach. We concentrated on - subjectively experienced or objectively diagnosed - more or less serious complaints and problems. The objective was to assess the relation between the presence of a child with a (chronic or long-term) health problem in a family and the amount of health problems in the child's parents. We based this cross-sectional study on the causative perspective that is represented in the figure.

We investigated the following questions:

Is their a difference in the amount of health problems between parents of a child with a health problem and parents of a child without a health problem?

Is their an interrelation between the amount of health problems in parents of a child with a health problem and their socio-economic status and family size?

\section{Method}

The survey was performed on the basis of data provided by 15 practices of the Registration Network Family Practices (RNH) of the University of Limburg ${ }^{2}$. The principal objective of the RNH is to set up a computerized family-practice randomized file, incorporating a limited set of anonymized background data and a complete problem list of each registered patient. A health problem is thereby defined as 'anything that has required, does or may require health care management and has affected or could significantly affect a person's physical or emotional wellbeing' ${ }^{2}$ Such a health problem was put on the problem list (classified as either a symptom or a diagnosis) if the problem was chronic (lasting 6 months), permanent, or recurrent ( 3 times per year) in nature. The recorded health problem was 
in addition classified as 'active' or 'inactive', which depended on the attention the GP had to pay to it. In our survey, we focused on active health problems, which generally need more attention than inactive problems.

For naming the health problems, we used the International Classification of Health Problems in Primary Care (ICHPPC-2-defined) ${ }^{3}$; coding was done in accordance with the International Classification of Primary Care (ICPC) ${ }^{4}$.

The survey population consisted of families (households) with at least one parent and one or more children years of age. The families were divided into two groups:

- problem group: families with one or more children with a health problem;

control group: families with one or more children without a health problem.

The family's socio-economic status (SES) was determined on the basis of the average level of education of the parent(s) ${ }^{5}$. Three levels were distinguished:

- lower-class: lower general education and lower professional training;

middle-class: secondary and higher general education and secondary professional training;

higher-class: higher professional training and university education.

In regard to family size, a distinction was made between families with 1 child, 2 children and 3 children.

The RNH household numbers were used to link the patients' background data to the collected data on family composition. In a few cases we were unable to assess whether the adults in the family were a father and/or a mother or, for example, a live-in brother or sister of one of them. To avoid the risk of erroneously excluding parents from the research population, we included in $15 \%$ of the cases more than two (mostly 3 ) adults per family in our analysis.

We repeated our analyses for the most common active health problems in children but found no difference with the all active health problems.

To determine the effect of background variables on the number of health problems, we applied 'elaboration, 6,7 . Statistical analysis was performed by means of the Student t-test for unpaired observations and the Chi-square test.

\section{Results}

\subsection{General}

The file of the 'Registration Network Family Practices' contained on March 1, 1992 a total number of 5943 families with one or more children years of age:

3095 problem-group families with a total number of 3952 children and

6161 active health problems (average 1.6);

2848 control-group families with a total number of 5814 children.

There was no difference in relation to age, socio-conomic status, civil status and household type between the parents in the problem group and the parents in the control group. 


\subsection{Connections yes or no.}

Table 1 shows a higher amount of health problems in larger families. Table 2 shows that socio-conomic status is only slightly connected with the amount of health problems. It must be pointed out that in $10 \%$ of the cases the family's socioneconomic status was unknown to us.

Table 1. Families with children with and without active health problems in relation to family size. Percentages.

\begin{tabular}{crrr}
\hline Number of children & $\begin{array}{r}\text { With } \\
\mathrm{n}=3095\end{array}$ & $\begin{array}{r}\text { Without } \\
\mathrm{n}=2848\end{array}$ & $\begin{array}{r}\text { Total } \\
\mathrm{n}=5943\end{array}$ \\
\hline 1 & 38 & 61 & 50 \\
2 & 48 & 32 & 40 \\
23 & 14 & 7 & 10
\end{tabular}

Chi-square $=315.62 ; \mathrm{p}<0.001, \mathrm{df}=2$.

Table 2. Families with children with and without active health problems in relation to socio-economic status. Percentages.

\begin{tabular}{lrrr}
\hline SES & $\begin{array}{r}\text { With } \\
\mathrm{n}=2877\end{array}$ & $\begin{array}{r}\text { Without } \\
\mathrm{n}=2450\end{array}$ & $\begin{array}{r}\text { Total } \\
\mathrm{n}=5327\end{array}$ \\
\hline low & 40 & 37 & 39 \\
middle & 46 & 49 & 47 \\
high & 14 & 14 & 14 \\
Chi-square $=5.30 ; \mathrm{p}=0.07, \mathrm{df}=2$. & & \\
\hline
\end{tabular}

\subsection{Relation with SES and family size.}

Table 3 leads us to conclude that:

parents of children with a health problem experience more health problems than parents of children without a health problem; this also proves to be the case when differentiating in family size and socio-economic status;

the larger the family is, the lower the average number of health problems in both family groups is; this also proves to be the case when differentiating in socio-economic status.

The picture painted above is confirmed by Table 4 . In families with a high SES and 3 or more healthy children, the parents experience relatively little health problems. The opposite is observed in families with a low SES and one child with a health problem. The greater the number of children, the more the figures differ between the two categories. 
Table 3. Average number of health problems in parents with and parents without a child with a health problem.

\begin{tabular}{llll}
\hline & With & Without & Difference \\
Total population: & 3,3 & 2,2 & 1,2 \\
\hline 1 child & 3,6 & 2,3 & 1,4 \\
2 children & 3,2 & 2,1 & 1,2 \\
3 children & 2,9 & 1,8 & 1,1 \\
SES low & 3,9 & 2,8 & 1,0 \\
SES middle & 3,5 & 2,4 & 1,2 \\
SES high & 2,9 & 2,1 & 0,8
\end{tabular}

The figures have been calculated with two decimals and have subsequently been rounded up or down. For all differences $p<0.001$

Table 4. Average number of health problems in parents with and parents without a child with a health problem, differentiated in socio-economic status and family size.

\begin{tabular}{lccc}
\hline & With & Without & Difference \\
SES low & & & \\
1 child & 4,2 & 3,1 & $1,1^{*}$ \\
2 children & 3,6 & 2,3 & $1,3^{*}$ \\
$\geq 3$ children & 3,5 & 2,1 & $1,4^{*}$ \\
& & & \\
SES middle & 4,1 & 2,6 & $1,6^{*}$ \\
1 child & 3,3 & 2,1 & $1,2^{*}$ \\
2 children & 2,9 & 2,0 & $0,9^{*}$ \\
$\geq 3$ children & & & \\
SES high & 3,1 & 2,1 & $1,0+$ \\
1 child & 3,0 & 2,0 & $1,0^{*}$ \\
2 children & 2,4 & 1,5 & $0,9 \dagger$ \\
$\geq 3$ children & &
\end{tabular}

\section{Discussion}

In general, it can be concluded that parents of a child with a health problem report more health problems to the family doctor than parents without a child with a health problem. Since the 'three-parent families' appear to be evenly spread over the problem group and the control group, it may be assumed that they have not influenced the results disproportionally.

When taking the family's socio-economic status and the number of children into account, the same difference may be observed. We found a general 'influence' of SES on the number of health problems in the parents: the higher the SES of the 
parents (in both the problem and the control group), the lower the amount of health problems in the parents. Van den Bosch found a similar pattern ${ }^{8}$. There is no reason to assume that the results present a biased view due to the fact that the SES of $10 \%$ of the parents was unknown: the lack of data was not systemic.

Family size proved to have a similar effect on the amount of health problems in the parents (in both the problem and the control group): the larger the family, the smaller the average number of problems. Van Eijk reported similar findings 1 .

In middle-class and higher-class families, the difference regarding the average number of problems between the problem and the control group proved to decrease as SES and family size increased. This finding contrasts remarkably with our observation in lower-class families, in which the difference between the problem and the control group appeared to increase as the number of children augmented. We cannot provide an explanation for this phenomenon.

The results of our study indicate that the nature of the children's health problems is not of importance. This finding is confirmed by literature on the subject: the burden on the parents is said to relate not so much to the nature and the seriousness of the child's disorder as to the family organization ${ }^{9}$, which may be seen as an indicator for coping resources. Up to this point we have exclusively written in terms of connection. On the basis of the model (see figure) a causal connection is suggested. We argue that problem-solving behaviour is the basic mechanism. Also hereditary factors may play a role in the occurrence of health problems, which applies, for example, to the majority of pulmonary conditions and eczema/allergy.

Figure. Development of diseases in families.

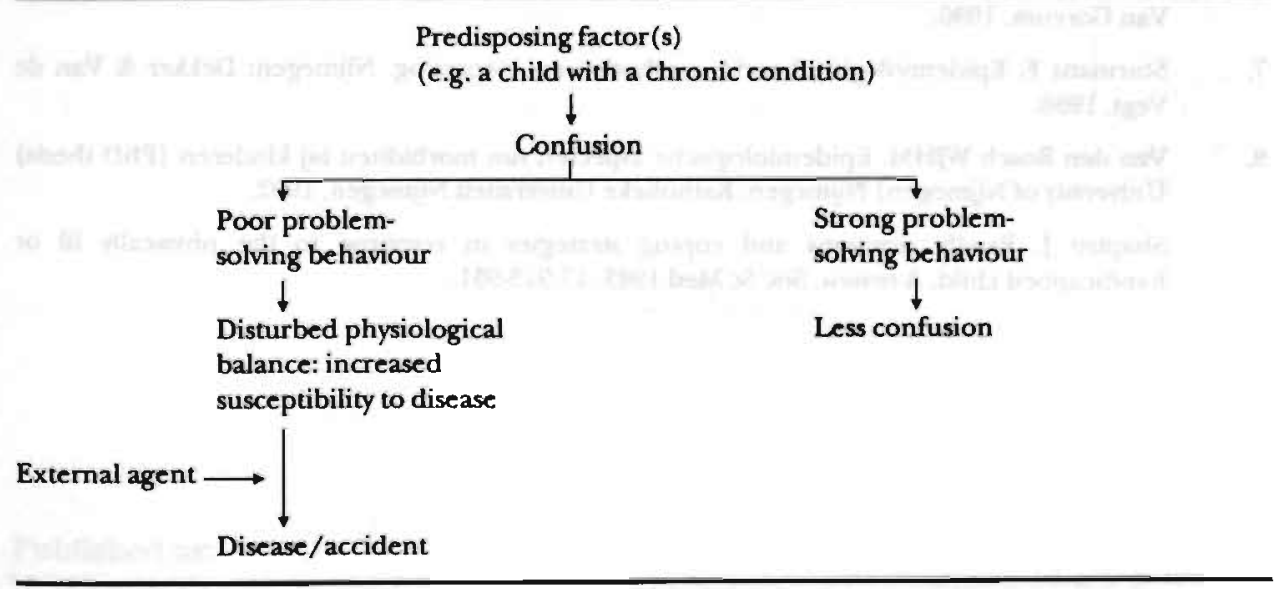


The following questions should be investigated in future studies:

What is the nature of the health problems experienced by the parents?

To what extent do the children's health problems precede the increase in problems in the parents?

To what extent do the severity of the children's health problems as perceived by the parents and the problem-solving ability of the parents influence the amount of health problems in the parents?

We would like to thank drs. J.C. Schuur, Medical Student, drs. C.G. Zijlstra, Medical Student, and drs. J.M.J.M. Beckers, Medical Student, for their valuable contributions.

\section{References}

1. Van Eijk JThM, Levensgebeurtenissen en ziekte [PhD thesis University of Nijmegen] Nijmegen: Katholieke Universiteit Nijmegen, 1979.

2. Hōppener P, Knottnerus JA, Metsemakers JFM, et al. Het Registratienet Huisartspraktijken van de Rijksuniversiteit Limburg. Huisarts Wet 1990; 33:66-69.

3. ICHPPC-2 (International Classification of Health Problems in Primary Care). Oxford: Oxford University Press, 1979.

4. Lamberts M, Wood M, eds. International Classification of Primary Care (ICPC). Oxford: Oxford University Press, 1987.

5. Berkel van-Schaick van $\mathbf{A B}$, Tax B. Naar een standaardoperationalisatie van sociaal-economische status voor epidemiologisch en sociaal-medisch onderzoek. Nijmegen: Infobever, 1990.

6. Seegers, JH, Hagenaars JAP. Sociologische methoden: technieken van causale analyse. Assen: Van Gorcum, 1980.

7. Sturmans F. Epidemiologie: theorie, methoden en toepassing. Nijmegen: Dekker \& Van de Vegt, 1986.

8. Van den Bosch WJHM. Epidemiologische aspecten van morbiditeit bij kinderen [PhD thesis) University of Nijmegen] Nijmegen: Katholieke Universiteit Nijmegen, 1992.

9. Shapiro J. Family reactions and coping strategies in response to the physically ill or handicapped child. A review. Soc Sc Med 1983, 17:913-931. 
Chapter 10:

\section{Computerization of General Practices and Quality Control.}

\section{Blood glucose regulation in type 2 diabetics} investigated in the Registration Network Family Practices.

Published as:

Hōppener P, Knottnerus JA, Grol R and Metsemakers JFM.

Computerization of general practices and quality control. Blood glucose regulation in type 2 diabetics investigated in the Registration Network Family Practices. Family Practice 1992;9:353-356. 


\section{Summary}

The extent to which computerized medical administration facilitates quality control was studied using as an example the quality of blood glucose regulation in diabetics supervised by general practitioners in 11 computerized practices. Systematic use of the general practice computer rapidly provided an unequivocal answer that $37 \%$ of such patients were not regulated in accordance with the guidelines for type 2 diabetes mellitus of the Dutch College of General Practitioners. The extra workload for the participating general practitioners was minimal. Automated recording of problem lists, as applied in the general practices belonging to the Registration Network, facilitates access to data on chronic diseases and risk factors for purposes of research, quality control and quality assessment. 
In a recent article we described structure and methods of the Registration Network Family Practices of the University of Limburg. ${ }^{1}$ In this article, we report on a study into the blood glucose regulation in patients with type 2 diabetes mellitus in the 11 practices concerned. This study should be considered mainly as a model; the underlying question is the extent to which computerization of medical administration in general practices facilitates this kind of research into the quality of health care.

In the Netherlands, several studies have been carried out into the blood glucose levels and regulation of patients with type 2 diabetes mellitus who are under the supervision of a general practitioner. ${ }^{2,3}$ It becomes increasingly evident that correct blood sugar regulation may prolong these patients' lives, and delay or even prevent the development of complications. In the practices belonging to the Registration Network we investigated how many type 2 diabetics supervised by a general practitioner were not regulated according to the guidelines in the standard protocol for type 2 diabetes mellitus of the Dutch College of General Practitioners. 4

A study into the quality of diabetes registration in eight general practices in the Nijmegen region showed that only $7 \%$ of the patient charts recorded the time at which blood was sampled to determine glucose (fasting or $2 \mathrm{~h}$ after a meal). The mean interval between two blood glucose determinations was 3 months in $76 \%$ of the cases and more than 6 months in only $9 \% .5$ A pilot study in two practices belonging to the Registration Network produced similar results. The study also reported that 3 - 6 months usually passed between two blood samplings. We did not therefore expect to be able to find reliable information on the time of blood sampling. Consequently, the criterion applied for 'good' regulation was the maximum acceptable, postprandial blood glucose value according to the new standard protocol of the Dutch College of General Practitioners: $10 \mathrm{mmol} / \mathrm{l}$.

\section{Method}

The study was carried out in the 11 practices of the Registration Network Family Practices of the University of Limburg.

The central database - the 'general practitioner register' at the Medical and Social Information Centre (MEMIC) - contained data from 9834 patients in June 1989. All patients with the International Classification of Primary Care (ICPC) code T90 were selected, i.e. all patients with some form of diabetes $(\mathrm{N}=306)$. The following data were recorded in an ASCII-file: practice, patient identification (as given by the General Practitioner Information System in each practice), date of birth, and gender.

These data were selected per practice and subsequently converted to a format. which could be read by the general practitioner's microHIS computer program. 
Each practice was provided with a floppy disk containing a database of its own diabetics together with the SQL-software procedures needed for the study.

With the aid of instructions included, a research form could be printed containing the data of all the diabetic patients (Figure 1). The personal data were printed on the left and could be removed before the form was returned to the researchers. The right side contained the data of interest to the researcher: the ICPC-code (in this case always T90); the status of the problem ( $\mathrm{A}=$ active; $\mathrm{B}=$ blind/inactive); the year and month in which the problem became active (for instance 6702 for February 1967); the patient's age; the form number. The comment by the general practitioner on the coded problem was given below that (the problem line), for instance diabetes II and tolbutamide 1 daily.

Finally the research questions were given:

Figure 1. Example of printed research form with fictitious data. The private data (left) can be removed before returning the research data.

Information on problem:

Information on patient:

Date of birth: 300301

Janssen-Bakhbier JN

If no insulin $=-$

Hours after meal: ....

Date of birth: 120702

Kalselis PH

If no insulin $==$

Date of birth: 241237

031224

Vermouten-Klabbeek BHI

If no insulin $=$
CODE S Date:

Age: no.

$\begin{array}{llll}\text { T90 } & \text { A } & 6702 & 88\end{array}$

01

Diabetes 2 diet and Tolbutamide 1 daily

Use of insulin $\mathrm{Y} / \mathrm{N}$ ? : ......

Last glucose but one $(\mathrm{mmol} / \mathrm{l}):$....

Last glucose (mmol/l): ....

Hours after meal : ....

Personal Assessment regulation: ....

$\begin{array}{llll}\text { T90 } & \text { A } & 8310 & 87\end{array}$

02

Type 2 diabetes mellitus

Use of insulin $\mathrm{Y} / \mathrm{N}$ ? : .....

Last glucose but one $(\mathrm{mmol} / \mathrm{l}):$.....

Hours after meal: ......

Last glucose (mmol/l): .....

Hours after meal: .....

Personal Assessment regulation: .....

$\begin{array}{llll} & \text { T90 } & \text { A } & 7511\end{array}$

03

Type 1 diabetes, supervision by internist

Use of insulin $\mathrm{Y} / \mathrm{N}$ ?: .....

Last glucose but one $(\mathrm{mmol} / \mathrm{l}): \ldots .$.

Hours after meal: .....

Last glucose ( $\mathrm{mmol} / \mathrm{l})$ : .....

Hours after meal: .....

Personal Assessment regulation: ..... 
Use of insulin $\mathrm{Y} / \mathrm{N}$.

If insulin not used:

last glucose but one $(\mathrm{mmol} / \mathrm{l}) /$ how long after the meal ?

last glucose $(\mathrm{mmol} / \mathrm{l}) /$ how long after the meal ?

personal assessment of regulation.

The right side of the completed form was to be sent to the researcher. The data compiled were processed by hand. The statistical tests applied were the 2 test for unpaired observations and Cohen's Kappa for inter-observer coherence.

If the mean value of the last two blood glucose determinations was more than 10 $\mathrm{mmol} / \mathrm{l}$ (fasting, postprandial, or unknown), it was considered 'not correctly' regulated (10+ criterion). The general practitioner's personal assessment on the regulation of blood sugar was often compared with the assessment of the researcher according to the $10+$ criterion.

In cases where the text in the problem line, the answers and/or extra remarks on the research form raised any questions, additional information was asked for by letter.

\section{Results}

As we anticipated, the time of blood sampling was often unknown or not filled in. This aspect could therefore not be included in the assessment of the results.

In total, 197 patients with type 2 diabetes mellitus were identified. The blood glucose values were unknown in 19 patients who were under the supervision of a physician at the hospital (Table 1). As far as we could conclude from the 'problem line' and further information from the general practitioner, seven patients in this group were receiving insulin. The remaining 178 patients were supervised by their general practitioners. Three patients were receiving insulin, the others being treated with oral antidiabetic agents and/or a diet. In 66 of the 178 patients (37\%), the blood glucose was not correctly regulated according to the $10+$ criterion. The pa-

Table 1. Composition of the group of patients found in the central database by selection on ICPC code T90 $(n=306)$

Data not available

Died in meantime

Pregnancy diabetes

High blood glucose once, no diabetes

Type 1 diabetes mellitus

(insulin-dependent)

Type 2 diabetes mellitus

(non-insulin-dependent),

- blood glucose value unknown

(supervision by physician in hospital)

- blood glucose value known 
Table 2. Assessment of blood glucose regulation in each practice by the general practitioner according to the $10+$ criterion. Numbers of patients.

\begin{tabular}{lcccc}
\hline $\begin{array}{l}\text { Practice } \\
\text { b }\end{array}$ & $\begin{array}{l}\text { General Practitioner } \\
\text { Correct }\end{array}$ & Not correct & $\begin{array}{c}10+\text { criterion } \\
\text { Correct }\end{array}$ & Not correct \\
\hline 1 & 6 & 6 & 6 & 6 \\
2 & 6 & 3 & 6 & 3 \\
3 & 6 & 1 & 6 & 1 \\
4 & 13 & 0 & 13 & 0 \\
5 & 16 & 13 & 16 & 13 \\
6 & 20 & 4 & 14 & 10 \\
7 & 2 & 1 & 3 & 0 \\
8 & 5 & 3 & 5 & 3 \\
9 & 11 & 9 & 14 & 6 \\
10 & 18 & 7 & 19 & 6 \\
11 & 17 & 2 & 10 & 9 \\
\hline Total & 120 & 58 & 112 & 66 \\
$:$ Correct: mean value of the last two blood glucose determinations $<10$ mmol/1. \\
b. The order of the practices is chosen at random. \\
\hline
\end{tabular}

tient's age scarcely made any difference: $39 \%$ of the patients over 75 years of age $(n=56)$ were not correctly regulated, and in those under $75(n=122)$ the corresponding figure was $36 \%$. This difference was not significant ( 2 test, $P=0.05$ ). Table 2 shows large differences in blood sugar regulation over the practices. Table 3 , however, shows that the assessment of the regulation by general practitioners and researchers agreed quite well.

Table 3. Assessment of blood glucose regulation by the general practitioners and according to the $10+$ criterion

General Practitioners

\begin{tabular}{lrrr} 
10+ criterion & Correct & Not correct & Total \\
\hline Correct & 107 & 5 & 112 \\
Not correct & 13 & 53 & 66 \\
Total & 120 & 58 & 178 \\
\hline
\end{tabular}

\section{Discussion}

Reading in the data from the floppy disk caused problems for some system operators, partly due to ambiguity in the given instructions, and partly due to failure to follow the software instructions correctly. The latter occurred mainly in a few computer users who were already experienced in the use of the computer. Further 
processing of the computerized data went smoothly. The system operators needed 40 - $60 \mathrm{~min}$ to read in the floppy disk and activate the software. Depending on the number of patients the general practitioners spent $10-60 \mathrm{~min}$ on looking up patient files and answering the questions on the research form.

An answer to the question posed was rapidly and unequivocally obtained. Approximately one-third of the patients with type 2 diabetes mellitus whose last two blood glucose values were known, were not correctly regulated. It should be mentioned that at the time of research, the standard protocol for type 2 diabetes mellitus of the Dutch College of General Practitioners had only been available for a short time.

The large differences in the regulation of blood glucose may be explained by the active policy on diabetes in some of the Registration Network practices. In general it can be stated that general practitioners who participate in research have more contact with the Department of General Practice than those who do not. It is not clear whether we have to take a certain degree of positive self selection into account: the quality of health care in the selected practices could have been higher than average. If so, this implies that the problem of regulating diabetics is generally bigger than suggested by our study. This is, however, a mere assumption, since we have no reason to believe that general practitioners who have less contact with the Department of General Practice provide health care of inferior quality.

Most general practitioners were well aware of the fact that they had not met the quality standard in a number of patients and realized that the regulation had often not been correct on the basis of their individual criteria. A general problem in the assessment of the quality of diabetes regulation lies in the fact that it is often not clear whether the blood glucose value is fasting or postprandial. Standard abbreviations for the two respective values would be desirable, enabling general practitioners to record their findings clearly and accurately. Considering the results, but moreover considering the anonymous data processing, the routine developed within the Registration Network, and the open attitude to practice audit, we assume that the data provided by general practitioners were correct.

The extra workload which this study required from participating general practitioners was small. It became clear that the compilation of research data took place rapidly and efficiently due to automated problem administration in the peripheral practices and central data storage at the Medical and Social Information Centre. The method described in this article is applicable in computerized general practices for research into all chronic diseases and risk factors which are coded and recorded in the problem list. If all doctor-patient contacts were recorded and coded, independent of research questions which are to be generated later, a completely computerized research procedure would be possible. This method was not applied within the Registration Network, since it would have involved a considerable extra work. The alternative method, the use of a data dictionary, was not chosen either. A similar compulsory vocabulary has already been used in the VAMP-project in England. ${ }^{6}$ The advantages and disadvantages of this method of compiling 
data have not yet been adequately investigated. The main problem is probably the reduction of the available information, because the possibilities for general practitioners to express themselves freely are limited. ${ }^{7,8}$

An advantage of the method described in this study is the active participation of general practitioners. If necessary they provide additional information, and in the meantime they are involved in a kind of self-testing. Moreover, the small workload for the general practitioner and the practice is an extra advantage.

Finally, the method described can be applied by individual general practitioners for monitoring their own practice. It is therefore a strong instrument for self-testing, adjusted to the specific priorities of each practice. With the aid of this method, a new dimension can be added to the possibilities for the exchange of information between colleagues as well as the auditing of practice performance.

\section{References}

1. Knotunerus JA, Metsemakers J, Hojppener P, Limonard C. Chronic illness in the community and the concept of social prevalence. Fam Pract 1992;9:15-21.

2. van Weel C, van Zelst PAM. Diabetes Mellitus in een huisartspraktijk II. Huisarts Wet 1983; 26: 214217.

3. Rutten GEHM, van Eijk JTM, Beek MML, van de Velden HGM. De type II diabeet: hoe staat het ermee? Een explorerend onderzoek in acht huisartspraktijken. Huisarts Wet 1988; 31: 124-129.

4. Nederlands Huisartsen Genootschap (Dutch College of general practitioners). Diabetes Mellitus Type II Standaard (Standard Protocol). Huisarts Wet 1989;32:15-18.

5. Rutten G, van Eijk J, Beek M, van der Velden $H$. The quality of diabetes registration in eight general practices. Allgemeinmed 1990;19:68-72.

6. Hall GC, Luscombe DK, Walker SR. Post-marketing surveillance using a computerised General Practice database. Pharmaceut Med 1988; 2: 345-351.

7. Knottnerus JA (ed.) Seminar on Clinical Epidemiology and Health Care Research. A meeting with Prof. Dr.Alvan R.Feinstein, Book of abstracts. Maastricht: University of Limburg, 1989.

8. Feinstein AR. Consultation Registration Network Family Practices. (Personal communication). Maastricht, January 1989.

\section{ACKNOWLEDGEMENT}

We would like to thank all the general practitioners of the Registration Network Family Practices for their cooperation. We are very grateful to dr. B.A. Davies $\mathrm{PhD}$ for checking the linguistic aspects. 
Chapter 11:

\section{Evaluation and perspectives}

Job FM Metsemakers 


\section{Summary}

This chapter will attempt to answer the original questions posed in this study: is it possible to establish a computerized anonymous database continuously fed by general practitioners, which can also be used for purposes of research, medical education and quality assurance. The growth of the database of the Registration Network Family Practices has been gradual and continuous, but slower than expected. The concept of the problem list has proved to be workable for general practitioners, although a continuous quality assurance approach is necessary to eliminate from the database those problems which do not comply with the problem definition. Several studies, some of them included in this thesis, have shown that the database is highly suitable as a sampling frame. Furthermore, the database is increasingly being used as a source of information by researchers and students. Researchers find the database a useful tool, but they have to keep in mind the limitations: only "problems" are registered in the database, which means that data on the process of care are not directly available. Furthermore, there is a limit to the number of studies which can be performed in the network practices, due to time limitations and the burden on the doctors and patients. On the whole, however the Registration Network Family Practices shows that it is possible to establish a computerized general practice database combining the interests of general practitioners and researchers. 


\section{Introduction}

This study focused on the Registration Network Family Practices, but the questions also apply to comparable general practice registrations.

The main questions were:

Is it possible to establish a computerized anonymous database continuously fed by general practitioners with certain patient characteristics and relevant health problems?

More specifically: does the concept of the problem list work ? are the data reliable?

Can the data from the Registration Network Family Practices be used for research, medical education and quality assurance?

More specifically: what are the possibilities?

what are the limitations?

In this chapter our findings will be reviewed on the basis of the data presented in the previous chapters. Furthermore, this chapter provides an outlook on the near future of the Registration Network Family Practices and offers some recommendations for general practice registrations.

\section{Is it possible to establish a computerized anonymous database continuously fed by general practitioners with certain patient characteristics and relevant health problems?}

This question has been dealt with in chapters 3, 4 and 5. It was shown in chapter 3 that a computerized anonymous database has indeed been established. On 1 September 1990 characteristics of 32072 patients had been entered in the database. A total of 94476 problems had been identified for these patients. Table 1 shows the gradual growth of the database over the recent years.

On 1 March 1994, the register included characteristics and problem lists of 60674 patients. ${ }^{1}$ It had been expected that the register would be complete by the end of 1993. It is clear that this is not the case, although several practices have now included all or nearly all their patients. There are several reasons for the deceleration of the growth. Several practices have had logistic difficulties with their general practice health information systems. Furthermore, several general practitioners with considerable registration experience have left their practices and have been replaced with general practitioners lacking the registration routine. The third ex- 
Table 1. Growth of the database of the Registration Network Family Practices from September 1990 to March 1994

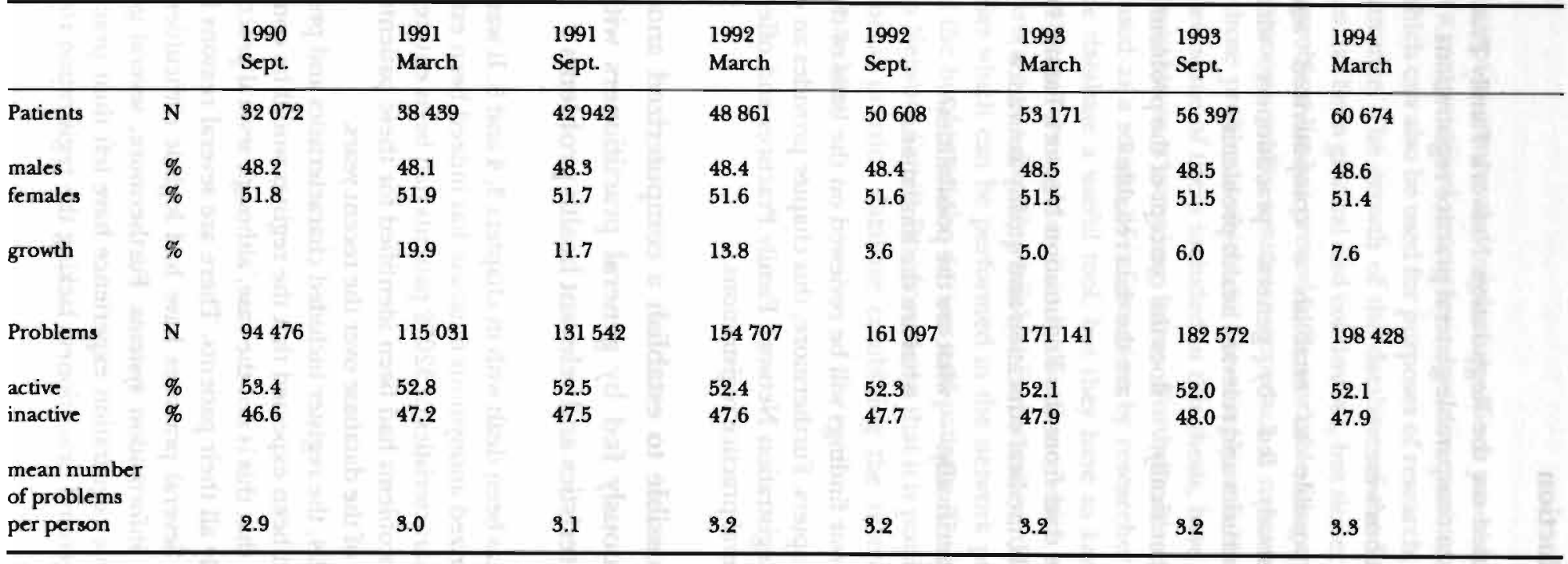


planation is that the fast workers have now included all patients and can no longer contribute to the growth, meaning that the pace now will be set by the "slower" general practitioners. For other GPs, the increasing burden of updating patient records after entrance in the system may slow down the review and entry of new patient records. Finally, all general practitioners have been participating in research projects based on the Registration Network Family Practices, which has reduced the time available for entering new patients into the database.

Table 1 also shows that the number of problems included has grown steadily, with the mean number of health problems per person slightly higher in March 1994 than in September 1990.

It can be concluded that it is possible to establish a computerized anonymous database. Moreover, it is possible to maintain the database of the Registration Network Family Practices.

The problem list, as explained in chapter 4 , is the essential basis of the registration. Diagnoses make up the greatest proportion of problems $(67.0 \%)$, complaints or patterns of complaints constitute the second largest group (14.3\%), while psychosocial problems, risk factors and other problems are also included on the problem list. In interpreting these percentages, it should be kept in mind that only chronic, recurrent or permanent health problems are registered. Efforts will have to be made to minimise inter- and even intra-doctor variability. By and large, however, the problem definition is workable for the general practitioners. Our problem list (which, in combination with patient background characteristics, is the basis for a general practice sampling frame) concept has been followed by other general practice registrations which have been established during the last two to three years. ${ }^{2-4}$

The quality control programme, as described in detail in chapter 5 , found that the database contained less than 1.0 percent incorrect entries. Furthermore, it was shown that important and essential problems had been placed on the problem list by the majority of general practitioners. An continuous quality assurance approach is necessary to maintain a good quality database and to eliminate from the database those problems which do not comply with the problem definition. The quality assurance experiment, and the comparison between the Maastricht Epilepsy Case Register and the Registration Network Family Practices have demonstrated both the need and the feasibility for this approach.

\section{Can the data of the Registration Network Family Practices be used for research, medical education and quality assurance?}

\subsection{The possibilities}

The database of the Registration Network Family Practices was set up in such a way to allow a variety of study designs: case control studies, prospective and retrospective cohort studies, chart review studies, clinical trials, quality assurance studies, 
practice audit studies. The growing number of projects based on samples drawn from the database indicates that researchers find the database a useful tool.

\subsubsection{Use of the database for the present study}

Chapters 6 to 10 of the present study show that data from the Registration Network Family Practices can be used for various types of study, regarding validation of the register contents, medical education and burden of illness, as well as the study of comorbidity, family studies, and quality assurance research. Chapter 6 describes the comparison between the data from the Epilepsy Case Register and those from the Registration Network. The comparison shows the value of a general practice registration which includes health problems from the past, even though they may be inactive. It further shows that comparing registers is not easy and that matching problems can disturb a good comparison. The comparison between the contents of the problem-based medical curriculum and primary health care data derived from the Registration Network Family Practices is one way to use the data for educational purposes, as was demonstrated in chapter ${ }^{7}$. The use of the data at a macro- level to assess the burden of illness in a community is described in chapter 8, while chapter 9 describes the use of problem list data for studying families. The extent to which the database of the Registration Network Family Practices can be easily used in a practice audit activity is demonstrated in chapter 10 , using diabetes mellitus as an example.

These five studies are examples of the possible use of the database. Other researchers making use of the database are following different lines of approach.

\subsubsection{Use of the database for other studies}

The database of the Registration Network Family Practices can be used in two ways.

\section{- as a source of information}

The researcher requests information available in the database at an aggregated level

- as a sampling frame

The researcher wants to study a certain group of patients and requests a sample to be drawn from the database (which is used as an index).

A detailed brochure outlining how the database can be used is available from the Medical and Social Information Center (MEMIC) which manages the database. ${ }^{5}$

\subsubsection{Use of the database as a source of information}

Information at an aggregated level is available on request and can be provided within a short time. Table 2 shows the number of requests for information and the reasons for these requests. Most requests have been made for research pro- 
Table 2. Requests for information from the database of the Registration Network Family Practices

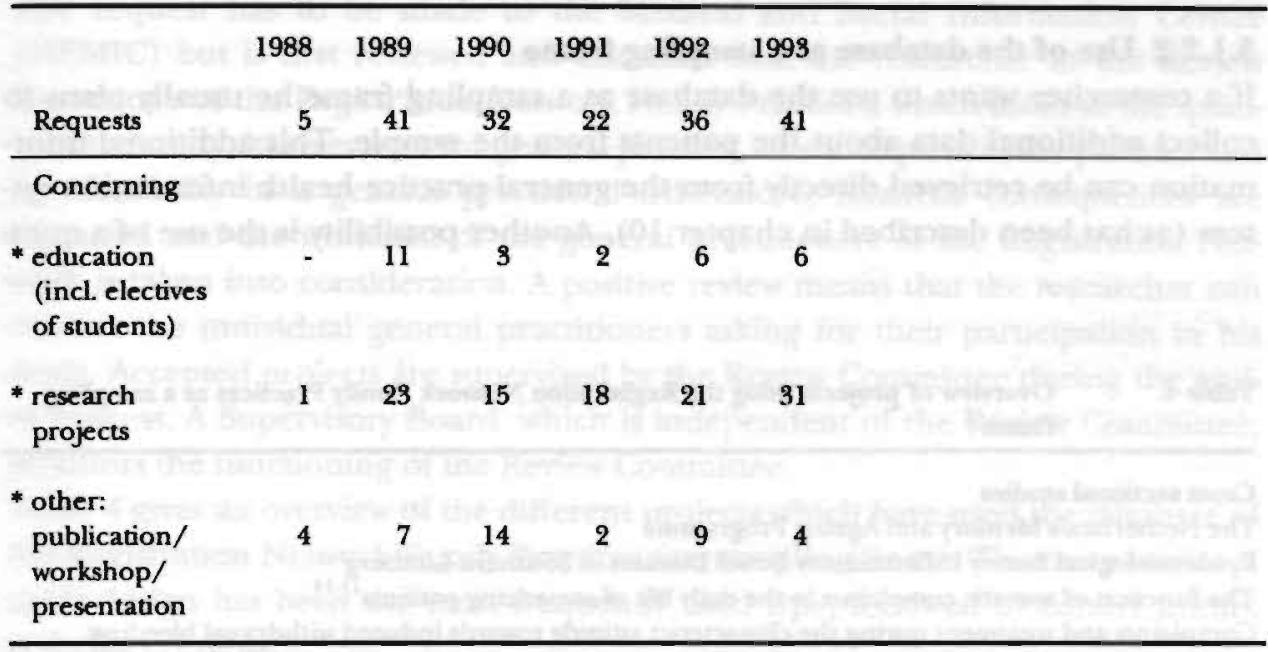

jects, but the data have also been used in presentations, publications and workshops.

Some requests have been made by teachers using the data in the medical curriculum. Table 3 shows that most requests are made by members of the Department of General Practice, but requests have also been made by members of other depart-

Table 3. Requests for information from the database of the Registration Network Family Practices by applicants

$\begin{array}{llllll}1988 & 1989 & 1990 & 1991 & 1992 & 1993\end{array}$

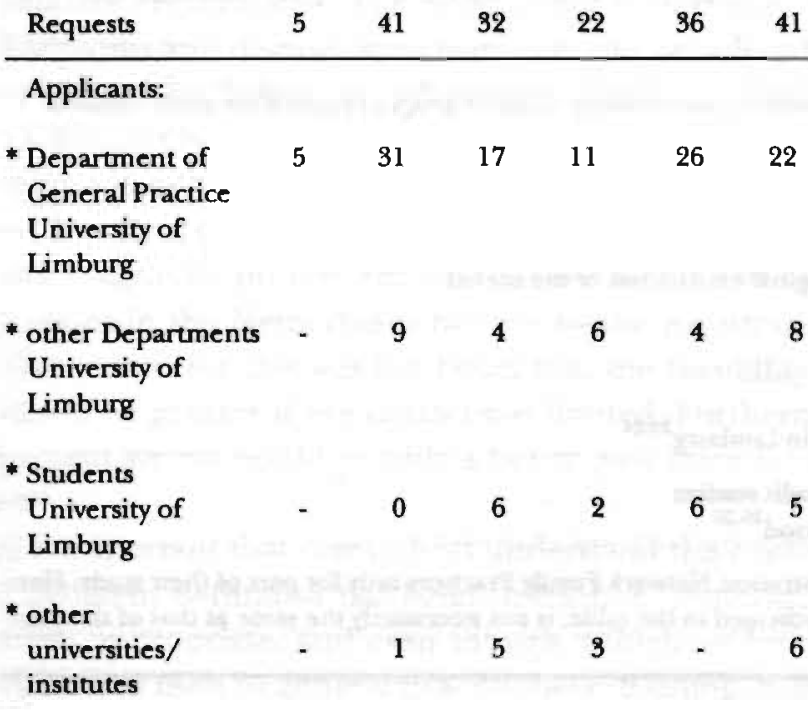


ments, other universities or institutes, and by students. The students have used the database mostly for small research projects during one of their elective periods.

\subsubsection{Use of the database as a sampling frame}

If a researcher wants to use the database as a sampling frame he usually plans to collect additional data about the patients from the sample. This additional information can be retrieved directly from the general practice health information system (as has been described in chapter 10). Another possibility is the use of a ques-

Table 4. Overview of projects using the Registration Network Family Practices as a sampling frame ${ }^{1}$

\section{Cross sectional studies}

The Netherlands Memory and Ageing Programme

Epidemiological Survey Inflammatory Bowel Diseases in Southern-Limburg

The function of somatic complaints in the daily life of somatizing patients ${ }^{\text {I-14 }}$

Complaints and treatment during the climacteric: attitude towards induced withdrawal bleeding

The social network of chronic mental patients treated in

community mental health care ${ }^{15,16}$

Long term use of benzodiazepines in general practice

Incidence and risk stratification in sudden cardiac death

The management of the postmyocardial infarction patient by the general practitioner

Falls in the elderly

\section{Retrospective cohort studies}

Patient careers in chronic low back pain

Prospective cohort studies

The Netherlands Memory and Ageing Programme

Patient careers in chronic low back pain

Diuretic drug cessation in general practice : withdrawing diuretic drugs prescibed for ankle oedema ${ }^{17}$

The function of somatic complaints in the dialy life of somatizing patients ${ }^{11-14}$

Falls in the elderly

\section{Randomized clinical trials}

Diuretic drug cessation in general practice : withdrawing diuretic drugs prescibed for ankle oedema ${ }^{17}$ Infants with asthma ${ }^{18,19}$

\section{Chart review studies}

\section{Infants with asthma ${ }^{18,19}$}

Relation between sterilisation and vaginal extirpation of the uterus

Health and unemployment ${ }^{20,21}$

Causes of death and dementia

\section{Validation studies}

Completeness of cancer registration in Limburg ${ }^{22-24}$

\section{Quality assurance studies/Practice audit studies}

Use of digitalis in the digital time period ${ }^{25,26}$

${ }^{1}$ Several projects have used the Registration Network Family Practices only for part of their study. Hence, the study design of that part, as indicated in the table, is not necessarily the same as that of the project, as a whole. 
tionnaire or a patient interview, while the general practitioner or a research physician may also have to examine the patient especially for the additional data.

The request has to be made to the Medical and Social Information Center (MEMIC) but is first reviewed and discussed with the researcher in the Review Committee of the Registration Network Family Practices, which looks at the quality of the study, its relevance for general practice, its consequences for patients and its feasibility in a general practice. Furthermore, financial consequences are discussed and the workload of the general practitioners of the Registration Network is taken into consideration. A positive review means that the researcher can contact the individual general practitioners asking for their participation in his study. Accepted projects are supervised by the Review Committee during the entire process. A Supervisory Board, which is independent of the Review Committee, monitors the functioning of the Review Committee.

Table 4 gives an overview of the different projects which have used the database of the Registration Network Family Practices as a sampling frame. The cross sectional study design has been the most frequently used type, followed by cohort studies and chart reviews.

The infrastructure of the Network has also attracted other types of studies, which do not use the sampling facility but use the Network for its computerized collaborating general practices.

A number of articles have already been published, while three published theses and three forthcoming ones are also based on data from the Network. Several other projects are in the initial stages.

\subsection{Limitations}

Researchers find the database a useful tool, but they have to keep in mind the limitations of the Registration Network Family Practices and comparable general practice registrations. The latter is not a morbidity study registering all contacts, symptoms and diseases seen over a certain period of time, nor is it a register of disease episodes linking several patient contacts concerning the same disease. Minor health problems are not monitored, since the problem definition only allows the inclusion of chronic health problems which are considered to have an influence on the patient's present or future functioning. Referral rates, frequency of visits and diagnostic procedures ordered are monitored by some general practice registrations in the Netherlands but not by the Registration Network Family Practices. The reason for this was the belief that the feasibility of a continuous registration would be greater if the dataset was limited. Furthermore, it was assumed that the present system would provide a better guarantee for the quality of the data gathered.

It is important that researchers understand the concept of "a problem". Although a problem definition has been developed, requiring the use of ICHPPC criteria when appropriate, and even though guidelines for registration have been developed and used in general practitioners' training, intra- and interdoctor variability 
cannot be ruled out even when studying clear diagnoses. ${ }^{6}$ The quality assurance experiments show these differences, as does the study on epilepsy. Several general practitioners had labelled patients as epileptic on the problem list even though they had serious doubts about this diagnosis. Some of this variability is caused by the registration of health problems which were diagnosed before data entry started. For such problems it is often very difficult to determine if criteria were used in the process of labelling. Retrospective studies therefore have to take into account that cases can be missing and that verification of the problem definition may sometimes be very difficult.

A further limitation to use of the Registration Network Family Practices is the number of participating practices. There is no limit to the use of the database at the Medical and Social Information Center (MEMIC), but practices can only participate in a limited number of studies, depending on the time general practitioners and their administrative assistants have available and of course on the burden to their patients. This aspect and the way patients are being asked to participate in a particular study have to be watched very carefully to preserve future participation of both practitioners and patients. Researchers have to realise that only the general practitioner himself can decide whether a project is appropriate for his practice at a given time. There may be numerous reasons why he feels that participation is not feasible, such as: association with a new colleague, moving the practice to a new building, participation in other research projects, educational obligations.

\section{Future developments}

Access to the medical records of the general practitioner is needed in order to study health care as it is presented and managed in general practice, and to investigate determinants of illness and the efficacy of medical interventions in an efficient way. Computerization of these records based on the guidelines of the Dutch College of General Practitioners means that problem lists in the future will become available for all patients in all general practices. ${ }^{7,8}$ Furthermore, other health care data such as consultation notes, prescriptions and results of laboratory and diagnostic investigations will be easily accessible on the basis of a computerized patient index. Hence, other kinds of studies such as post marketing surveillance of drugs or monitoring of referral rates would become possible in nearly all general practices. The Nationwide Information Network GP Care is exploring possibilities for quality assurance monitoring. ${ }^{9}$

Since there is a limit to the number of studies a given general practice can participate in, it seems logical to expand the Registration Network Family Practices by including new practices. An analysis of the problem lists of external practices which are recording on the basis of the guidelines of the Registration Network has revealed that the data of many practices contained many incorrect entries and sometimes differed 
greatly from the Registration Network data. Participation in the existing Registration Network would involve a time-consuming process of instruction, training and setting up new consensus groups, maybe at larger distances from Maastricht. A good balance will have to be found between the benefits of expanding and the costs of doing so with acceptable validity.

Furthermore, several general practice registrations are being established in different regions of the Netherlands, as has been described in chapter 1 . The aims and designs of some of these registrations are comparable to those of the Registration Network Family Practices.

A good collaboration between these general practice registrations on methodological and logistic aspects would be very useful. Thus, mistakes could be prevented and exchangeability of data could be enhanced.

Computerization of the medical record is a necessary prerequisite for these future developments, but it would be a fallacy to believe that these records could contain all possible patient data and would therefore enable all (also future) research questions to be pursued very easily. It will always be the general practitioner who will decide, on the basis of relevance for his daily work, what to enter in the medical record. Only if the research data collection(s) blend very well with his normal record keeping habit or enrich this medical record without interfering too much with his normal recording pattern, will he be able and willing to do so for a longer period of time.

The Registration Network Family Practices shows that it is possible to establish a computerized general practice database combining the interests of general practitioners and researchers.

The difficult task for the years to come will be to build on the strength of these registrations, enabling researchers and especially the participating general practitioners to study relevant topics in general practice, and enabling teachers to use these data in health education construction and also in postgraduate medical education. Furthermore, it will be a challenge to engage general practitioners in practice audit activities based on their own data. These general practice registrations will also allow longitudinal studies and analyses, although the methodology of longitudinal data analyses in such dynamic populations will have to be improved.

\section{General conclusion}

Retrieval of health care information from hand-written records is very difficult and time-consuming. Most morbidity data and other items of information in general practice have, therefore, been collected in special projects. These usually require special forms to be used to collect the necessary data. The amount of information has to be limited, especially in a continuous registration. Chapter 2 has provided 
an overview of current sentinel stations and general practice health information systems in the Netherlands, Europe and elsewhere. It also has been shown that several registration projects in the Netherlands are considering the use of general practice computers to collect project data. Hoppener has demonstrated that computerization of general practices facilitates research. ${ }^{10}$ This may, therefore, be a good moment to stress once again the advantage of a computerized general practice health information system for practice based studies, as the proportion of general practitioners who have computerized their practices is steadily increasing. ${ }^{8}$ Networks of computerized general practices have been established in Rotterdam, Groningen and Leiden, based on the concept of the Registration Network Family Practices. Our experience leads us to believe that this concept can indeed be used to provide access to the wealth of information on health available in the computerized medical records of the GP, without putting too great a burden on the general practitioner and his patients. The incompleteness of hospital based registrations, such as the Maastricht Epilepsy Case Register, furthermore indicates the need for a general practice based database.

\section{The principles of this concept are:}

- a (regional) group of computerized general practices

- an anonymous central database, including:

- a limited set of personal characteristics which do not change too often over time;

- a limited set of health care data which are routinely recorded by the general practitioners and can be easily retrieved from the GP's practice computer;

- use of the anonymous central database in different ways:

- $\quad$ to provide data at an aggregated level;

- as a sampling frame allowing researchers to identify patient panels based on the data available for various study designs;

- use of the study sample to collect data:

directly from the GP medical records;

from the patients by interview or examination;

- $\quad$ providing the participating general practitioners with:

a continuous quality control programme including instructions, guidelines, feedback, and stimuli to use the data themselves; a network structure which enables researchers to make use of the possibilities without unduly inconveniecing the general practitioners.

The role of the general practitioner is crucial in such a registration. 
1. Progress report Registration Network Family Practices (Internal report). Maastricht: MEMIC, March, 1994.

2. Registration Network Leiden (RNH-LEO). Gezondheidsproblemen en diagnoses in de huisartspraktijk. Leiden: Department of General Practice, 1992

3. Werf $\mathrm{G}$ van der. Registratienet Groningen. Projectbeschrijving (Internal report). Groningen: Department of General Practice, 1992

4. Middelkoop B, Beek A, Boon WM, van der Does E. Geautomatiseerde huisartspraktijken als basis voor onderzoek. TMI 1992;21:75-78

5. Department of General Practice/ Medical and Social Information Center. Information brochure for future users of the Registration Network Family Practices. Maastricht: Department of General Practice/MEMIC, 1993

6. Classification Committee of WONCA. ICHPPC-2 defined. International Classification of Health Problems in Primary Care. Oxford: Oxford University Press, 1983

7. Meyboom WA, Metsemakers JFM, Hofstra ML, Beusmans GHMI. Medische Verslaglegging. Huisarts Wet. 1990;33:114-117

8. Westerhof HP, Berden HJM. De meerwarde van het elektronisch medisch dossier. Tussenresultaten van het NUT II project. Huisarts Wet 1993;36(11):380-383

9. Stokx L, Van der Velden J, Grol RPTM, Berden BDM. De noodzaak van goede informatievoorziening in de gezondheidszorg. Med Contact 1994 (Accepted for publication)

10. Hōppener P. Automatisering en wetenschappelijk onderzoek in de huisartspraktijk. [PhD thesis University of Limburg] Maasuricht: 1990

11. Portegijs PJM, Kraan HF, Knottnerus JA, Stoffers HEJ. Wat heet somatisatie? 1.Een zoektocht in de internationale literatuur. Huisarts Wet 1992;35:18-25.

12. Portegijs PJM, Kraan HF, Knottnerus JA, Stoffers HEJ. Wat heet somatisatie? 2. Een antwoord uit de internationale literatuur getoetst aan 19 jas Huisarts en Wetenschap. Huisarts Wet 1992;35(2):65-69.

13. Portegijs PJM, Kraan HF, Horst FG van der. Prevalence of somatization and depression among dutch general practice patients [abstract]. 18 th European conference on Psychosomatic Research. Helsinki, august 13-17, 1990.

14. Portegijs PJM, Kraan HF, Knotunerus JA, Proot IM. Somatisatie in de huisartspraktijk: Relaties met depressie, angst, jeugdervaringen en stress [abstract]. NHG-HGV/EMGO Referatendag 1993: Amsterdam, 1993.

15. Buiks A. Afwijkende sociale rolvervulling. (scriptie) Begeleiders : Philipsen H. Noorthoom van der Kruijff EO. Augustus 1993

16. Noorthoorn van der Kruijff EO. Social roles and lifetime development in the chronic mentally ill. [PhD thesis University of Limburg] Maastricht: Universitaire Pers, 1994

17. Jonge JW de. Diuretic drug cessation in general practice - Withdrawing diuretic drugs prescribed for ankle oedema. [PhD thesis University of Limburg] Maastricht: 1993

18. Mesters EPE. Infants with asthma : towards a multidisciplinary education protocol for primary care [PhD thesis University of Limburg] Masstricht: Universitaire Pers, 1993.

19. Mesters I, Meertens R, Kok GJ, Crebolder HFJM, Parcel G. Patientenvoorlichting aan ouders van kinderen met asthma. In: Crebolder HFJM, Stevens FCJ (red). De eerste lijn in Limburg nu en straks. Maastricht: Rijksuniversiteit Limburg, 84-88. 
20. Horst FGEM, Nijhuis FJN, Muris JWM, Philipsen H, Grinten RF van der. Causality in the relation between health and unemployment. In: Verhaar CHA, Jansma LG, Goede MPM de, Ophem JAC, Vries A (eds). On the Mysteries of Unemployment: Causes, Consequences and Policies. Amsterdam: Kluwer Academic Publishers, 1992:225-252

21. Horst FGEM, Muris JWM, Nijhuis FJN. Morbidity among unemployed and work-incapacited men in the Netherlands. Scand J Work Environ Health 1993; 19:168-174.

22. Completeness of the IKL Cancer Registration, Maastricht, The Netherlands. Rotterdam, april 1992; WEON-congres.

23. Schouten LJ, Hōppener P, Brandt PA van den, Knottnerus JA, Compleetheid van kankerregistratie [abstract] Tijdschr Soc Gezondheidszorg 1992;70;42.

24. Schouten LJ, Hōppener P, Brandt PA van den, Knottnerus A, Jager JJ. Completeness of cancer registration in Limburg, the Netherlands. Intern J Epidemiol 1993;22:369-376.

25. Nunen M. van, Hōppener P, Knoutnerus JA. Indicaties voor digoxine? Ned Tijdschr Geneeskd 1992; 136, 34:1633-1634.

26. Höppener P, Knottnerus JA. Digoxinetherapie in 24 geautomatiseerde huisartspraktijken. Ned Tijdschr Geneeskd 1992;34:1647-1651. 
Chapter 12:

\section{Summary}

Job FM Metsemakers 
The purpose of this thesis is to describe the Registration Network Family Practices as an instrument, its possibilities and limitations. The leading questions were:

- Is it possible to establish a computerized anonymous database continuously fed by general practitioners with certain patient characteristics and relevant health problems?

- Can the data from the Registration Network Family Practices be used for research, medical education and quality assurance?

Before these issues are studied, the Dutch history of registration in general practice is described in Chapter 2. Based on the different types of general practice registrations, such as time limited morbidity studies, continous morbidity registrations, and sentinel stations, an overview is provided of the 13 current general practice registrations. Although the purpose of all registrations is to collect data on general practice, the specific aim and, therefore, the nature of the data collection vary considerably. Nevertheless, the entire spectrum of morbidity and related activities is covered.

A general picture of the general practice based registrations in many other European countries, Canada, and the United States is given.

Computerization of general practices has facilitated the creation of national and international networks of collaborating practices, which can harvest the wealth of information on the health of patients available in general practice.

Chapter 3 describes the Registration Network Family Practices in greater detail. Forty two general practitioners in 15 practices, with a patient population of 80000 people, are using a general practice health information system to establish a central computerized anonymous database containing certain patient characteristics and all relevant health problems. By September 1990 patient characteristics and problem lists for 32072 patients had been entered and a total of 94476 health problems had been identified. The database has been set up primarily as a sampling frame, allowing researchers to identify patients with particular health problems. The database can also provide descriptive data on prevalence and incidence rates, fulfil a monitoring function and provide data for practice audit, medical education and health management.

How and when health problems and diagnoses are to be defined and recorded is described in Chapter 4. By December 1990 patient characteristics of 35740 patients with 110017 health problems had been identified in the database of the Registration Network. Diagnoses make up the greatest proportion of problems $(67 \%)$, followed by complaints or patterns of complaints $(14,3 \%)$. Risk factors, congenital or social problems are also included on the problem lists. 
The problem list, as part of a general practice health information system, can become an important tool for research.

In Chapter 5 characteristics of general practitioners and patients of the Registration Network are compared with those of the general practitioners in general and the population in general. Furthermore, the process of quality control of the data is described including instruction and training sessions, a registration handbook, regional consensus groups and special software for data control. The accuracy of the data collected, registered and coded is evaluated on the basis of a special software control program and two quality control experiments.

The general practitioners of the Registration Network Family Practices are found to be only partly comparable with the entire group of Dutch general practitioners. The practice population resembles the Dutch general population very much as regards at gender, age, type of health insurance and level of education. Minor differences were only found in household composition. The special software program for data control detected less than 1.0 percent incorrect entries in the database and made it possible to identify the most frequent mistakes. One of the quality control experiments shows that important and essential problems are placed on the problem list by the majority of general practitioners. Evaluation of the database looking for possible incorrect problems, also shows that problems have been indicated in the database which do not comply with the problem definition.

On the basis of this approach of continuous quality assurance we conclude that the Registration Network Family Practices can serve as a reliable dynamic sampling frame.

While the abovementioned chapters deal with the description of the instrument, the remaining chapters focus on the use of the database.

Chapter 6 describes a comparison between the Maastricht Epilepsy Case Register and the Registration Network Family Practices. The Maastricht Epilepsy Case Register was set up to gather data on epileptic patients seen in the 6 hospitals of the southern Limburg region. General practitioners participating in the Registration Network Family Practices are to include epilepsy on the problem list and hence also in the database of the network. A comparison between these two registers was therefore expected to provide information on the completeness and reliability of each register.

The two databases were matched using a matching key consisting of date of birth, gender and four digits of the postal code. The general practitioners of the Registration Network received a questionaire for patients in the discordant groups and for a control group, asking for more detailed information on these patients.

The results show that 75 of the 116 epilepsy cases which should have been included in both registers, were indeed found in both. 38 patients under specialist treatment and receiving medication were found in the Registration Network but 
were missing from the MECR. Only 3 patients had been missed by the Registration Network Family Practices. Furthermore, it was found that at least 72 epileptic patients were being treated by general practitioners only.

The analysis shows that the matching process is difficult and may have led to incorrect matches, resulting in unjustified inclusion of patients in the discordant groups. The Registration Network Family Practices is more complete than the Maastricht Epilepsy Case Register. The guidelines for registering a problem in the Registration Network will have to be followed by general practitioners more precisely, since 23 patients had been included with a diagnosis of epilepsy, even though the GP had serious doubts about the diagnosis.

Collaboration between the registers could prove beneficial to both.

Chapter 7 describes the analysis of the content of a problem-based medical curriculum with reference to educational and medical characteristics. The data have been compared with primary health care data obtained from the Registration Network Family Practices. The analysis reveals differences between curriculum and health care data on several aspects such as reasons for encounter/complaints, problems/diagnoses, chronic diseases, health problems of children and referrals to specialists. Although the analysed material reflects only part of the curriculum, it can be concluded that the primary care orientation of the curriculum is meagre and that a critical review of the patient cases used in the problem-based curriculum is needed.

General practice is an important source of information on the occurence and distribution of chronic disease in the population. In Chapter 8, the burden of chronic illness was expressed as different indices of prevalence. Morbidity data concerning the actual health status of 25357 subjects, as recorded by their GPs, were classified following the International Classification of Primary Care using the diagnostic criteria of the International Classification of Health Problems in Primary Care-2-Defined. The most frequent single disease was asthma $(3.5 \%)$, while locomotor problems represented the most prevalent category $(8.3 \%)$. The overall prevalence of chronicdisease was $29.4 \%$, with a clear positive correlation with age and, to a lesser extent, with a lower educational level. The 'social prevalence' of chronic illness (including individuals related to chronically diseased patients via their households) could be measured in a subset of the database $(n=4577)$, and amounted to $56 \%$. It is concluded that the role of the GP as a family doctor involved with chronic disease concerns the majority of the general population.

Use of registration data at the level of families is described in Chapter 9. A group of 5943 families listed in 15 practices affiliated with the Registration Network Family Practices was examined for differences in the amount of health problems between parents of a child with a health problem and parents of a child without a health problem. In addition, the influence of socio-economic status (SES) and fa- 
mily size on the amount of health problems in the parents was investigated. The amount of health problems appeared to be relatively high in parents of a child with a health problem. This also proved to be the case when controlled for SES and family size. The amount of health problems was shown to decrease as the family's SES rose and the number of children per family increased. This applied to both parents of children with a health problem and parents of children without a health problem. Problem-solving behaviour is believed to be the basic mechanism in explaining the differences found in this study. Also hereditary factors may play a role in the occurrence of health problems.

Chapter 10 describes the extent to which computerized medical administration facilitates quality control using as an example the quality of blood glucose regulation in diabetics supervised by general practitioners in 11 computerized practices. Systematic use of the general practice computer rapidly provided an unequivocal answer that $37 \%$ of such patients were not regulated in accordance with the guidelines for type 2 diabetes mellitus of the Dutch College of General Practitioners. The extra workload for the participating general practitioners was minimal. Automated recording of problem lists, as applied in the general practices belonging to the Registration Network Family Practices, facilitates access to data on chronic diseases and risk factors for purposes of research, quality control and quality assessment.

Chapter 11 answers the original questions posed in this study:

- Is it possible to establish a computerized anonymous database continuously fed by general practitioners with certain patient characteristics and relevant health problems?

- Can the data from the Registration Network Family Practices be used for research, medical education and quality assurance?

The growth of the database of the Registration Network Family Practices has been gradual and continuous, but slower than expected. The concept of the problem list has proved to be workable for general practitioners, although a continuous quality assurance approach is necessary to eliminate from the database those problems which do not comply with the problem definition. Several studies, some of them included in this thesis, have shown that the database is highly suitable as a sampling frame. Furthermore, the database is increasingly being used as a source of information by researchers and students. Researchers find the database a useful tool, but they have to keep in mind the limitations: only "problems" are registered in the database, which means that data on the process of care are not directly available. Furthermore, there is a limit to the number of studies which can be perfor- 
med in the network practices, due to time limitations and the burden on the doctors and patients.

On the whole, however the Registration Network Family Practices shows that it is possible to establish a computerized anonymous general practice database combining the interests of general practitioners and researchers.

Our experience leads us to believe that this concept can indeed be used to provide access to the wealth of information on health available in the computerized medical records of the GP.

The principles of this concept are:

- a (regional) group of computerized general practices

- an anonymous central database, including:

- a limited set of personal characteristics which do not change too often over time;

- a limited set of health care data which are routinely recorded by the general practitioners and can be easily retrieved from the GP's practice computer;

- use of the anonymous central database in different ways:

- to provide data at an aggregated level;

- as a sampling frame allowing researchers to identify patient panels based on the data available for various study designs;

- use of the study sample to collect data:

- directly from the GP medical records;

- from the patients by interview or examination;

- providing the participating general practitioners with:

- a continuous quality control programme including instructions, guidelines, feedback, and stimuli to use the data themselves;

- a network structure which enables researchers to make use of the possibilities without unduly inconveniecing the general practitioners. 
Chapter 13:

\section{Samenvatting}

Job FM Metsemakers 
Het doel van dit proefschrift is het beschrijven van het Registratienet Huisartspraktijken als instrument, met de mogelijkheden en beperkingen ervan. De hoofdvragen waren:

- Is het mogelijk om een geautomatiseerd en geanonimiseerd gegevensbestand op te bouwen waaraan huisartsen voortdurend een aantal patient achtergrondgegevens en relevante gezondheidsproblemen toevoegen?

- Kunnen de gegevens van het Registratienet Huisartspraktijken benut worden voor wetenschappelijk onderzoek, medisch onderwijs, en kwaliteitsbewaking en bevordering ?

Voordat deze vragen aan de orde komen, worden in Hoofdstuk 2 eerst de Nederlandse huisartsgeneeskundige registraties beschreven. Op basis van de verschillende vormen van huisartsgeneeskundige registraties, zoals de in tijd gelimiteerde morbiditeitsstudies, de continue morbiditeitsregistraties, en de peilstations, wordt een overzicht gegeven van de huidige 13 huisartsgeneeskundige registraties. Alhoewel het doel van al deze registraties is gegevens over de huisartsgeneeskunde te verzamelen, is er aanzienlijk verschil in het specifieke doel en daardoor ook de wijze van gegevensverzameling. Het hele spectrum van morbiditeit en daaraan gekoppelde aktiviteiten wordt desalniettemin gedekt.

Verder wordt een overzicht gegeven van de de registraties in andere Europese landen, Canada, en de Verenigde Staten.

Automatisering van huisartspraktijken heeft het ontstaan van nationale en internationale netwerken van samenwerkende praktijken bevorderd, waardoor de grote hoeveelheid informatie over de gezondheid van patienten die aanwezig is in de huisartspraktijk benut kan gaan worden.

Hoofstuk 3 beschrijft het Registratienet Huisartspraktijken in detail. 42 huisartsen uit 15 praktijken, met een patiēntenpopulatie van 80000 personen, hanteren een elektronisch medisch dossier. Daarin verzamelen ze een aantal patientachtergrondgegevens en alle relevante gezondheidsproblemen die vervolgens opgeslagen worden in een centraal geautomatiseerd en geanonimiseerd gegevensbestand. In september 1990 waren van 32072 patienten de patientachtergrondgegevens en probleemlijsten opgenomen. Daarop stonden in totaal 94476 gezondheidsproblemen vermeld. Het gegevensbestand is in eerste instantie opgezet als steekproefkader, waardoor onderzoekers de mogelijkheid hebben patienten met bepaalde gezondheidsproblemen te identificeren. Op basis van het gegevensbestand kunnen ook prevalentie en incidentie cijfers berekend worden. Verder kunnen bepaalde gezondheidsproblemen vervolgd worden, terwijl ook gegevens beschikbaar zijn voor toetsing, medisch onderwijs en gezondheidszorgbeleid. 
Op welke wijze gezondheidsproblemen en diagnoses benoemd en vastgelegd dienen te worden staat beschreven in Hoofdstuk 4. In december 1990 bevatte het gegevensbestand van het Regi-stratienet Huisartspraktijken de patientachtergrondgegevens van 35740 patienten met daarbij 110017 gezondheidsproblemen. Het grootste deel zijn diagnoses $(67 \%)$, gevolgd door klachten of klachtencomplexen (14.3\%). Risicofaktoren, aangeboren afwijkingen of sociale problemen zijn ook op de probleemlijsten opgenomen. De probleemlijst kan, als onderdeel van het elektronisch medisch dossier, een belangrijk hulpmiddel voor wetenschappelijk onderzoek worden.

In Hoofdstuk 5 worden de kenmerken van huisartsen en patienten uit het Registratienet Huisartspraktijken vergeleken met die van alle huisartsen en de algemene bevolking. Verder wordt het proces van kwaliteitsbewaking beschreven. Dat omvat instructie en oefensessies, een registratie handboek, regionale consensusgroepen en speciale computersoftware voor gegevenscontrole. De juistheid van de verzamelde gegevens, zoals geregistreerd en gecodeerd, wordt beoordeeld op basis van een speciaal softwareprogramma en twee kwaliteits controle experimenten. De huisartsen van het Registratienet Huisartspraktijken blijken slechts gedeeltelijk vergelijkbaar met de gehele groep Nederlandse huisartsen. De patienten populatie komt goed overeen met de Nederlandse bevolking wat betreft geslacht, leeftijd, verzekeringswijze en opleidingsniveau. Alleen de samenstelling van het huishouden verschilt enigszins. Het speciale computerprogramma voor gegevenscontrole toonde aan dat er minder dan 1.0 procent onjuiste invoer in het gegevensbestand was en maakte het mogelijk de meest gemaakte fouten te benoemen. Een van de kwaliteitscontrole experimenten laat zien dat het merendeel van de huisartsen de relevante problemen inderdaad op de probleemlijst plaatst. Beoordeling van het gegevensbestand op mogelijk onterecht opgenomen problemen laat inderdaad zien dat niet alle problemen voldoen aan de probleem definitie. Op basis van dit voortdurende kwaliteitscontrole programma kan vastgesteld worden dat het Registratienet Huisartspraktijken als betrouwbaar steekproefkader kan dienen.

In bovenstaande hoofdstukken is het Registratienet Huisartspraktijken als instrument beschreven. In de volgende hoofstukken ligt de nadruk op het gebruik van het gegevensbestand.

Hoofdstuk 6 beschrijft de vergelijking tussen het Epilepsie Register Maastricht en het Registratienet Huisartspraktijken. Het Epilepsie Register Maastricht is opgezet om gegevens te verzamelen over epilepsie patienten die gezien worden in de 6 ziekenhuizen van Zuidelijk Limburg. De huisartsen, die deelnemen aan het Registratienet Huisartspraktijken, dienen epilepsie op de probleemlijst te plaatsen en daardoor ook op te nemen in het gegevensbestand van het Registratienet. Een vergelijking tussen deze twee registers zou inzicht kunnen geven in de volledigheid en betrouwbaarheid van elk der registers. 
De twee gegevensbestanden werden met elkaar vergeleken middels een sleutel bestaande uit geboortedatum, geslacht en 4 cijfers van de postcode. De huisartsen van het Registratienet Huisartspraktijken ontvingen een vragenlijst voor patienten uit de niet overeenkomende groepen en voor een controlegoep. Daarin werd meer informatie gevraagd over deze patienten.

De resultaten laten zien dat 75 van de 116 epilepsie gevallen die in beide registers aanwezig hadden moeten zijn ook aanwezig waren in beide. 38 patienten die onder controle van de specialist waren en medicatie ontvingen werden wel in het Registratienet aangetroffen maar niet in het Epilepsie Register. Slecht 3 patienten bleken gemist door het Registratienet Huisartspraktijken. Bovendien bleek dat minstens 72 patienten alleen door de huisarts werden behandeld. De analyse geeft aan dat het proces van vergelijken moeilijk is en mogelijk tot onjuiste koppelingen heeft geleid, waardoor sommige patienten in een verkeerde groep zijn ingedeeld. Het Registratienet Huisartspraktijken is vollediger dan het Epilepsie Register Maastricht. De richtlijnen voor het opnemen van problemen in het Registratienet moeten beter gevolgd worden door de huisartsen, aangezien 23 patienten met de diagnose epilepsie waren geregistreerd, alhoewel de huisarts ernstige twijfel had over de diagnose.

Een probleemgestuurd medisch curriculum met betrekking tot onderwijskundige en medische kenmerken wordt in hoofdstuk 7 vergeleken met eerstelijnsgezondheidszorg gegevens afkomstig uit het Registratienet Huisartspraktijken. De beoordeling brengt verschil aan het licht tussen de curriculum en gezondheidszorg gegevens als het gaat om redenen van komst/klachten, gezondheidsproblemen/diagnoses, chronische ziektes, gezondheidsproblemen bij kinderen en verwijzingen naar specialisten. Alhoewel het bij de beoordeling van het materiaal gaat om slechts een deel van de inhoud van het curriculum, mag vastgesteld worden dat de gerichtheid op de eerste lijn erg beperkt is en dat een kritische herbeoordeling van de casuistiek, die in het probleemgestuurd curriculum gebruikt worden, noodzakelijk is.

De huisartspraktijk is een belangrijke bron van informatie over het voorkomen en de verdeling van chronische ziekten in de bevolking. De zwaarte van chronische ziekten wordt in hoofdstuk 8 uitgedrukt in verschillende prevalentie maten. Morbiditeitsgegevens met betrekking tot de huidige gezondheidsituatie van 25357 personen, zoals vastgelegd door de huisarts, werden geclassificeerd met de International Classification of Primary Care, gebruik makend van de diagnostische criteria van de International Classification of Health Problems in Primary Care. De meest voorkomende ziekte was astma $(3.5 \%)$, terwijl problemen met het bewegingsapparaat de meest voorkomende categorie was $(8.3 \%)$. De prevalentie van chronische ziekte was $\mathbf{2 9 . 4 \%}$, met een duidelijk positieve correlatie met leeftijd, en in mindere mate met een lager opleidingsniveau. De "sociale prevalentie" van chronische ziekten (inclusief personen die binnen een huishouden gerelateerd 
zijn aan een chronisch zieke patient) kon in een subset van het gegevensbestand $(n=4577)$ worden bestudeerd, en deze bedroeg $56 \%$. De conclusie is dan ook dat de huisarts, als gezinsarts betrokken bij chronische ziekten, te maken heeft met het merendeel van de algemene bevolking.

Het gebruik van registratiegegevens op gezinsniveau is beschreven in hoofdstuk 9 . Een groep van 5943 gezinnen, ingeschreven in 15 bij het Registratienet Huisartspraktijken betrokken huisartspraktijken, werden beoordeeld. Gekeken werd naar het verschil in het aantal gezondheidsproblemen tussen ouders van een kind met een gezondheidsprobleem en ouders van een kind zonder een gezondheidsprobleem. Bovendien werd de invloed van de sociaal economische status en gezinsgrootte onderzocht. Het aantal gezondheidsproblemen bleek bij ouders met een kind met gezondheidsproblemen relatief hoog. Dat was ook zo als gecontroleerd werd voor sociaal economische status en gezinsgrootte. Het aantal gezondheidsproblemen bleek te dalen als de sociaal economische status steeg en het aantal kinderen in het gezin toenam. Dit gold voor beide onderzochte groepen. Probleem oplossend gedrag wordt beschouwd als het verklarend mechanisme voor de verschillen die gevonden werden. Verder kunnen erfelijke faktoren een rol spelen in het voorkomen van gezondheidsproblemen.

In hoofstuk 10 wordt beschreven in welke mate het elektronisch medisch dossier toetsing faciliteert. De toetsing betrof de regulatie van bloedglucose in diabetes mellitus patienten die onder controle stonden bij huisartsen in 11 geautomatiseerde praktijken. Het systematisch gebruik van de praktijkcomputer gaf snel het onomstotelijk antwoord dat $37 \%$ van deze patienten niet waren ingesteld volgens de richtlijnen voor diabetes mellitus van het Nederlands Huisarts Genootschap. De extra werkbelasting voor de huisartsen was beperkt. Geautomatiseerde verslaglegging van probleemlijsten, zoals dat wordt toegepast bij de praktijken die deelnemen aan het Registratienet Huisartspraktijken, bevordert de toegang tot gegevens over chronische ziekten en risicofaktoren ten behoeve van wetenschappelijk onderzoek, toetsing en kwaliteitsbewaking.

Hoofdstuk 11 beantwoordt de oorspronkelijke vraagstellingen van dit proefschrift:

- Is het mogelijk om een geautomatiseerd en geanonimiseerd gegevensbestand op te bouwen waaraan huisartsen voortdurend een aantal patient achtergrondgegevens en relevante gezondheidsproblemen toevoegen ?

- Kunnen de gegevens van het Registratienet Huisartspraktijken benut worden voor wetenschappelijk onderzoek, medisch onderwijs, en kwaliteitsbewaking en bevordering?

De groei van het gegevensbestand van het Registratienet Huisartspraktijken is geleidelijk en voortdurend, maar trager dan verwacht. Het probleemlijst concept 
blijkt bruikbaar voor de huisartsen, hoewel een voortdurende kwaliteitsbewaking nodig is om problemen, die niet voldoen aan de probleemdefinitie, uit het gegevensbestand te verwijderen. Verschillende onderzoeken, waarvan enkele in dit proefschrift zijn opgenomen, tonen aan dat het gegevensbestand zeer bruikbaar is als steekproefkader. Verder blijkt het gegevensbestand in toenemende mate gebruikt te worden als informatiebron door onderzoekers en studenten. Onderzoekers mogen het gegevensbestand een nuttig instrument vinden, ze dienen wel te bedenken dat er ook beperkingen zijn: alleen gezondheidsproblemen worden in het gegevensbestand opgenomen. Dat betekent dat andere zorggegevens niet direkt beschikbaar zijn. Bovendien is het aantal onderzoeken, dat in de deelnemende praktijken kan worden uitgevoerd, beperkt door het tijdsbeslag en de belasting voor huisartsen en patienten.

Het Registratienet Huisartspraktijken toont aan dat het mogelijk is een geautomatiseerd en geanonimiseerd huisartsgeneeskundig gegevensbestand op te bouwen rekening houdend met de belangen van huisartsen en wetenschappelijk onderzoekers.

Op basis van onze ervaring geloven we dat dit concept gebruikt kan worden om toegang te verwerven tot de rijkdom aan gezondheidszorggegevens die opgeslagen is binnen het elektronische medische dossier van de huisarts.

De basiskenmerken van dit concept zijn:

- een (regionale) groep geautomatiseerde huisartspraktijken

- een geanonimiseerd centraal gegevensbestand, met daarin:

- een beperkte set patient achtergrondgegevens die gedurende de tijd niet te vaak wijzigen;

- een beperkte set gezondheidszorggegevens die routinematig door de huisartsen worden vastgelegd en die op eenvoudige wijze kunnen worden opgeroepen uit de praktijkcomputers;

- gebruik van het centrale geanonimiseerde gegevensbestand op verschillende manieren:

- het verschaffen van gegevens op geaggregeerd niveau;

- als steekproefkader dat onderzoekers in staat stelt patienten groepen samen te stellen voor verschillende onderzoeks designs;

- gebruik van het steekproefbestand om verder gegevens te verzamelen:

- direkt uit de medische verslaglegging van de huisarts;

- bij de patienten door interviews of onderzoek;

- voorzieningen voor de deelnemende huisartsen zoals:

- een voortdurende kwaliteitsbewaking met instructie, richtlijnen, terugkoppeling, en aanmoediging om zelf ook gebruik te maken van de gegevens;

- een netwerk structuur die onderzoekers in staat stelt gebruik te maken van de mogelijkheden zonder de huisartsen onnodig lastig te vallen. 


\section{Dankwoord}

Voor een succesvolle afronding van een proefschrift is het nodig dat er zowel een goede wetenschappelijke ondergrond bestaat alsook goede werkomstandigheden.

Aangezien een groot deel van het proefschriftwerk buiten de normale werkuren verricht dient te worden gaat het dan eigenlijk om de gezinsomstandigheden. Ik heb van Henriētte, Maarten, Stefanie en Evelien ruim de gelegenheid gekregen om steeds maar weer "even te werken" terwijl er nog zoveel gezellige dingen samen te doen waren geweest. Deze openbare dankzegging is het minste wat ik aan hen verplicht ben.

Mijn dank voor het leggen van een goede wetenschappelijke ondergrond gaat in de eerste plaats naar personen die zich waarschijnlijk niet bewust zijn van hun specifieke bijdrage. Een aantal hoogleraren heeft mij in de eerste jaren van mijn studie een kritische en nieuwsgierige houding bijgebracht, die hebben bijgedragen aan mijn wetenschappelijke houding. Ik denk daarbij met name aan Riet Drop, Coen Hemker, Hans Philipsen, Rob Reneman, Harry Hulsmans, Roelof Willighagen en Wijnand Wijnen.

De eerste stappen op weg naar verdere ontplooing werden gezet binnen de groep van Evert Reerink tijdens een keuzeonderwijsperiode. De discussies met Pim van Arkel, Pie Bartholomeus, Evert Reerink en Bart Sikkens over gezondheidszorgonderzoek, quality assurance en met name over het belang van goede verslaglegging voor de kwaliteit van zorg maar ook als voorwaarde voor goed wetenschappelijk onderzoek, zijn van grote invloed geweest op mijn blijvende belangstelling voor medische verslaglegging.

De keuzeonderwijsstage bij Dan Barr (Rockford Medical School, Ill, USA), opgezet door Evert Reerink, deden mij kennismaken met de fundamenten van Health Services Research en met de eerste moeizame stappen van onderzoek.

Deze belangstelling voor onderzoek bleef bestaan en leidde tijdens mijn opleiding tot huisarts tot mijn keuze om te streven naar de combinatie huisarts-onderzoeker. Samen met mijn studiegenoten Paul Hulshof, Jan Nijhof, Koen van Vugt en Rob Winter werden plannen ontwikkeld om een samen met de Vakgroep Huisartsgeneeskunde een geacademiseerde praktijk op te zetten. Ons plan is niet verwezenlijkt maar heeft wel bijgedragen aan het academiseringsproces in zijn algemeen en mijn toekomst in het bijzonder.

Deze toekomst werd in april 1982 gestuurd door Co Greep, de toenmalige Dekaan van de Faculteit Geneeskunde en Wim Brouwer, op dat moment voorzitter van de Vakgroep Huisartsgeneeskunde. Door hun toedoen kreeg ik de gelegenheid parttime huisarts en onderzoeker te worden.

Al deze personen dank ik omdat ze in belangrijke mate hebben bijgedragen aan mijn ontwikkeling tot onderzoeker of hebben bijgedragen aan mijn werkomstandigheden. 
Binnen de projectgroep Verslaglegging en Registratie in de huisartspraktijk ( $\mathrm{Ba}$ sisproject), later omgevormd naar het Registratienet Huisartspraktijken, heb ik met zeer velen samengewerkt die ieder hebben bijgedragen aan de ontwikkeling van het Registratienet Huisartspraktijken, waarover ik nu dit proefschrift schrijf. Het gaat daarbij om de huisartsen uit verleden en heden die meegedacht hebben over opzet, classificatiesysteem, probleemlijst, persoonsachtergrondgegevens en die enquetes hebben ingevuld, dummy oefeningen hebben besproken en ICPC codes opnieuw hebben bestudeerd. Ik stel met voldoening vast dat een aantal van hun nu voor hun eigen onderzoek gebruik kunnen maken van de voorziening die ze zelf mee hebben opgezet. Met een aantal personen heb ik zeer nauw samengewerkt gedurende kortere of langere tijd ten aanzien van een specifiek onderdeel van het project. Ik denk daarbij aan Jan Bergers, François Dupuits, Edzo Ebbens, Gregor Franssen, Arie Hasman, Jos Hendrix, Theo Heumakers, Rudiger von Hōfen, Paul Hōppener, Frans van der Horst, Jos Kleynen, Rene Kocken, Marlene Kruijen, Charles Limonard, Paula Muyrers, Martijn van Nunen, Henri Plagge, Karin Pouls, Toon Seelen ( $\dagger$ ), Geert-Jan van Schendel, Frits Schoonbrood, Zahira Schuurs, Wim van Zutphen( $\dagger$ ). In de loop der jaren hebben Jim Tatipata, Frits Ruyters en Judith Janssen het secretariaat vervult, waarbij Frits en in de laatste periode Judith heel wat werk hebben verzet. De werktijden van Judith bleken zeer flexibel als het nodig was dat iets werd afgerond. Bep Kōhlen heeft als onderzoeks-assistente al zeer veel jaren een belangrijke plaats in het Registratienet Huisartspraktijken en ze heeft ook aan bijna alle hoofstukken van dit proefschrift haar onmisbare bijdrage geleverd.

Ik wil ook nog andere medewerkers van de Vakgroep Huisartsgeneeskunde bedanken die me ander werk uit handen namen, soms met spoed een klusje deden of me door hun belangstelling hebben aangemoedigd. Ik denk daarbij aan Harry Crebolder, Richard Grol, Marlies Noevers en Ine Siegelaer.

Ook de assistentes uit de Huisartspraktijk Geulle: Kitty Keysers, Marie-Louise Smeets en Yvonne Welzen hebben bijgedragen aan dit proefschrift door met name in de eerste fase typewerk te verrichten.

Jan Klerkx heeft nauwgezet maar steeds op korte termijn de Engelse tekst gecorrigeerd.

De opmaak van de tekst en tabellen werd verzorgd door Marie-José van Gasteren van het Drukkerskollektief Geulle.

Henny Rooijackers werd niet zenuwachtig bij het naderen van de deadline om te drukken.

Aan allen ben ik dank verschuldigd voor hun inzet en medewerking.

Enkele personen wil ik apart noemen:

Jacques Kuijpers nam in 1982 een risico door een samenwerking aan te gaan met de Vakgroep Huisartsgeneeskunde in het voortraject van het academiseringsproces. Niet alleen kon niemand op dat moment precies vertellen hoe dat proces zou verlopen, ook kreeg hij zomaar een collega om mee samen te werken. Hij heeft de 
stap gezet en mij de gelegenheid gegeven te groeien als huisarts en als onderzoeker. Ik ben hem en zijn vrouw Luke zeer veel dank verschuldigd.

Mijn huidige collegae Jean Muris en Paul Zwietering weten wat het is om onderzoek te doen en een proefschrift te schrijven. Ze hebben daarmee naar vermogen rekening gehouden en me in de zomer van 1993 in de gelegenheid gesteld enige weken alleen aan dit proefschrift te werken. Dat was de stimulans die ik nodig had om tot afronding te komen.

Cees de Geus vroeg mij in 1982 lid te worden van de projectgroep Verslaglegging en Registratie in de huisartspraktijk. Samen hebben we getracht de toekomstige richting van het project te bepalen binnen een Faculteit die op dat moment veel bedenkingen had tegen het Basisprojekt. Ik heb veel geleerd van het geduld en de tact waarmee hij manoevreerde. Ook de warme belangstelling voor de persoonlijke aspecten van mijn leven hebben me altijd getroffen en dat zal ik altijd blijven herinneren.

Mijn eerste baantje binnen de Faculteit der Geneeskunde kreeg ik als eerste jaars student van Peter Bouhuijs. Ik mocht samen met Wip Bakx de vertaling maken bij anatomische modellen. $\mathrm{Na}$ mijn huisartsopleiding vroeg hij me voor een onderzoeksproject waaruit mijn eerste zelfstandige publikatie volgde. En een van de artikelen die deel uit maken van dit proefschrift is het resultaat van onze blijvende samenwerking. Het betrekken van gegevens uit de gezondheidszorg bij de constructie van een onderwijscurriculum zal onze blijvende aandacht houden. Hij heeft op verschillende momenten een belangrijk sturende rol in mijn loopbaan gespeeld.

Mijn dank aan André Knottnerus mag uiteraard niet ontbreken. Op zijn bekende rustige maar volhardende wijze heeft hij de richting van het Basisprojekt omgebogen in die van het Registratienet Huisartspraktijken. Hij heeft de voorwaarden geschapen waarop we als projectgroep samen de fundamenten hebben gelegd. Hij beheerst als geen ander de gave om met eenvoudige kritische vragen die to the point zijn het denkproces te stimuleren, terwijl hij altijd blijk geeft van zijn waardering voor het verrichte werk. Ik kreeg de nodige eigen ruimte bij de invulling van mijn taak maar kon altijd rekenen op tijd voor nader overleg als ik het nodig vond. Deze werkwijze gaf me vertrouwen en ik heb bewondering voor de stimulerende werking die van ervan uitgaat.

Aan allen ben ik dank verschuldigd.

Zonder hen was dit proefschrift niet verschenen. 


\section{Eygelshoven:}

Huisartspraktijk

\section{Heerlen:}

Huisartspraktijk

Huisartspraktijk

Hoensbroek:

Gezondheidscentrum Hoensbroek Nrd
Victor Kaiser

Jan Veldhuizen

Bram de Wit

Paul Höppener

Martin Op den Kamp

Bas Maiburg

Ruud Helmers

Martijn van Nunen

John Paas

Geert-Jan van Schendel

Marleen van Venrooy

Peter Voorhoeve

\section{Kerkrade:}

Huisartspraktijk

Huisartspraktijk

\section{Landgraaf:}

Huisartspraktijk

\section{Frank Soomers}

Marianne Soomers-Turlings

Jelle Stoffers

Hans van der Ploeg

Harry Eussen
Carla Stuurman
Hans Ypma

Maastricht:

Gezondheidscentrum Heer

Annemarie Muysken

Giel Peeters

Frans Vissers

Gezondheidscentrum Dr. van Kleef

Huisartspraktijk
Pie Castermans

Bèr Huijnen

Mieke Maaskant

Paul Stalenhoef

Vincent Zwietering 
Stein:

Huisartspraktijk

Phile Govaert

Raymond Leclercq

Geert-Jan Dinant

Saskia Mol

\section{Ubachsberg:}

Huisartspraktijk

Frank Guldemond

\section{Venlo:}

Gezondheidscentrum Withuis

Harry Crebolder

Henk van Dam

Peter Jansen

Tonnie van Kessel

Gijsbert de Koning

Hans Vlek

\section{Voerendaal:}

Huisartspraktijk

Yvonne Guldemond-Hecker

Paul Hulshof

Rudolf Panhuysen

Well:

Huisartspraktijk Groote Schuur
Wil van den Broek

Tink van Putten

Huub Schōnberger 
Job Metsemakers was born on September 13th, 1952 in Roermond, the Netherlands. He finished his secondary education, Gymnasium bêta, at the Bisschoppelijk College in Roermond in 1973. He spent a short period in military service. In 1974 he entered the Medical School in Maastricht, which was then starting up, and which later became the Faculty of Medicine of the University of Limburg. He graduated among the first group of students in 1980. In 1981 he completed his vocational training in General Practice at he University of Limburg and in the Health Center Maasniel (Roermond) under the supervision of Bert ten Berge.

He started work at the Faculty of Medicine in September 1981 on an educational project (Problem Orientated Medical Record Keeping) and on a research project (Evaluation of a Post-graduate Course). In May 1982, he became a part-time general practitioner in Geulle, working in the practice of Jacques Kuijpers, and a staff member of the Department of General Practice in Maastricht. He joined the Registration Project group, now known as the Registration Network Family Practices. This thesis is the result of his research activities in that project. He is also involved in an innovative educational project of the undergraduate curriculum (Adoption Programme). He has participated in a working group of the Dutch College of General Practitioners (NHG), preparing a "standard" for "Record keeping in General Practice". He has been a member of the Council of the Diagnostic Coordinating Centre Maastricht since 1989. In addition, he has been a member of several educational and research societies.

He still works as a part-time general practitioner in Geulle, presently in collaboration with Jean Muris and Paul Zwietering.

He lives in Geulle with Henriëtte van Hout and their three children: Maarten, Stefanie and Evelien. 



\section{Unlocking patients' records in general practice for research, medical education and quality}

assurance: the Registration Network Family Practices

\section{Job FM Metsemakers}

General practitioners possess a wealth of information on the health of their patients, and on many aspects of their medical treatment. Retrieval of health care information from hand-written records is very difficult and time-consuming. The use of computerized records in general practice greatly facilitates the accessibility of this information.

This book describes the chief goal of the Registration Network Family Practices: to establish an anonymous, computerized database containing certain patient characteristics and all relevant health problems, on the basis of data provided by 42 general practitioners in 15 practices located in the southern part of the Netherlands. This database has been set up primarily as a sampling frame, allowing researchers to identify patients with particular health problems or combinations of problems. Several studies based on the data from the Registration Network Family Practices are presented.

As the proportion of general practitioners who have computerized their practices is steadily increasing, it can be noted that other networks have been established, based on the concept described in this book.

Job FM Metsemakers studied medicine at the University of Limburg (Maastricht, the Netherlands). Since 1982 he has been working as a general practitioner in Geulle and as staff member of the department of General Practice at the University of Limburg.

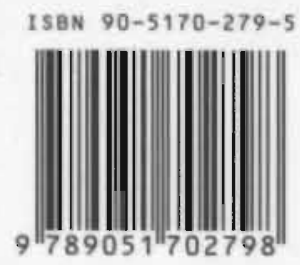

